\title{
A study of the effects of well and fracture design in a typical Marcellus shale well
}

\author{
Ross T. Schweitzer \\ West Virginia University
}

Follow this and additional works at: https://researchrepository.wvu.edu/etd

\section{Recommended Citation}

Schweitzer, Ross T., "A study of the effects of well and fracture design in a typical Marcellus shale well" (2009). Graduate Theses, Dissertations, and Problem Reports. 2017.

https://researchrepository.wvu.edu/etd/2017

This Thesis is protected by copyright and/or related rights. It has been brought to you by the The Research Repository @ WVU with permission from the rights-holder(s). You are free to use this Thesis in any way that is permitted by the copyright and related rights legislation that applies to your use. For other uses you must obtain permission from the rights-holder(s) directly, unless additional rights are indicated by a Creative Commons license in the record and/ or on the work itself. This Thesis has been accepted for inclusion in WVU Graduate Theses, Dissertations, and Problem Reports collection by an authorized administrator of The Research Repository @ WVU. For more information, please contact researchrepository@mail.wvu.edu. 


\title{
A study of the effects of well and fracture design in a typical Marcellus shale well.
}

\author{
Ross T. Schweitzer \\ Thesis submitted to the \\ College of Engineering and Mineral Recourses \\ at West Virginia University \\ in partial fulfillment of the requirements \\ for the degree of \\ Master of Science \\ in \\ Petroleum and Natural Gas Engineering \\ H. Ilkin Bilgesu, Ph.D., Chair \\ Sam Ameri, M.S. \\ Len Paugh
}

Department of Petroleum and Natural Gas Engineering

Morgantown, West Virginia

2009

Keywords: Marcellus Shale, Shale Gas Production, Simulation, Well Design, Economics Copyright 2009 Ross T. Schweitzer 


\begin{abstract}
A study of the effects of well and fracture design in a typical Marcellus shale well.

Ross Schweitzer
\end{abstract}

The problem with typical Marcellus shale wells is the lack of information that has been accumulated and the amount of information that is commercially available to the public. The Marcellus formation is a relatively new play and details involving ways to maximize production through well and fracture design has yet to be published. The Marcellus shale is important due to its large size and the economic impact that it could have on the U.S. While some companies have certain ideas about the best way to produce the Marcellus shale other companies have different ideas. Through reservoir simulation, the Marcellus could be studied to find effects of these parameters. The objective of this study is to compare and contrast the gas production in vertical wells, to the gas production in the horizontal wells of the Marcellus shale play. Along with the horizontal well study, the effects of varying fracture half lengths and horizontal wellbore lateral lengths on gas production in these shale wells are investigated. In each of the studies, only one parameter is changed at a time. Parameters include, propped fracture half length, number of fractures, number of wells, type of wells, horizontal lateral length and fracture spacing. An economic analysis is then conducted to understand the optimal design for these Marcellus shale wells. 


\section{Acknowledgements}

I would like to thank Dr. Ilkin Bilgesu first off for being my advisor and working with me on this project. His skills as an educator, his thoughts and suggestions along with all of his help have been much appreciated. Next, I would like to thank Schlumberger and West Virginia University for providing me with the necessary software to complete my analysis.

Next, I would thank the other members of my committee. First, Professor Sam Ameri, I would like to thank you for everything you have done for me over the past few years, from the classroom all the way to your excellent advice. I would also like to thank Mr. Len Paugh from Range Resources. Len I appreciate the experience and knowledge that you taught me since I first met you. I am also looking forward to possibly working with you again in the future. A thanks, also goes out to the rest of the faculty and staff in the Department of Petroleum and Natural Gas Engineering at West Virginia University.

I have two special thanks to give, one goes to Walter Sawyer from Schlumberger, for his assistance with most of my reservoir modeling questions and getting me up to speed with the Eclipse software. The other goes to Ray Frear from Range Resources who has been an excellent mentor to me while I have been with Range. Along with everyone and anyone that has come before me in the oil and gas industry. I couldn’t be where I am today if it wasn't for them.

Lastly, I can’t go on any further without thanking my parents. No matter what, they have always been there for me my entire life. They were the ones that instilled my pursuit for success and lifelong knowledge. I can't thank them enough for everything that they have done for me. Finally, I would like to thank the rest of my family, friends and girlfriends for their support throughout this journey. 


\section{Table of Contents}

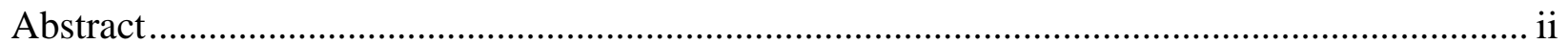

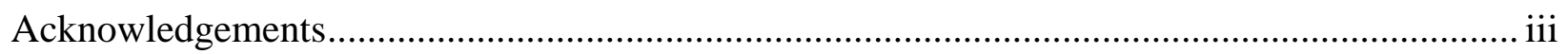

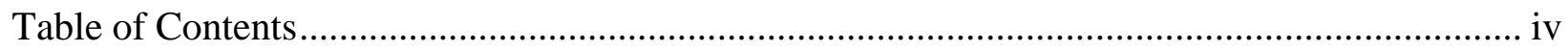

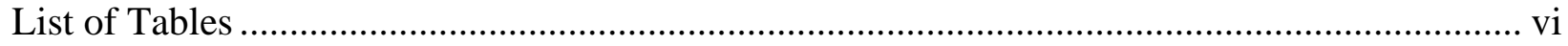

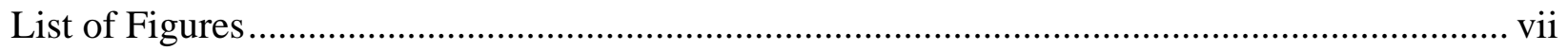

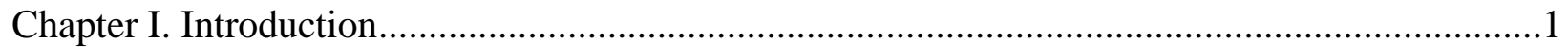

I-1 Statement of the Problem ...................................................................................... 4

Chapter II. Literature Review .........................................................................................

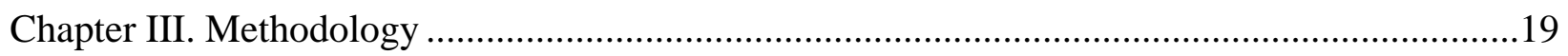

III-1 Model Verification Run with Barnett Shale ............................................................. 22

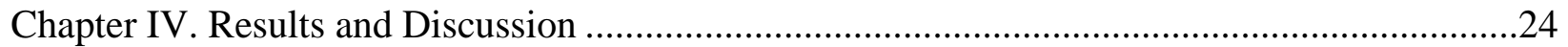

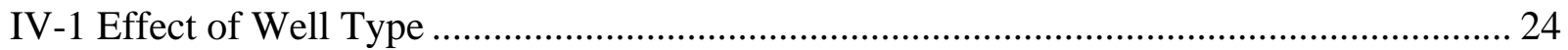

IV-2 Effect of Lateral Length in the Horizontal Wellbore................................................. 25

IV-3 Effect of a Single Fracture in the Wellbore .............................................................. 26

IV-4 Effect of Multiple Fractures in Horizontal Wellbore ................................................... 29

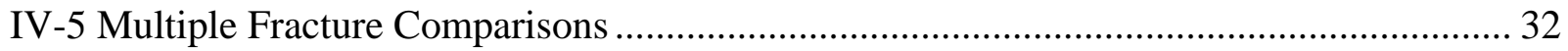

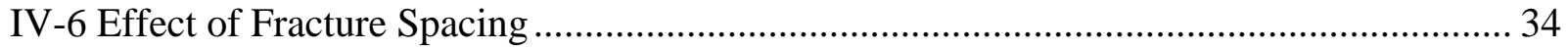

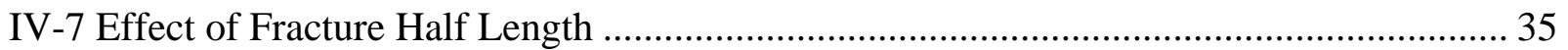

IV-8 Effects of Fracture Half Length and Lateral Length ................................................ 38

IV-9 Comparison of Fracture Half Length and Lateral Length through SRV ....................... 39

IV-10 Effect of Gas Production on Field Pressure.............................................................. 46

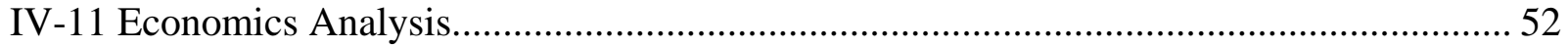

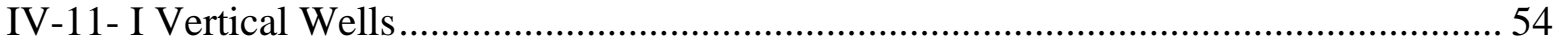

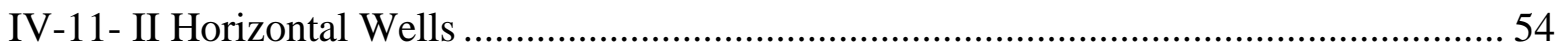

IV-11- III Wells with a Single or No Fractures....................................................... 61

IV- 11- IV Wells with Three Fractures ....................................................................... 63

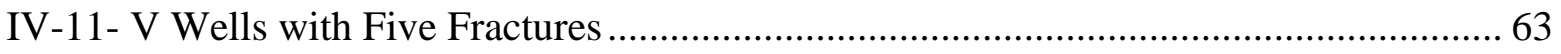

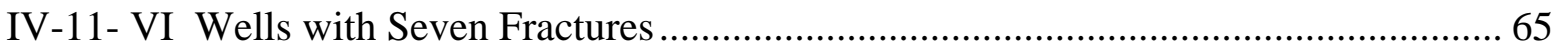

IV-11- VII Wells with Nine Fractures....................................................................... 67

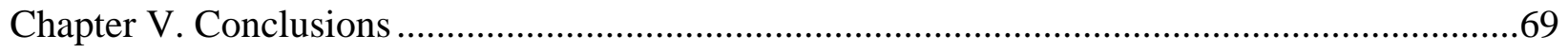




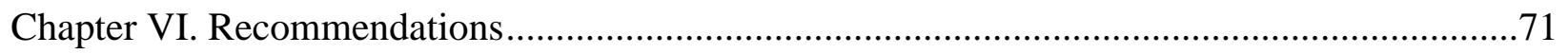

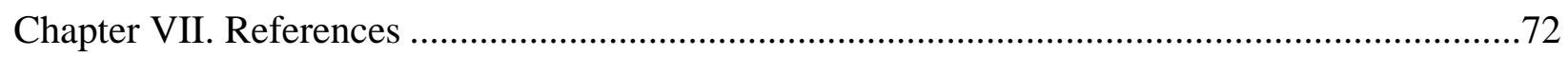

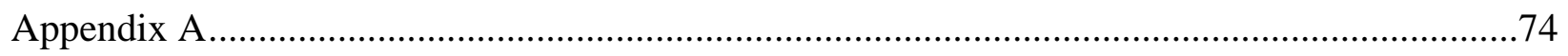

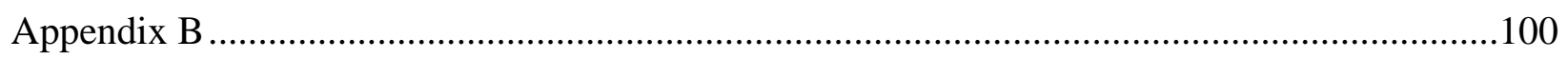




\section{List of Tables}

Page

Table III-1 Matrix of the tests conducted with the reservoir simulator ..........................................20

Table III-2 Marcellus Shale properties used in this study .........................................................21

Table III-3 Production data for the Barnett well .........................................................................22

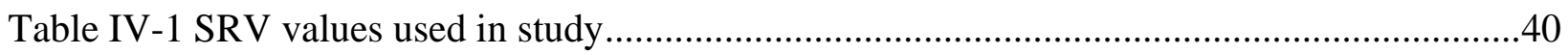

Table IV-2 Drilling cost values used in the economics study .......................................................52

Table IV-3 Completion costs used in the economic study ……………………………................53

Table IV-4 Parameters used in the economics analysis.................................................................53

Table IV-5 Standard cash flow model run for a vertical well........................................................55

Table IV-6 Standard cash flow model run for a horizontal well .....................................................56

Table IV-7 Description of abbreviations used in figures..........................................................60

Table IV-8 Comparison of NPV and \% IRR for different designs for horizontal and vertical wells with zero and one fracture...........................................................................62

Table IV-9 Comparison of NPV and \% IRR for different designs for the single horizontal well with three fractures .........................................................................................63

Table IV-10 Comparison of NPV and \% IRR for different designs for the single horizontal well with five fractures ..........................................................................................64

Table IV-11 Comparison of NPV and \% IRR for different designs for the single horizontal well with seven fractures ......................................................................................66

Table IV-12 Comparison of NPV and \% IRR for different designs for the single horizontal well with nine fractures ........................................................................................67

Table B-1 Comparison of NPV and IRR values at 15\% and \$3/MCF .....................................100 


\section{List of Figures}

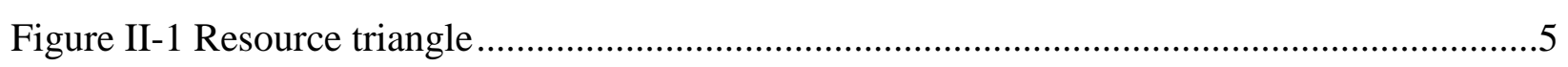

Figure II-2 Annual U.S. natural gas gross production per year ......................................................6

Figure II-3 Average wellhead price, \$/MCF and average gas rate, MCFD/well..............................7

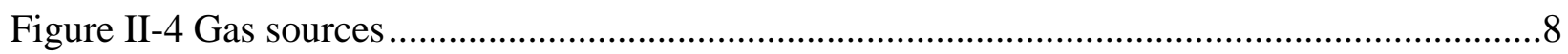

Figure II-5 Unconventional gas production in lower 48 states.................................................

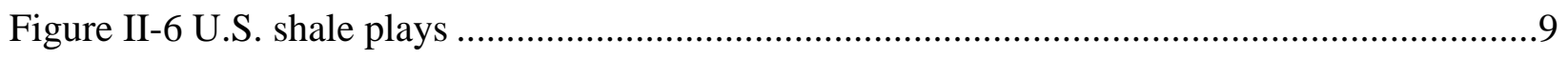

Figure II-7 Pretax internal rate of return at 8-10/MMBtu NYMEX gas .....................................10

Figure II-8 Breakeven economics (\$MMBtu* .....................................................................11

Figure II-9 Production forecast of major US shale plays (Bcf/d) ..................................................12

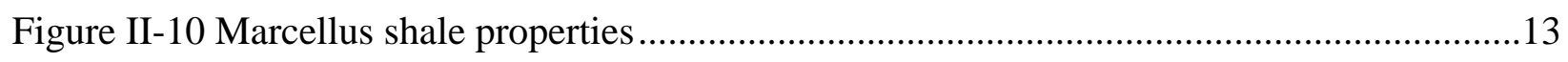

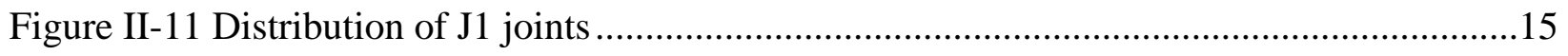

Figure II-12 Number of frac jobs per well in the Barnett Shale ..................................................18

Figure III- 1 Comparison of gas production from Barnett Shale well with simulated results.......23

Figure IV-1 Total gas production with time for three well designs..............................................25

Figure IV-2 Effect of lateral length on total gas production with time (horizontal wells) .............26

Figure IV-3 Effect of fracture treatment on total gas production for vertical and

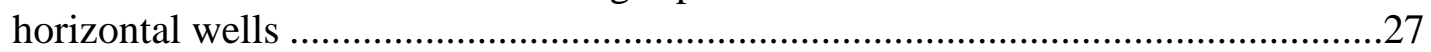

Figure IV-4 Comparison of total gas production for wells with one fracture treatment $(\mathrm{XF}=500 \mathrm{ft})$......

Figure IV-5 Comparison of total gas production for wells with one and three fracture treatments $(\mathrm{XF}=500 \mathrm{ft})$

Figure IV-6 Comparison of total gas production for horizontal wells with three and

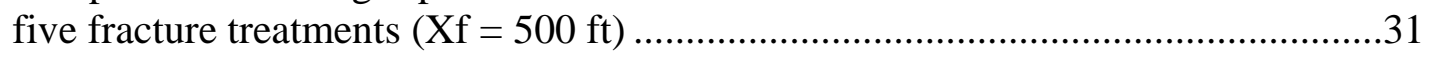

Figure IV-7 Comparison of total gas production for horizontal wells with five and seven fracture treatments $(\mathrm{Xf}=500 \mathrm{ft})$

Figure IV-8 Comparison of total gas production for horizontal wells with $4000 \mathrm{ft}$ lateral length and different number of fracture treatments and three vertical well design $(\mathrm{XF}=500 \mathrm{ft})$.

Figure IV-9 Comparison of total gas production for horizontal wells with different number of fracture treatments and spacing between treatments $(\mathrm{XF}=500 \mathrm{ft})$.

Figure IV-10 Comparison of total gas production from vertical wells with differnet fracture half lengths

Figure IV-11 Comparison of total gas production from three vertical wells with different fracture half lengths 
Figure IV-12 Comparison of total gas production from horizontal wells with $4000 \mathrm{ft}$ lateral lengths and nine fracture treatments with different fracture half lengths.....

Figure IV-13 Comparison of total gas production from horizontal wells with 3000 and $4000 \mathrm{ft}$ lateral lengths and seven fracture treatments with different fracture half lengths.....39

Figure IV-14 Comparison of total gas production for two well designs with same SRV and seven fracture treatments

Figure IV-15 Comparison of total gas production for one and one and a half million stimulated rock volume with five fracture treatment designs

Figure IV-16 Comparison of total gas production for two and three milion stimulated rock volume with five fracture treatment design

Figure IV-17 Comparison of total gas production for two and three million stimulated rock volume with three fracture treatment designs

Figure IV-18 Comparison of total gas production for one and one and a half million stimulated rock volume with one fracture treatment design .

Figure IV-19 Comparison of total gas production for one and one and a half million stimulated rock volume for the last ten years

Figure IV-20 Variation of GIP for the horizontal well with seven fracture treatments and 4000 foot lateral section and $750 \mathrm{ft}$ fracture half length

Figure IV-21 Variation of reservoir pressure for the horizontal well with seven fracture treatments and 4000 foot lateral section and $750 \mathrm{ft}$ fracture half length

Figure IV-22 Reservoir pressure distribution at the end of 50 years (horizontal well with one fracture treatments).

Figure IV-23 Reservoir pressure distribution at the end of 50 years (horizontal well with three fracture teatments)

Figure IV-24 Reservoir pressure distribution at the end of 50 years (three vertical wells with one fracture treatments)

Figure IV-25 IRR of 7 fracture 3000 foot lateral and 1000 foot half length well design ..............57

Figure IV-26 Comparison of NPV at 15\% interest rate for well designs used in this study .........58

Figure IV-27 Comparison of NPV values for different designs for the single horizontal well with five fractures.

Figure IV-28 Comparison of NPV values for different designs for the single horizontal well with seven fractures.

Figure IV-29 Comparison of NPV values for different fracture half length designs for the single horizontal well with $4000 \mathrm{ft}$ lateral length and nine fractures 68

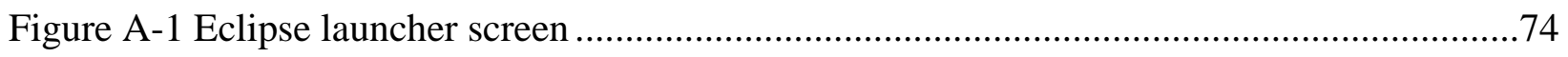

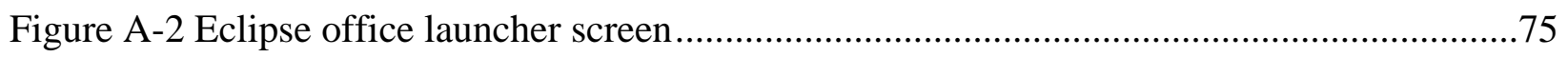

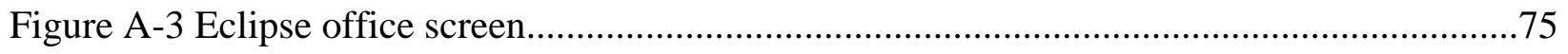


Figure A-4 Eclipse file directory screen …………….............................................................76

Figure A-5 Eclipse add template case screen …………….......................................................77

Figure A-6 Coal bed methane template selection screen..............................................................78

Figure A-7 Model definition screen................................................................................

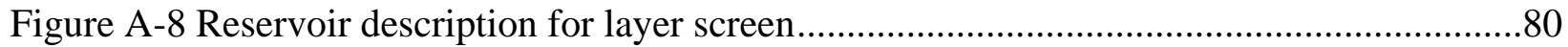

Figure A-9 Reservoir description for rock properties screen........................................................81

Figure A-10 Reservoir description for non-equilibrium initial conditions screen..........................82

Figure A-11 Reservoir description for aquifers screen ...............................................................82

Figure A-12 Reservoir description for fractures screen..............................................................84

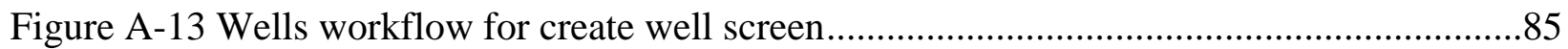

Figure A-14 Wells workflow for wells deviation survey screen ..............................................86

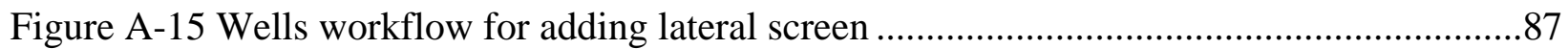

Figure A-16 Wells workflow for horizontal section deviation survey screen ...............................88

Figure A-17 Production well control options ..............................................................................

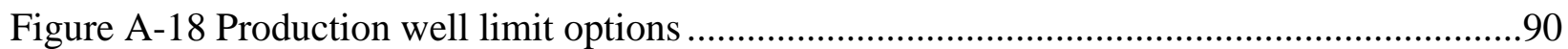

Figure A-19 Production well perforation addition for at vertical section.......................................91

Figure A-20 Production well perforation addition for horizontal section ......................................91

Figure A-21 Fluid properties workflow for PVT correlations.....................................................92

Figure A-22 Fluid properties workflow for relative permeability correlations (gas) .....................92

Figure A-23 Fluid properties workflow for relative permeability correlation (water) ...................93

Figure A-24 Fluid properties workflow for coal bed methane ………........................................93

Figure A-25 Fluid properties workflow for advanced controls .....................................................94

Figure A-26 Simulation controls workflow for gridding controls.................................................94

Figure A-27 Simulation controls workflow for tuning controls ...................................................95

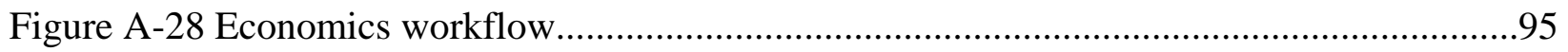

Figure A-29 Generated reservoir model with $4000 \mathrm{ft}$ horizontal wellbore with three fracture

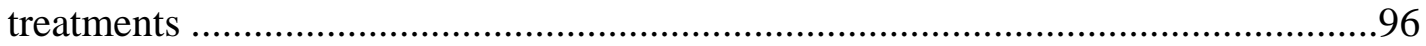

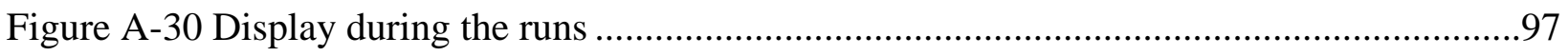

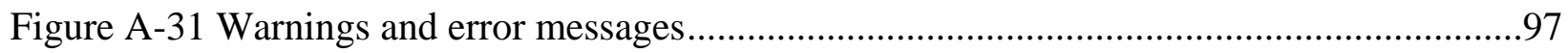

Figure A-32 Results viewer example of field production totals ....................................................98

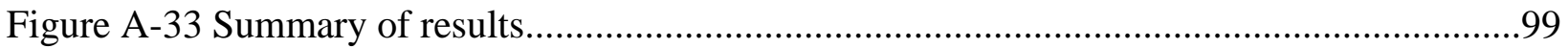




\section{Chapter I. Introduction}

Once ignored by exploration and development companies, organic rich, low permeability, naturally fractured shale reservoirs were considered taboo. Now due to increasing technology, a projected increase in gas prices, along with diminishing amounts of conventional reservoirs, these unconventional shale plays are now the up and coming thing of the future. In Nomes analysis in the article "From Shale to Shining Shale", numerous independent producers acreage positions and current plans of production growth have been studied. Based on the current U.S. shale plays development along with supply and demand balances, it is currently estimated that shale plays account for $10 \%$ of daily U.S. gas production, and it is believed that the number will double in the next three years (Nome, 2008).

A shale gas by definition is an unconventional, continuous natural gas reservoir contained in fine-grained rocks, dominated by shale. Shale is the Earth’s most common rock, rich in organic content, but with ultra low permeability. In many fields, the shale produces a seal that retains the hydrocarbons within the producing reservoir, thus being both the source rock and the reservoir for the natural gas. However, in some fields, the shale has been the source rock for older shallower formations.

For this paper, the focus will be on one such shale play, the emerging Marcellus shale. Gas from the Marcellus shale is estimated to have been produced initially in 1880 (Drake, 2007). While it has been known as a gas reservoir for quite some time, the Marcellus became much more attractive recently due to the increase in natural gas prices and the availability of better technologies for drilling and completion (Harper, 2008). Currently, activity in the Marcellus 
shale is moving from the exploratory stage to commercial production as a number of companies have already brought wells online (Nome, 2008). The Marcellus shale is typically described as a black shale at the base of the Middle Devonian Hamilton Group; the upper part of the group is occupied by gray and dark-gray shales, siltstones, and (to the east) sandstones of the Mahantango Formation. The organic richness within the Hamilton Group in the subsurface varies from place to place due to the boundary fluctuations (Harper, 2008). These Devonian shales are approximately 350 - 415 million years old and are composed from muddy sediments on the floors of inland seas (Sumi, 2008).

In reality, current production started in 2005, when Range Resources-Appalachia, LLC (Range) formerly Great Lakes Energy Partners, LLC found success in the Marcellus shale. Range started by drilling a well to the Lower Silurian Rochester Shale, in Washington County, Pennsylvania, in 2003. The deeper formations, the Oriskany and Lockport were unfavorable but the Marcellus had some promise, after applying fracturing techniques adopted from the Missississippian Barnett Shale gas play in Texas, Range found success. Since 2005, Range has permitted 150 wells in Washington County alone (Harper, 2008).

The Marcellus can be found at depths of 5,000-8,500 ft and generally ranges in thickness from 50-200 ft (Nome, 2008). The name Marcellus is reportedly derived from the town Marcellus, NY where an outcrop was found during a geological survey in 1839 (Sumi 2008). The Marcellus covers approximately 54,000 square miles and can be found throughout West Virginia, the eastern half of Ohio, the western part of Pennsylvania, and the southern tier of New York (Sumi, 2008). 
Researchers from Penn State University and the State University of New York at Fredonia have estimated that there is 168-516 trillion cubic feet (Tcf) of original gas in place. When calculating the total recoverable gas $10 \%$ is usually employed, thus $16.8-50$ Tcf of natural gas could be recovered (Armas, 2008) (Chernoff, 2008) (Sumi, 2008). By classification, if greater than 30 Tcf of gas is recoverable, then the field would be considered a super giant (Suhy, 2008). When stimulated with modern techniques, this shale has been predicted to produce for 30-100 years almost 100\% of the time (Newswire Today, 2008).

The U.S. produces approximately 19 Tcf of gas per year, with approximately $85 \%$ of the U.S. gas supply produced within the country (Armas, 2008). The remainder is mostly supplied by Canada (Contrarian, 2008). In 2007, the U.S. consumed 23.0 Tcf of natural gas and 21.0 Tcf of gas in 2006 (EIA, 2008) (Sumi, 2008). Thus, at the current estimate of recoverable gas and the 2007 consumption rate, the Marcellus shale could provide the U.S. with 1 to 2.4 years of production.

One useful tool to understand the potential of the Marcellus shale may be reservoir modeling. Reservoir modeling can be a useful tool in an established play, to determine where slight changes can be made in order to increase production. Reservoir modeling can also be useful in an emerging play such as the Marcellus in order determine to approximate potential of the play. Once a base file is set, numerous runs can be conducted by using a simulator. In each run, a different value can be used for certain parameters to determine the best possible combinations in a well, in order to maximize production. 


\section{I-1 Statement of the Problem}

The problem with analyzing typical Marcellus shale reservoirs is the lack of information that has been gathered and that is commercially available to the public. The Marcellus formation is a relatively new play and details involving ways to maximize production though well and fracture design have yet to be published. The Marcellus shale is important due to its large size and the economic impact that it could have on the U.S. As often happens, different companies have certain ideas about the best way to produce the Marcellus shale, while other companies have different development ideas. Through reservoir simulation, the Marcellus formation could be studied to find the effects of these parameters. The premise of this work is to use a reservoir modeling software package to investigate the Marcellus shale reservoir in a selected area that is deep and over pressured. The objective of the study is to compare and contrast the gas production changes between a single vertical well with no fractures, versus a single vertical well with a varying hydraulic fracture half lengths. This study will also be conducted with three vertical wells. All of these wells will be modeled with four different hydraulic fracture half lengths. Once the production performances of different vertical well designs are compared, comparisons will then be made to a single horizontal wellbore in the same reservoir. This study will be made with four different lateral lengths and five different fracture designs along the wellbore. The fracture designs are considered for four different fracture half lengths for vertical and horizontal wells. Once, all of the production data are obtained, an economic analysis will be conducted to determine the most optimal designs for the parameters studied. All of the modeling and production forecasting will be completed utilizing a reservoir simulator. This paper discusses the results of these designs and the effects of fracture length and horizontal well length on the gas production of Marcellus shale wells. 


\section{Chapter II. Literature Review}

Reservoirs with medium to high permeability, for the most part need little or no technical assistances, these reservoirs are said to be conventional reservoirs. Whereas reservoirs with lower permeability generally need improved technology to be produced and are more costly, these reservoirs are considered unconventional reservoirs. Conventional reservoirs are usually small and hard to find, yet easy to develop. Unconventional reservoirs are much larger and easier to find, yet difficult to develop (Lane 1989). As the supplies of the smaller easier conventional reservoirs are depleted, the need to develop larger difficult unconventional reservoirs increases. These unconventional reservoirs need increased technology and are much more costly to develop. As the price of gas continues to increase and technology has developed, the unconventional gas shales can be put on production.

\section{Resource Triangle}

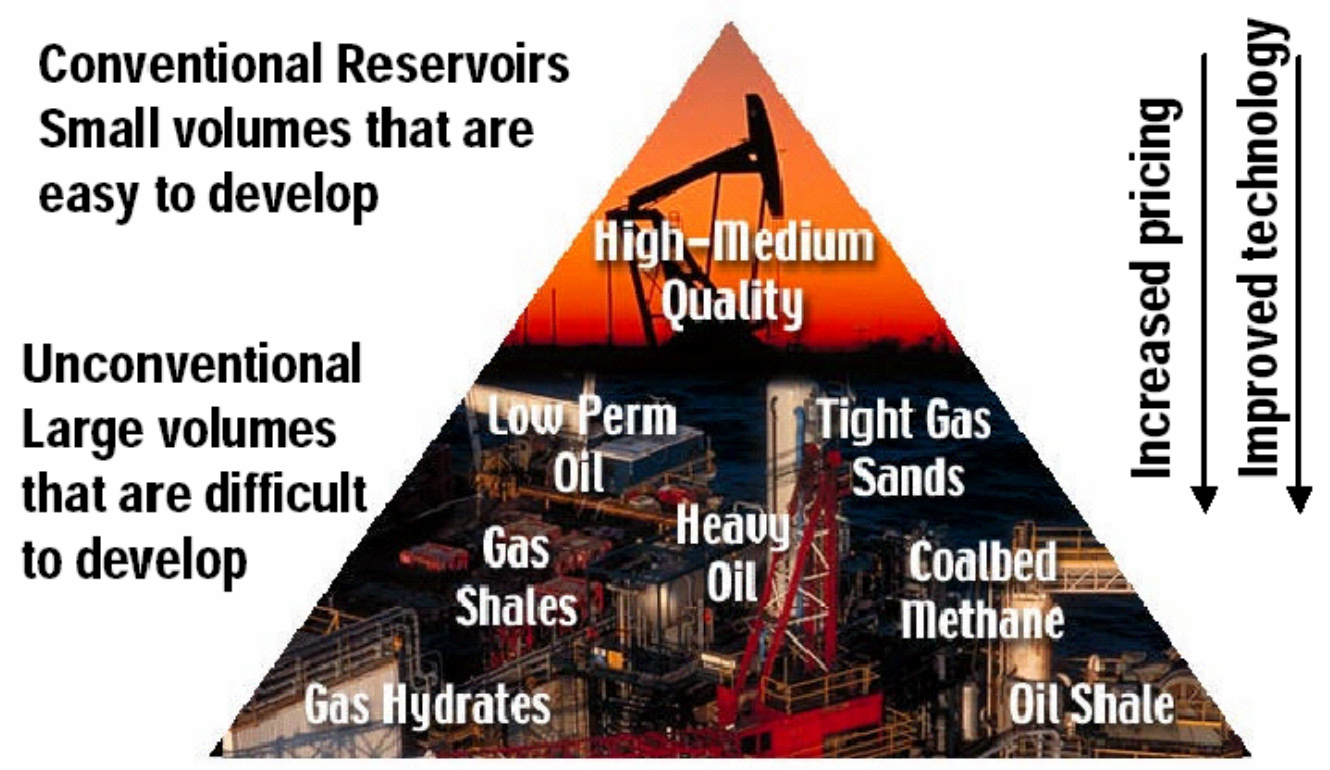

Figure II-1 Resource triangle (Lane, 1989). 
From the 1940's to the 1970's U.S production steadily increased mostly from those conventional reservoirs as seen in Figure II-2. In the late 1970's, the production started to decline, primarily due to fact that most of the easier conventional reservoirs had or were being produced. The Barnett shale in Texas was first produced in 1982 and the Antrim shale of Michigan in 1985 (Drake, 2007). Around this point in time, the U.S. gas production continued to increase due to the increase in production of those unconventional reservoirs.

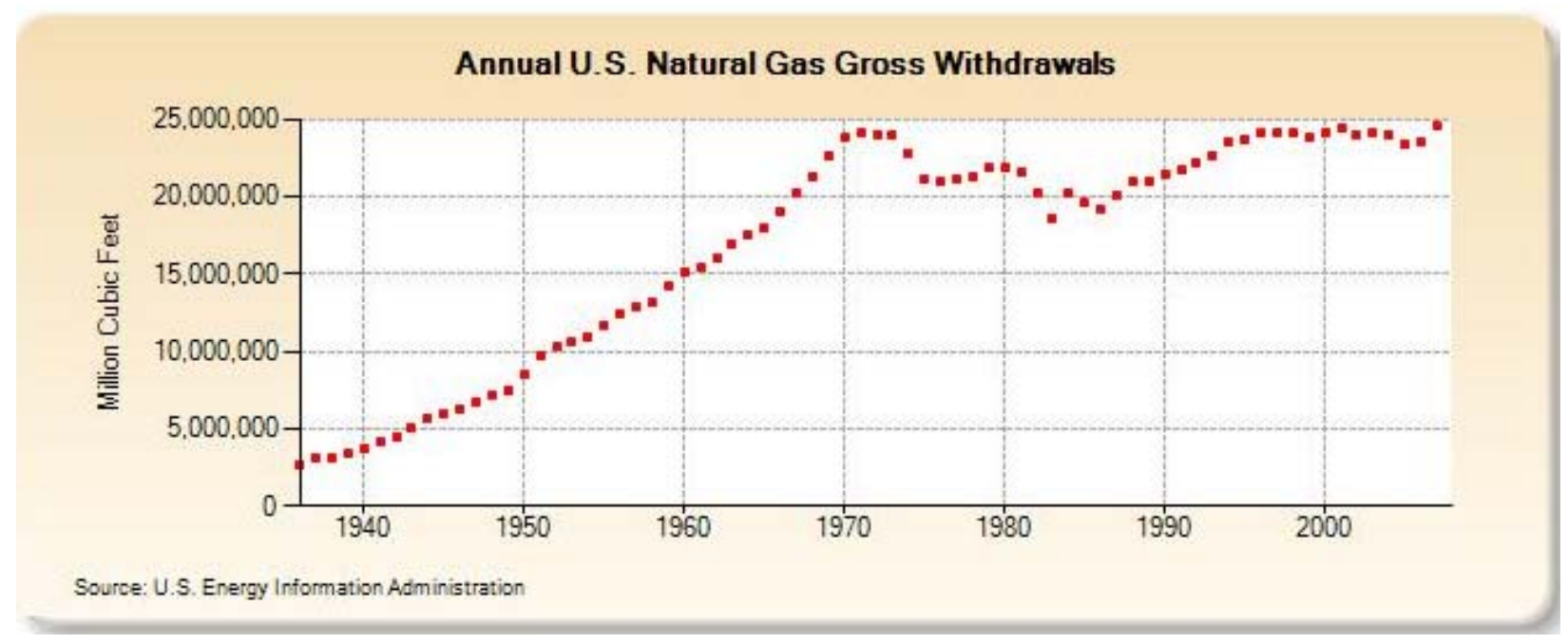

Figure II-2 Annual U.S. natural gas gross production per year (EIA, 2008).

Figure II-3 shows, the average values well head price and gas rate as rate as afunction of time between 1967 and 2005. It shows that over time the conventional wells gave way to unconventional wells around the mid 1980's. This is noted from the decrease in the average gas rate per well. As the price of gas increased, the unconventional wells now could become profitable and more companies were willing to go after them. As of 2000, it became even more profitable and thus the emergence of all of these new gas plays such the Marcellus, Haynesville and many others. 


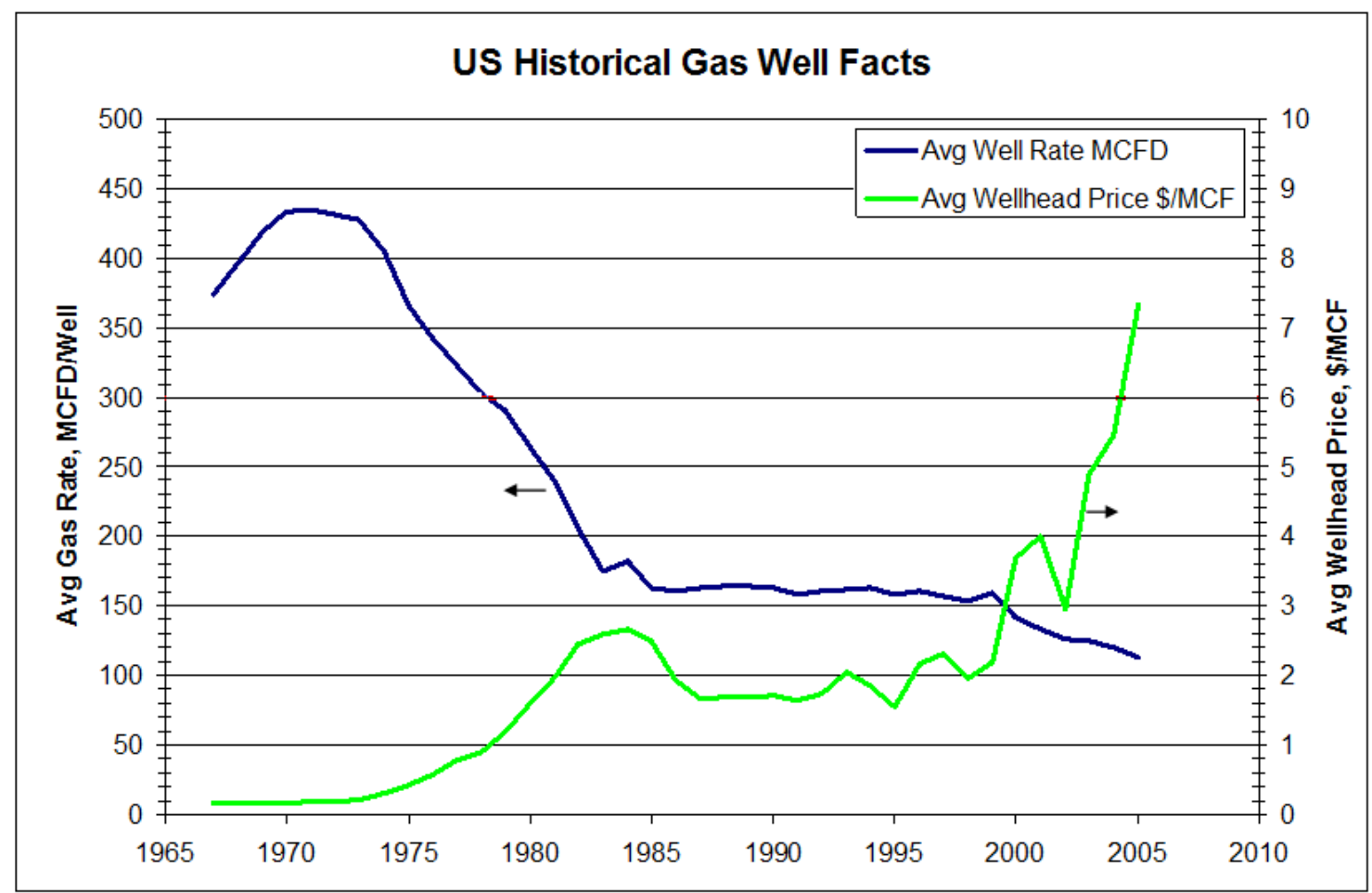

Figure II-3 Average wellhead price, \$/MCF and average gas rate, MCFD/well (EIA, 2008).

As seen in Figure II-4, while conventional and offshore gas production is declining, onshore unconventional resources are thriving. This figure shows that the future of natural gas production is going to come from unconventional onshore reservoirs such as shales, coalbed methane and tight sands for at least the next twenty years. (Nome, 2008) (EIA, 2008). 


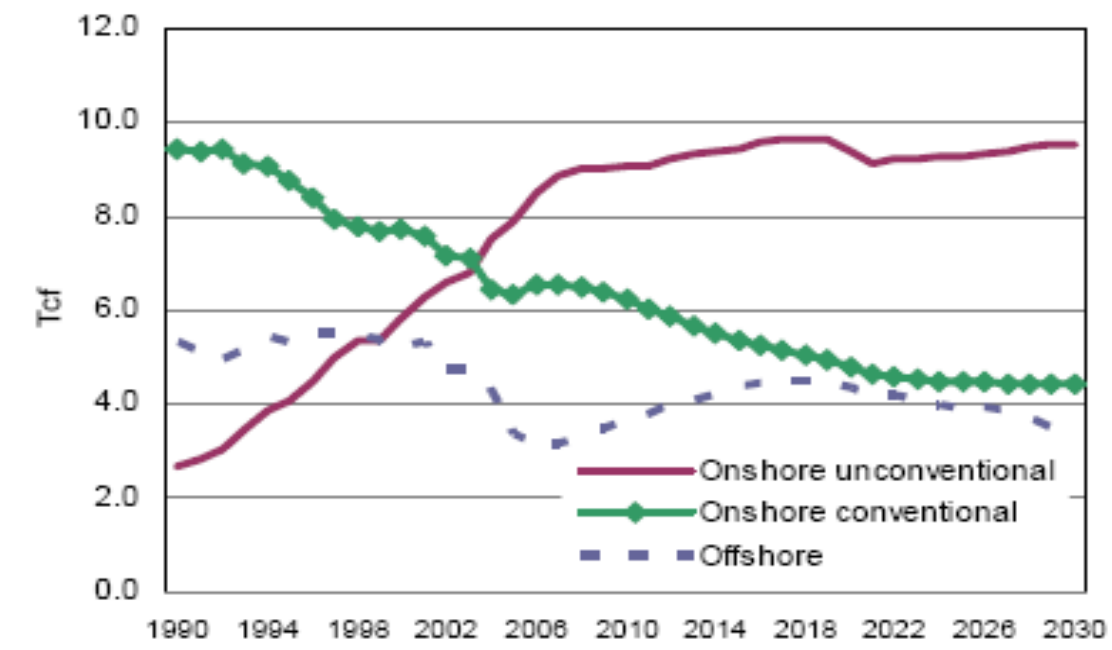

Sounce: ELA, AEO 2008

Figure II-4 Gas sources (EIA, 2008).

The history and future projections of tight sands, coal bed methane, and gas shales production is shown in Figure II-5. While tight sands and coal bed methane are tending to level out over time, gas shales are continuing to rise (Nome, 2008) (EIA, 2008).

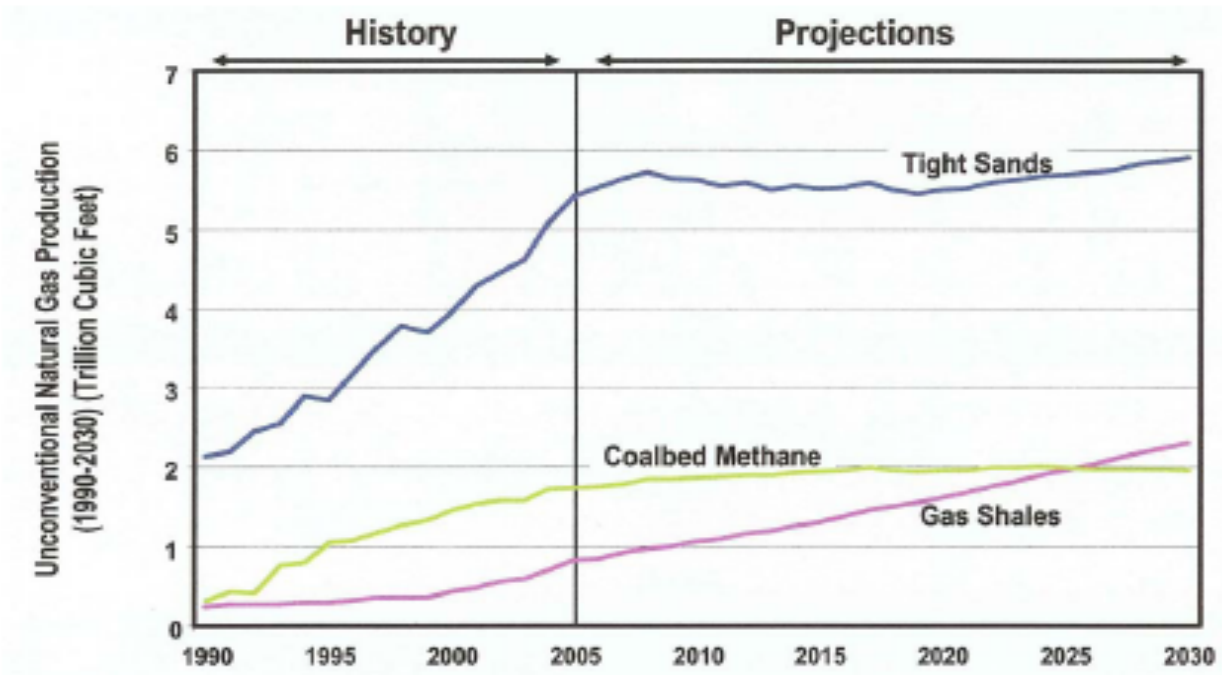

Sowce: ELA AEO 2007

Figure II-5 Unconventional gas production in lower 48 states (EIA, 2007). 
The major U.S. shale plays are shown in Figure II-6. The Marcellus shale is not shown but it is contained within the Devonian/Ohio shale. The Marcellus formation has an estimated gas in place at 168 - 516 TCF or 70 - 150 (BCF/sq mile) (Armas, 2008) (Chernoff, 2008) (Sumi, 2008). Another new large field not shown is the Haynesville shale with an estimated a GIP/sq mi BCF of 150-250 (Nome, 2008).

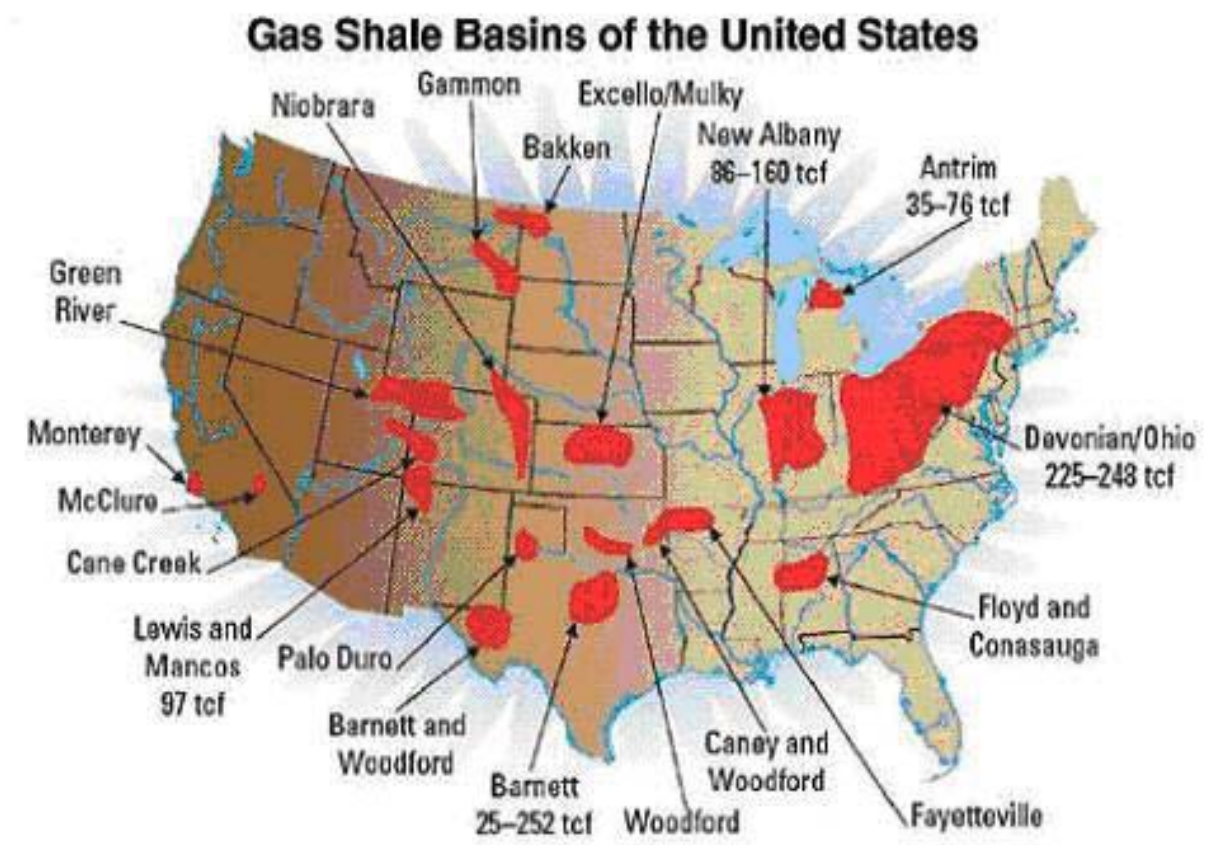

Figure II-6 U.S. shale plays (Nome, 2008).

According to estimates generated by Deutsche Bank, the range of internal rate of return (IRR) for the Marcellus shale is $72-100 \%$ as shown in Figure II-7 (Nome, 2008). IRR is a capital budgeting metric used by firms to decide whether they should make investments. It is an indicator of the efficiency or quality of an investment, as opposed to net present value, which indicates value or magnitude. The IRR is greater for the Marcellus than for other U.S. shales 
because of premium natural gas pricing due to location and relatively low royalties in Appalachia.

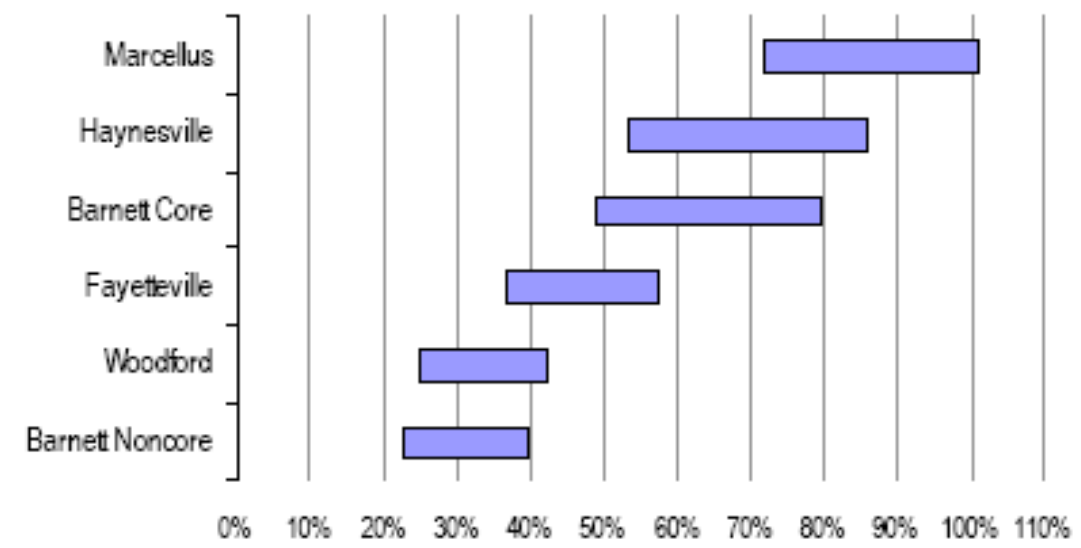

Source: Deutsche Bank estimates

Figure II-7 Pretax internal rate of return at 8-10/MMBtu NYMEX gas (Nome, 2008).

In addition, the Marcellus is estimated to have the lowest breakeven price (\$3.17) when compared to the Haynesville, Barnett, Fayetteville, and Woodford shales. Figure II-8 depicts the NYMEX natural gas prices required to drive the individual plays’ returns down to a $10 \%$ weighted average cost of capital. Notably, this study believes that the six plays that were analyzed represent the "best of breed" among U.S. shale plays, and would not expect most other shale and tight gas plays to compare to these strong metrics (Nome, 2008). 


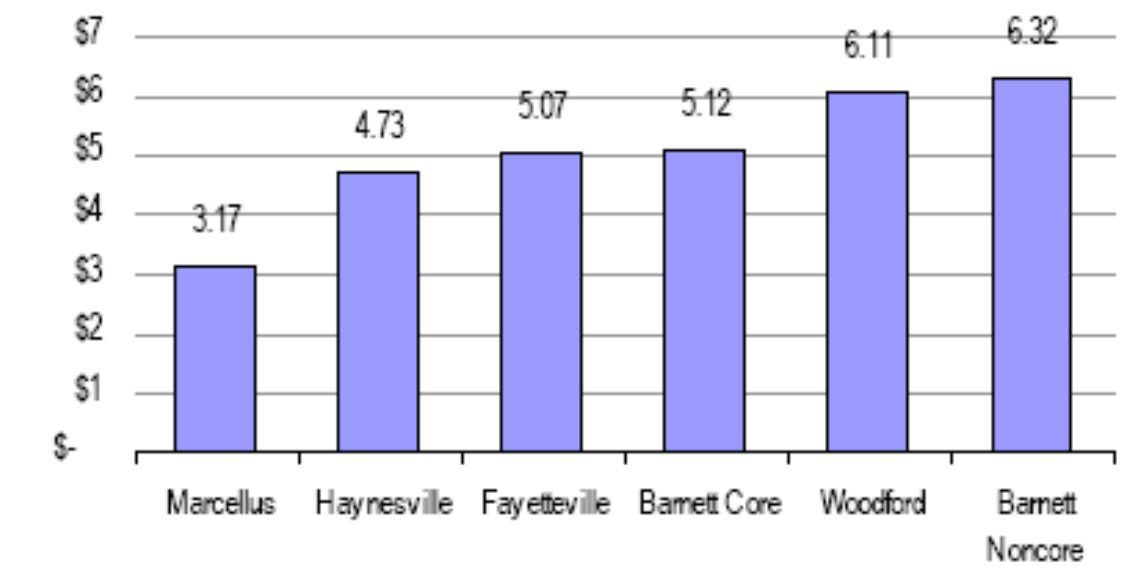

Source: Deutsche Bank estimates "NYMEX; for a $10 \%$ pretax iRf

Figure II-8 Breakeven economics (\$MMBtu*) (Nome, 2008).

As seen in Figure II-9 the total production of U.S. gas shales predicted at year end 2011 will be nearly eight times greater than at year end 2006. The Woodford, Fayetteville, and Haynesville gas production are currently increasing greatly while the Marcellus shale is not predicted to really take off until about 2010 (Nome, 2008). The slower transition in the Marcellus is due to the difficult terrain, uncertain regulatory environment, lack of infrastructure and proper equipment (Perkins, 2008). 


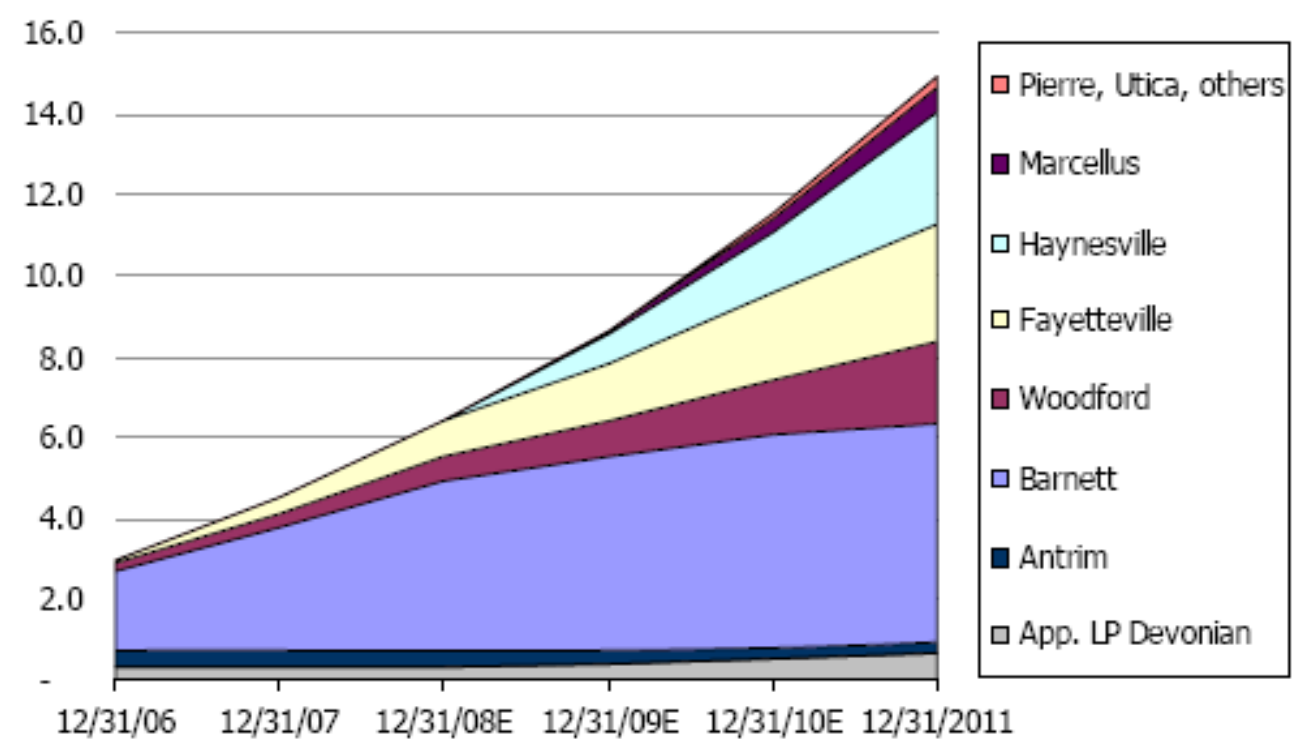

Source: Company dsta, Wood Mackenzie, Deutsche Bank estimstes

Figure II-9 Production forecast of major US shale plays (Bcf/d) (Nome, 2008).

Figure II-10 shows the Marcellus fairway along with some important characteristics used in this study. Some of these characteristics are depth, thickness, typical fracs, and lateral lengths along with others. As seen on the map, the Marcellus covers a large area, approximately 600 miles in length. By comparison, the Barnett shale has a linear extent totaling about 120 miles (Sumi, 2008). 


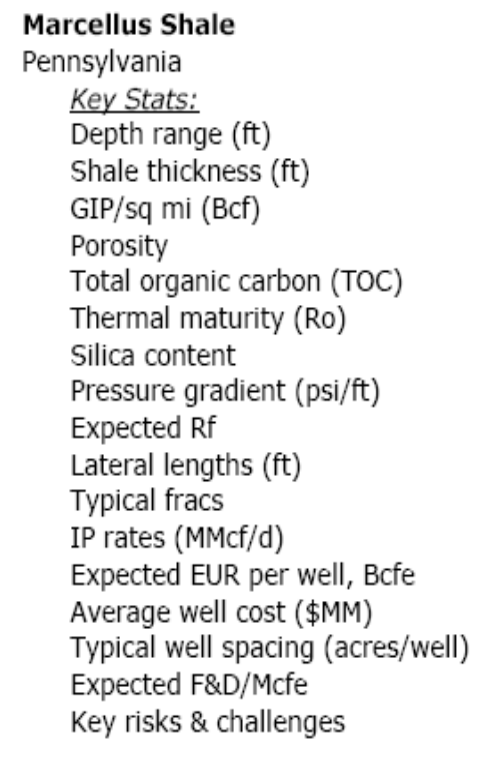

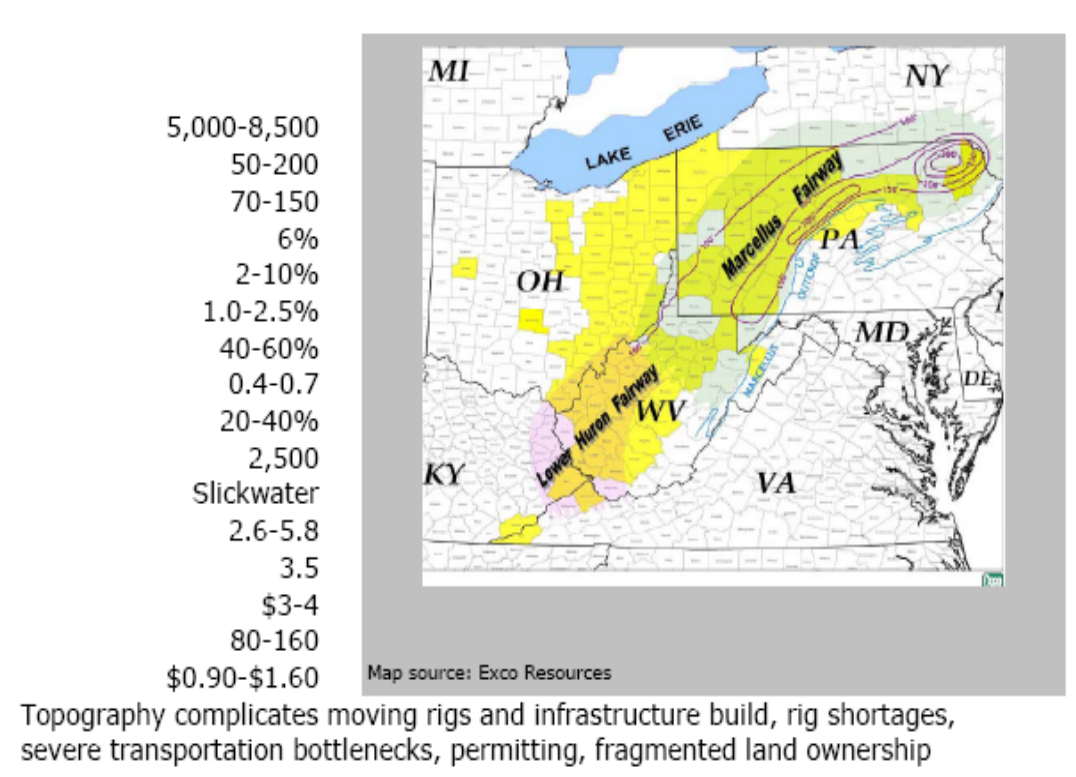

Topography complicates moving rigs and infrastructure build, rig shortages, severe transportation bottlenecks, permitting, fragmented land ownership

Figure II-10 Marcellus shale properties (Nome, 2008).

What is the best method to drill in the Marcellus is the question to be answered. Maybe it is vertical wells or possibly horizontal wells; maybe it is a combination of both. Maybe some areas will be better suited for verticals due to geology. Either way, these shale wells need stimulation to increase the permeability. Currently, the pore spaces in shales are typically not large enough for even tiny methane molecules to flow through easily. Shale’s may contain natural fractures due to stress from overlying rocks. Shale gas has long been produced when natural fractures are present. Recently, however, there has been more development of gas shales due to the use of techniques that create artificial fractures around well bores known as hydraulic fracturing (Sumi, 2008). The shale formations are naturally fractured, and made up of two distinct porous media, a shale matrix and a fracture network. Gas can be stored in the molecular size micropore space of the shales, it can also be absorbed on the surface of the shale, or may be dissolved in the organic content of the shales. The shale matrix contains most of the gas stored in 
the reservoir, but possesses a low permeability. The fracture network has a high permeability, but a low storage capacity. It is believed that natural gas is stored in the Devonian shales as both conventional "free" gas and as adsorbed gas, or gas that is physically attached to the surface of the shales by Van der Waals-type forces (Lane, 1990). These natural fractures and adsorbed gas have to be accounted for in the reservoir modeling.

As for the location of the natural fractures, Dr. Lash and Dr. Engelder have been studying the Devonian shales for years. They have concluded, "ENE-trending $\left(\mathrm{J}_{1}\right)$ joints parallel the maximum compressive normal stress of the contemporary tectonic stress field $\left(\mathrm{S}_{\mathrm{H}}\right)$ and are crosscut by NW-trending $\left(\mathrm{J}_{2}\right)$ joints. Horizontal drilling should target $\mathrm{J}_{1}$ by drilling to the NNW to take advantage of a permeability anisotropy arising from the more densely developed $\mathrm{J}_{1}$ set that is subject to a lower normal stress (i.e, $\mathrm{S}_{\mathrm{h}}$ of the contemporary tectonic stress field) than $\mathrm{J}_{2}$ ” in the Marcellus shale (Engelder \& Lash, 2008).

Figure II-11 shows semi-proprietary reports of J1 joints in fullbore formation microimager (FMI) logs or reports of north north west horizontal drilling. This is in order to drill across the maximum amount of J1 joints thus to theoretically produce the most gas in the Marcellus shale (Engleder \& Lash, 2008). 


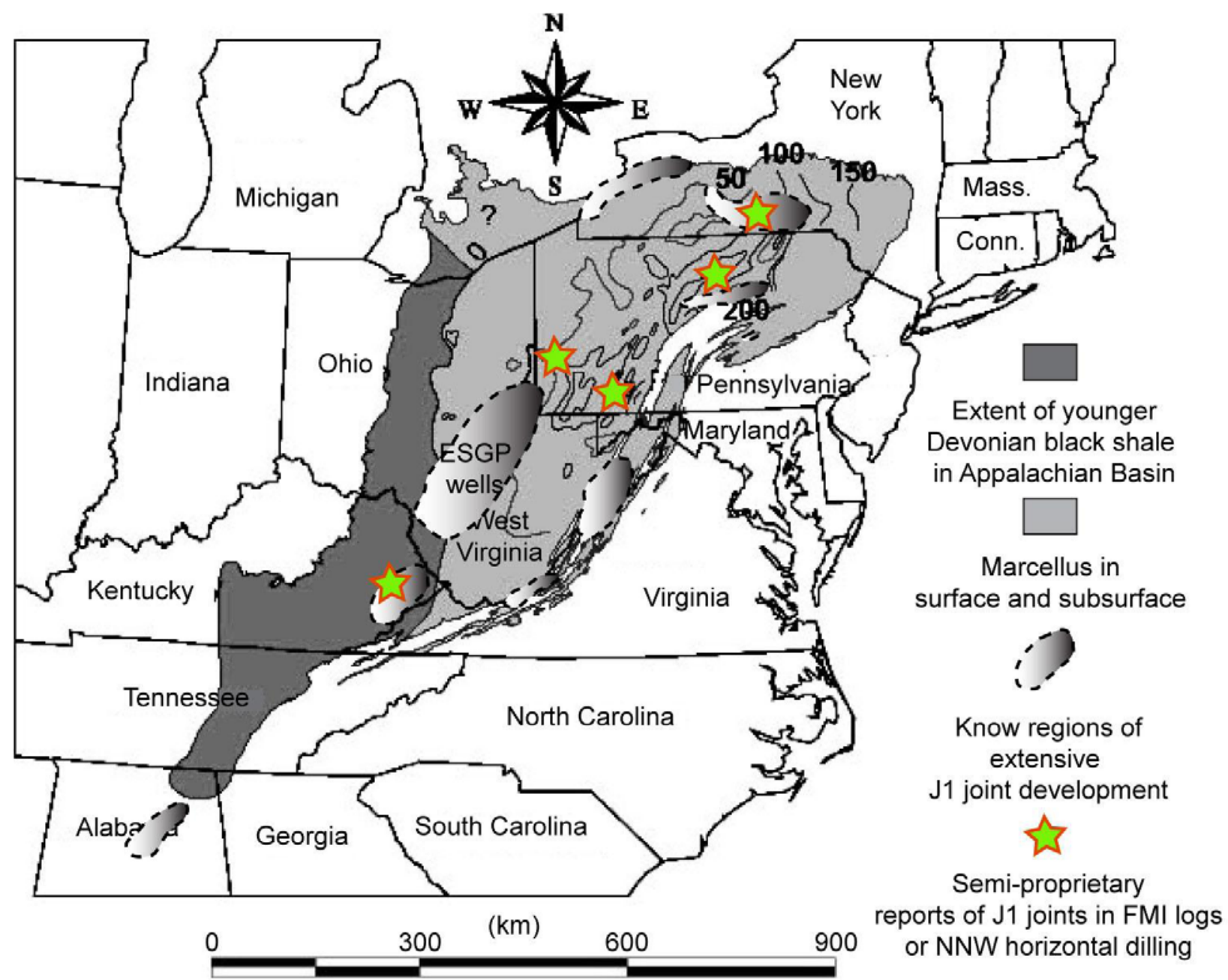

Figure II-11 Distribution of J1 joints (Engelder \& Lash, 2008).

Some companies like Range Resources are drilling horizontal wells while others such as Atlas are drilling both, but mostly vertical wells. At the beginning of March 2008, Range had 60 wells to be completed in the Marcellus shale in their 2008 budget (Company News Mar, 2008). Forty of those were intended to turn horizontal (Area Drilling Mar, 2008). Fifteen horizontal wells had been drilled, and eleven of those had been completed. Initial producing rates ranged from 1.4-4.7 MMcfd of gas equivalent. By July 14, 2008, Range had drilled over 100 wells in the Marcellus; twenty of those were horizontal (Range Resources, Jul 14, 2008). As of 
November 2008, Range had seven wells that are tied into the gas processing facility and net sales from these wells total 30 Mmcfe per day (Range Resources Nov, 2008). “A cryogenic plant is expected to be online by the end of first quarter 2009, increasing gas processing capacity to 60 Mmcf per day. By year-end 2009 or early 2010, processing capacity is anticipated to be 180 Mmcf per day. As additional gas processing capacity is completed, Range will turn on additional wells. Range currently plans to enter 2009 with three horizontal rigs, increasing to six rigs by the end of 2009. By year-end 2009, Range anticipates that production will reach 80 to100 Mmcfe per day, net to its interest.” (Range Resources Nov, 2008). Range has since stated, “Of the last eleven Marcellus wells announced, four had initial rates of 9.9 Mmcfe per day or more. The best well had an initial rate of 24.5 Mmcfe per day.” (Range Resources Feb, 2009).

Atlas America, Inc. had, twenty one of the twenty seven vertical wells it had drilled were already producing and connected to a pipeline with six slated to be connected. After drilling one horizontal well with a partner, Atlas planned to drill four additional horizontal wells in 2008. It forecasted to drill and complete over 150 vertical wells in the next year and a half. By the end of May, Atlas had drilled 52 vertical wells, with 35 of those producing into pipeline (Atlas America, 2008). The average peak daily rate per vertical well was greater than one million cubic feet. By the close of 2009, they predicted to drill 24 horizontal wells. Atlas Energy recently announced that after reviewing the effective length of its hydraulic fractures, the company believes that it will be able to develop its southwestern Pennsylvania Marcellus leases using vertical wells (Sumi, 2008). The average cost for one of these vertical wells is approximately 1 million dollars and a horizontal well would cost approximately 3.5 million (Nome, 2008) (Sumi, 
2008). Atlas has since changed their philosophy of drilling vertical wells and are planning to drill more horizontal wells.

As for the completion of these wells, initially there were three thoughts according to the Independent Oil and Gas Association of West Virginia in 2006, straight nitrogen gas, nitrogen foam and slickwater hydraulic fracs. The slickwater fracturing method was made popular in the Barnett shale and is moving into the new emerging shale plays like the Marcellus, Haynesville, Woodford and Fayetteville shales. Slickwater is used in the deeper over pressured shales and foam is used in shallow low pressure shales (Sumi, 2008). The first large slickwater fracture occurred in the Marcellus shale occurred in 2004 (Fontaine, 2008).

These slickwater fracturing jobs also create water acquisition and disposal issues. While water has always been used in drilling, hydraulic fracturing requires a considerably larger amount of water (Falchek, 2008). The Railroad Commission of Texas states that in a typical Barnett shale vertical well 1.2 million gallons of water are used, and 3.5 million gallons are used in a horizontal well. Figure II-12 shows that a more recent trend in the Barnett shale is to have more frac jobs per well (Sumi, 2008). In this research there will be zero, one, three, five, seven and nine stages in horizontal wells and zero and one frac stages in the vertical wells. 


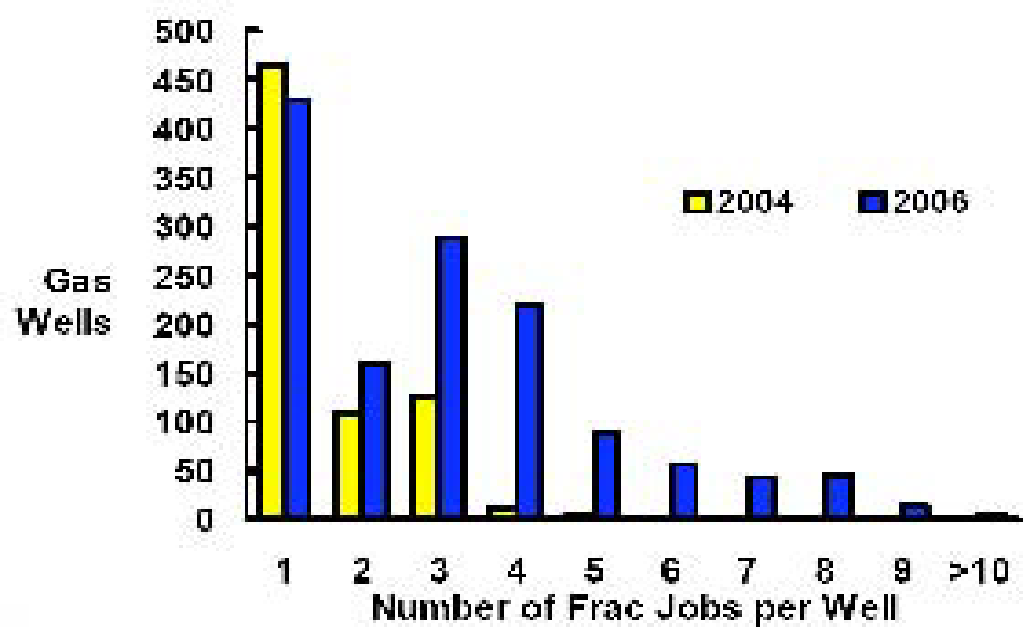

Figure II-12 Number of frac jobs per well in the Barnett Shale (Sumi, 2008). 


\section{Chapter III. Methodology}

To study the effects of fracture half length and lateral lengths on shale gas production, reservoir modeling study was conducted. To simulate production data for Marcellus shale wells, Schlumberger's Eclipse software was used. A total of seventy four different simulations were conducted. Only one parameter was changed at a time to hold the validity of the effect of the parameter that was investigated. Comparisons were then made to the effects of the changes. Prior to runs with Marcellus shales properties, a Barnett shale well was modeled using the same software and the results were compared to field production data. The primary purpose of the run conducted for the Barnett shale reservoir was to validate the model setup used in the Marcellus reservoir. Once, all of the production data was simulated, an economic analysis was conducted to determine the most optimal designs for the parameters studied.

The Table III-1 shown below summarizes all seventy four of the tests conducted in this study. A coal bed methane template was used to enter shale properties for all cases. The reservoir simulator does not have a shale template and after personal discussions with simulator experts a coal bed methane template was considered as the best option to properly model the adsorbed gas and the natural fractures in shale. A procedure to run the software and enter data through the template is given in Appendix A. 
Table III-1 Matrix of the tests conducted with the reservoir simulator.

\begin{tabular}{|c|c|c|c|c|c|c|c|}
\hline & \multicolumn{2}{|c|}{ Vertical Wells } & \multicolumn{5}{|c|}{ One Horizontal Wells } \\
\hline & One Well & $\begin{array}{l}\text { Three } \\
\text { Wells }\end{array}$ & $\begin{array}{l}\text { Lateral = } \\
1000 \mathrm{ft} .\end{array}$ & $\begin{array}{l}\text { Lateral = } \\
2000 \mathrm{ft} .\end{array}$ & $\begin{array}{l}\text { Lateral = } \\
3000 \mathrm{ft} .\end{array}$ & $\begin{array}{l}\text { Lateral = } \\
4000 \mathrm{ft} \text {. }\end{array}$ & $\begin{array}{l}\text { Lateral= } 4000 \mathrm{ft} \text {. } \\
\text { with } 800 \mathrm{ft} \\
\text { fracture spacing }\end{array}$ \\
\hline No Hydraulic Fracture & $\mathbf{x}$ & $\mathbf{x}$ & $\mathbf{x}$ & $\mathbf{X}$ & $\mathbf{x}$ & $\mathbf{x}$ & \\
\hline $\begin{array}{l}\text { Single Hydraulic Fracture } \\
\text { with } \mathrm{Xf}=250\end{array}$ & $\mathbf{x}$ & $\mathbf{x}$ & $\mathbf{x}$ & $\mathbf{x}$ & $\mathbf{x}$ & $\mathbf{x}$ & \\
\hline $\begin{array}{l}\text { Single Hydraulic Fracture } \\
\text { with } \mathrm{Xf}=500\end{array}$ & $\mathbf{x}$ & $\mathbf{x}$ & $\mathbf{x}$ & $\mathbf{X}$ & $\mathbf{x}$ & $\mathbf{x}$ & \\
\hline $\begin{array}{l}\text { Single Hydraulic Fracture } \\
\text { with } \mathrm{Xf}=750\end{array}$ & $\mathbf{x}$ & $\mathbf{x}$ & $\mathbf{x}$ & $\mathbf{X}$ & $\mathbf{x}$ & $\mathbf{x}$ & \\
\hline $\begin{array}{l}\text { Single Hydraulic Fracture } \\
\text { with } \mathrm{Xf}=1000\end{array}$ & $x$ & $\mathbf{x}$ & $\mathbf{x}$ & $\mathrm{X}$ & $\mathbf{x}$ & $\mathbf{x}$ & \\
\hline $\begin{array}{l}\text { Three Hydraulic Fracture } \\
\text { with } X f=250\end{array}$ & & & & $\mathbf{X}$ & $\mathbf{x}$ & $\mathbf{x}$ & $\mathbf{x}$ \\
\hline $\begin{array}{l}\text { Three Hydraulic Fracture } \\
\text { with } \mathrm{Xf}=500\end{array}$ & & & & $\mathbf{x}$ & $\mathbf{x}$ & $\mathbf{x}$ & $\mathbf{x}$ \\
\hline $\begin{array}{l}\text { Three Hydraulic Fracture } \\
\text { with } \mathrm{Xf}=750\end{array}$ & & & & $\mathbf{X}$ & $\mathbf{x}$ & $\mathbf{x}$ & $\mathbf{x}$ \\
\hline $\begin{array}{l}\text { Three Hydraulic Fracture } \\
\text { with } \mathrm{Xf}=1000\end{array}$ & & & & $\mathbf{X}$ & $\mathbf{x}$ & $\mathbf{x}$ & $\mathbf{x}$ \\
\hline $\begin{array}{l}\text { Five Hydraulic Fracture } \\
\text { with } \mathrm{Xf}=250\end{array}$ & & & & $\mathbf{X}$ & $\mathbf{x}$ & $\mathbf{x}$ & $\mathbf{x}$ \\
\hline $\begin{array}{l}\text { Five Hydraulic Fracture } \\
\text { with } \mathrm{Xf}=500\end{array}$ & & & & $\mathbf{X}$ & $\mathbf{x}$ & $\mathbf{x}$ & $\mathbf{x}$ \\
\hline $\begin{array}{l}\text { Five Hydraulic Fracture } \\
\text { with } \mathrm{Xf}=750\end{array}$ & & & & $\mathbf{X}$ & $\mathbf{x}$ & $\mathbf{x}$ & $\mathbf{x}$ \\
\hline $\begin{array}{l}\text { Five Hydraulic Fracture } \\
\text { with } \mathrm{Xf}=1000\end{array}$ & & & & $\mathbf{X}$ & $\mathbf{x}$ & $\mathbf{x}$ & $\mathbf{x}$ \\
\hline $\begin{array}{l}\text { Seven Hydraulic Fracture } \\
\text { with } \mathrm{Xf}=250\end{array}$ & & & & & $\mathbf{x}$ & $\mathbf{x}$ & \\
\hline $\begin{array}{l}\text { Seven Hydraulic Fracture } \\
\text { with } \mathrm{Xf}=500\end{array}$ & & & & & $\mathbf{x}$ & $\mathbf{x}$ & \\
\hline $\begin{array}{l}\text { Seven Hydraulic Fracture } \\
\text { with } \mathrm{Xf}=750\end{array}$ & & & & & $\mathbf{x}$ & $\mathbf{x}$ & \\
\hline $\begin{array}{l}\text { Seven Hydraulic Fracture } \\
\text { with } \mathrm{Xf}=1000\end{array}$ & & & & & $\mathbf{x}$ & $\mathbf{x}$ & \\
\hline $\begin{array}{l}\text { Nine Hydraulic Fracture } \\
\text { with } \mathrm{Xf}=250\end{array}$ & & & & & & $\mathbf{x}$ & \\
\hline $\begin{array}{l}\text { Nine Hydraulic Fracture } \\
\text { with } \mathrm{Xf}=500\end{array}$ & & & & & & $\mathbf{x}$ & \\
\hline $\begin{array}{l}\text { Nine Hydraulic Fracture } \\
\text { with } \mathrm{Xf}=750\end{array}$ & & & & & & $\mathbf{x}$ & \\
\hline $\begin{array}{l}\text { Nine Hydraulic Fracture } \\
\text { with } \mathrm{Xf}=1000\end{array}$ & & & & & & $\mathbf{x}$ & \\
\hline
\end{tabular}


Table III-2 shows some of the important parameters that were used in the modeling process. For all runs, the simulation was continued for a 50 year period. The depth and thickness values are based on a typical southwestern Pennsylvania location with an approximate depth of 6000 feet (Sumi, 2008). The total thickness is selected as 90 feet (Harper, 2008). The reservoir used in this study consisted of a 20,000 ft. by 10,000 ft. rectangle drainage area. This size was chosen to encompass the drainage area of the largest well selection in this research. The permeability of the Marcellus shale was studied as early as 1988 by Soeder and reported as $0.005909 \mathrm{mD}$ (Soeder, 1988) (Miller, 2008). Operators compare the Marcellus shale with the Barnett shale which has a permeability value of $0.0001 \mathrm{mD}$ (Pickering, 2005). Based on the published data and personal communication with companies a rather conservative number of $0.0004 \mathrm{mD}$ was selected as the permeability of Marcellus shale for all runs. A porosity value of four percent was used (Nome, 2008) (Hayden, 2005). Initial reservoir pressure of 3500 psia was used based on personal communications with local companies. The parameters used in this study are listed in Appendix A.

Table III-2 Marcellus shale properties used in this study.

\begin{tabular}{|l|r|l|}
\hline Property & Value & Units \\
\hline Time & 50 & Years \\
\hline Depth & 6000 & $\mathrm{Ft}$ \\
\hline Thickness & 90 & $\mathrm{Ft}$ \\
\hline Reservoir Length & 20000 & $\mathrm{Ft}$ \\
\hline Reservoir Width & 10000 & $\mathrm{Ft}$ \\
\hline Porosity & 4 & $\%$ \\
\hline Perm & 0.0004 & $\mathrm{mD}$ \\
\hline Reservoir Pressure & 3500 & Psia \\
\hline
\end{tabular}




\section{III-1 Model Verification Run with Barnett Shale}

A run with the Barnett shale formation properties was conducted and the results were compared against field production data available from the Texas Railroad Commission. Devon Energy Production Company, L.P., was producing the Barnett shale well that was chosen. The well is located in the East Newark (Barnett Shale) field in Johnson County, Texas. The well had a true vertical depth of 6,531 feet and a lateral length of 3,962 feet. The horizontal segment of the well had a $5 \frac{1}{2} 2$ inch casing set in the wellbore and was being produced through the $23 / 8$ inch tubing set at 6522 feet. The well was completed with four frac stages and each stage being approximately four hundred foot sections (Devon, 2008). The shale thickness of $200 \mathrm{ft}$, permeability of less then 0.0001 and porosity of $4.5 \%$ were taken from Nomes work and the Barnett Shale Report along with the initial reservoir pressure of 3500 psi and other properties such as water saturation (Nome, 2008)(Pickering, 2005). Reservoir size, fluid properties, production, perforation characteristic, and simulation controls were kept the same in all runs. The monthly gas production totals are given in Table III-3 for the Barnett shale well.

Table III-3 Production data for the Barnett well (Devon, 2008).

\begin{tabular}{|r|r|}
\hline $\begin{array}{r}\text { Time } \\
\text { (Months) }\end{array}$ & $\begin{array}{l}\text { Monthly } \\
\text { Production (MCF) }\end{array}$ \\
\hline 1 & 12,160 \\
\hline 2 & 75,077 \\
\hline 3 & 34,443 \\
\hline 4 & 51,945 \\
\hline 5 & 46,579 \\
\hline 6 & 38,848 \\
\hline 7 & 37,117 \\
\hline 8 & 35,071 \\
\hline 9 & 34,976 \\
\hline 10 & 20,453 \\
\hline Total & $\mathbf{3 8 6 , 6 6 9}$ \\
\hline
\end{tabular}


Figure III-1 compares the total gas production values predicted by the model with field data from the Barnett shale well. The production values calculated by the model are slightly off due to estimation of several Barnett shale properties in Johnson County. The well information came from the drilling and completion reports, and a best estimate is used for some formation properties.

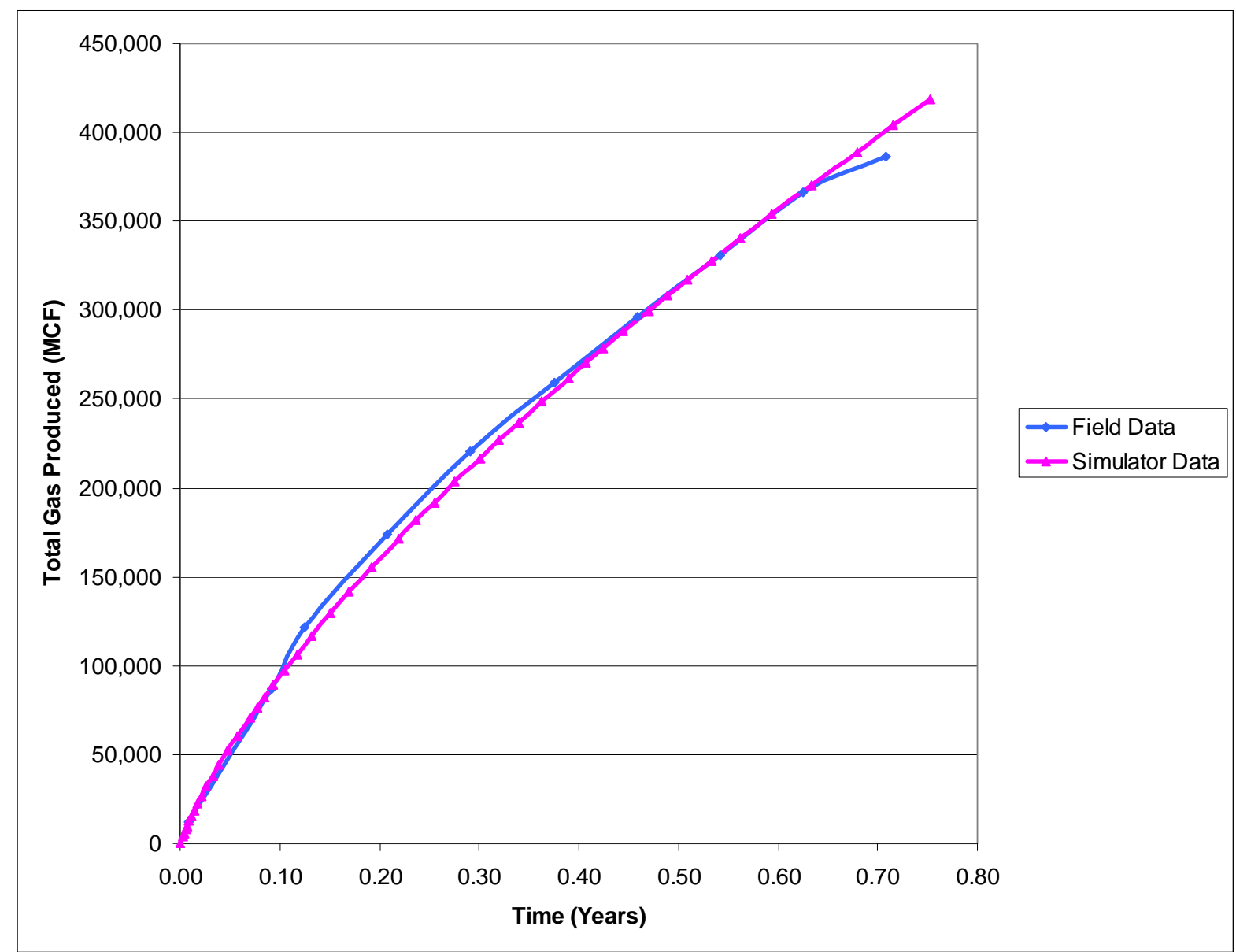

Figure III- 1 Comparison of gas production from Barnett Shale well with simulated results.

In spite of the deviation in the total gas production with model calculations, the same trend was observed for both predicted and actual values. Thus, the template used to represent the gas production from shales was adequate to model the Marcellus shale reservoir. 


\section{Chapter IV. Results and Discussion}

In this section, the results from runs are presented with discussion on the production performance difference of well designs. Two well types, vertical and horizontal, were studied. For horizontal wells, four lateral lengths were considered with five different fracture designs of varying half lengths. All runs were conducted for fifty years due to low gas desorption rates and long term production potential of Marcellus shale.

\section{IV-1 Effect of Well Type}

Figure IV-1 shows the base case for the one vertical well, three vertical wells and one horizontal well with a lateral length of one thousand feet. In these base cases, there are no additional fractures other then the natural fractures. In this case, the results show that a single vertical well produced approximately 87 MMSCF and the three vertical wells produce about three times as much gas as the single vertical well. This shows that when three vertical Marcellus wells spaced at 5,000 feet apart there is no commingling of the gas production and thus each of these wells are acting independently. As for the horizontal well, the results show that the well produces more gas than the vertical wells this is primarily because the horizontal well has more surface area of contact with shale and intersects more natural fractures. The horizontal well

produces over 250 MMSCF more gas over fifty years when compared to the single vertical well. 


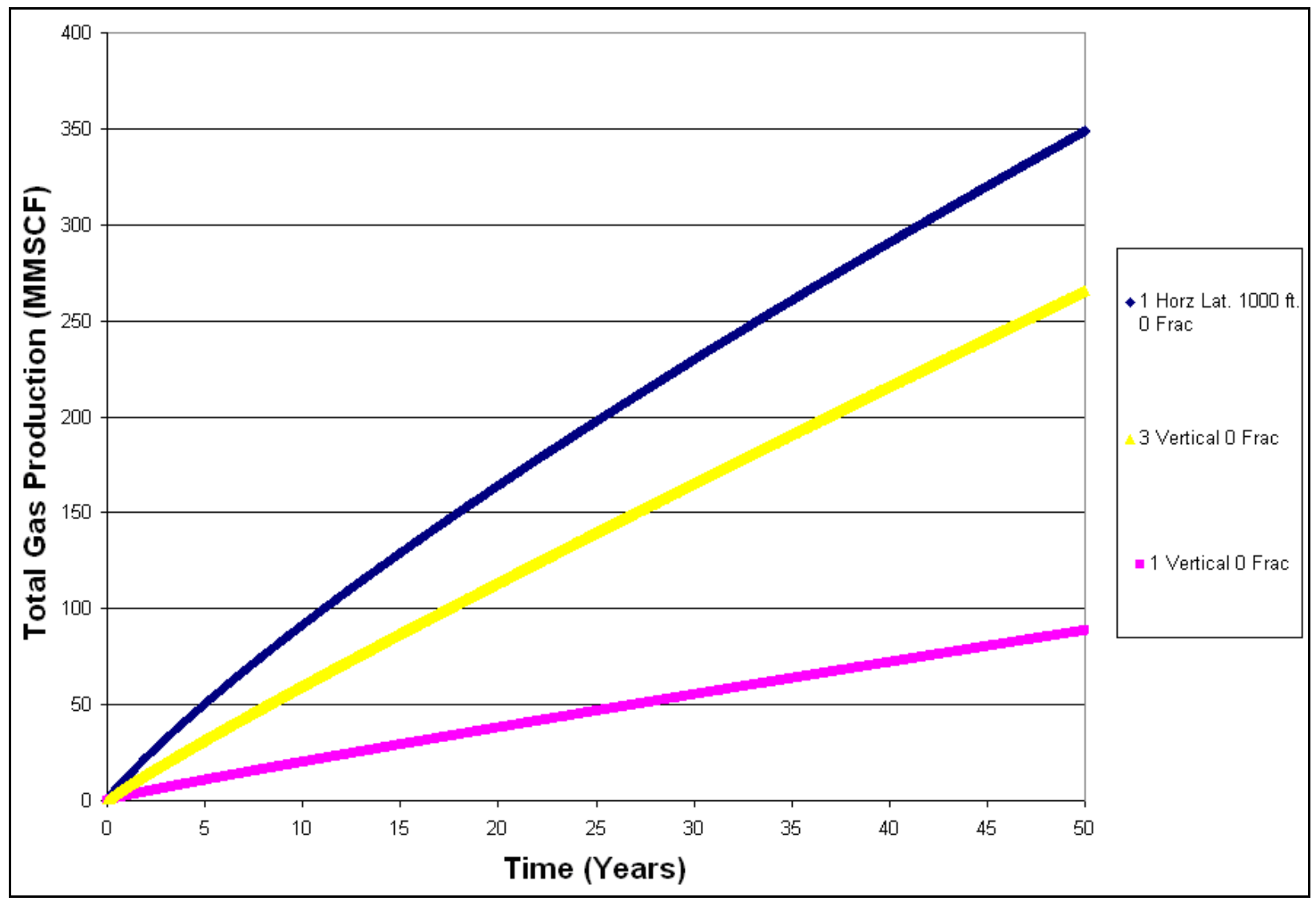

Figure IV-1 Total gas production with time for three well designs.

\section{IV-2 Effect of Lateral Length in the Horizontal Wellbore}

Figure IV-2 shows the well designs that were studied in the reservoir modeling of a single horizontal well. Besides the verticals wells and the horizontal well with a lateral length of 1000 feet, three other horizontal wellbore configurations were considered. These configurations were the variation of lateral lengths as 1000, 2000, 3000 and 4000 feet. In Figure IV-2 the base cases are shown for these four configurations. The results show that as the length of the wellbore increases the total gas production increase is approximately 250 MMSCF per 1000 feet of wellbore with no fractures. 


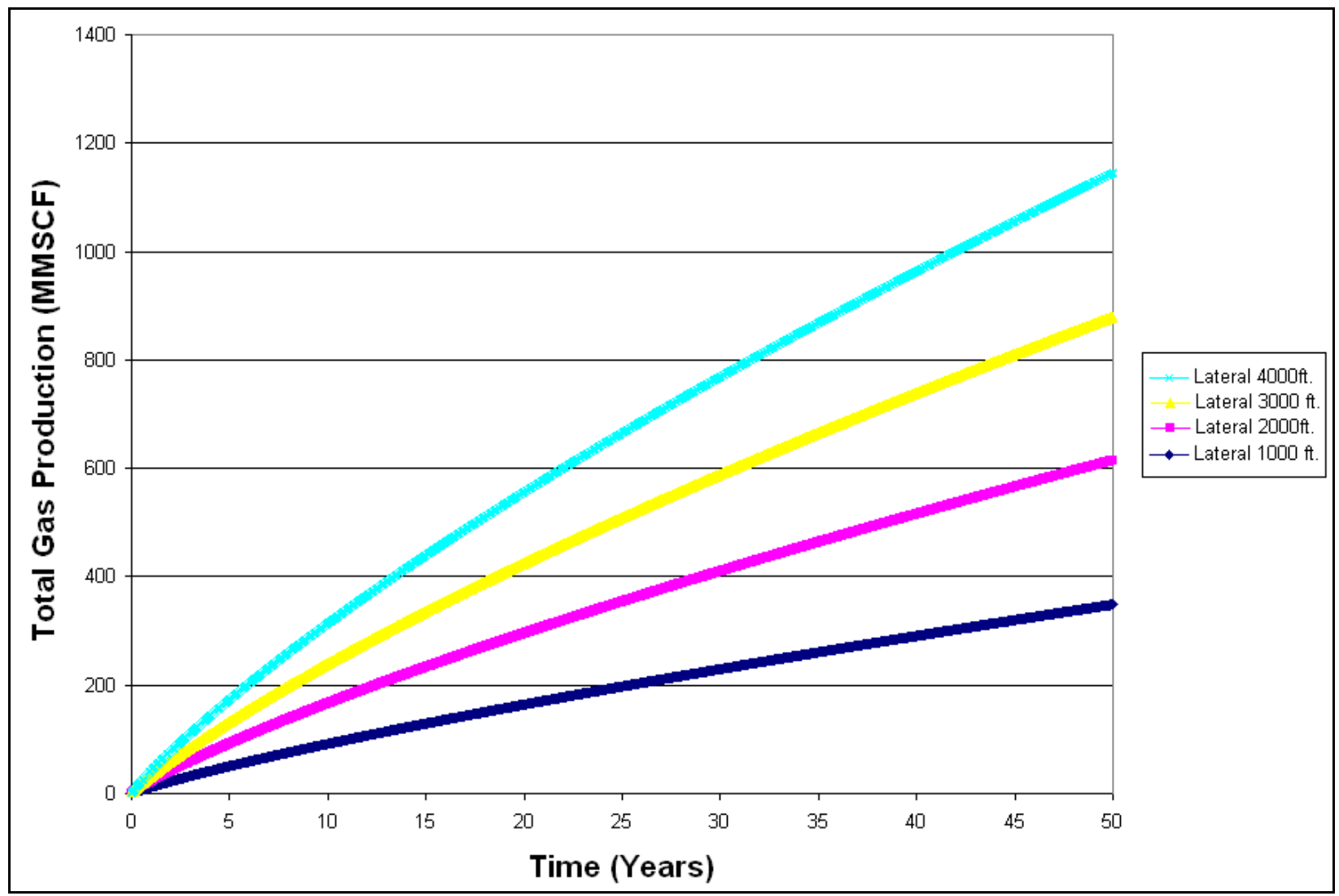

Figure IV-2 Effect of lateral length on total gas production with time (horizontal wells).

\section{IV-3 Effect of a Single Fracture in the Wellbore}

Figure IV-3 shows the effects of added fractures to the wellbore. In the fracture design segment of the research, each fracture is added as a stage of a hydraulic fracture treatment. The next few comparisons shown are with the varying amount of fractures with a 500 foot propped half length. Half length studies were also conducted and will be discussed later. Figure IV-3 shows the same data presented in Figure IV-1 along with the same wellbore configurations with one hydraulic fracture. In this figure, the effects of the fracture stimulation are presented. For the single vertical well, the total gas production increased over seven times the initial production with a fracture compared to the well without a fracture. Similarly, the three vertical wells make 
three times as much gas as the single vertical well with a single fracture. The results support industry standards in fracturing shale compared to not fracturing. In fact, most Devonian shales and some of the current Marcellus shale production comes from single stage hydraulically fractured vertical wells. The results show that there is no commingling of the gas with the vertical well spaced apart at 5,000 feet. In the case of the horizontal wellbore, adding one fracture in the center only increased the total production slightly more than two fold, however, the total production was still slightly greater than the single vertical well. The same fracture half length is used in both wells thus the only differences is the added contact of the 1000 feet horizontal section intersecting natural fractures.

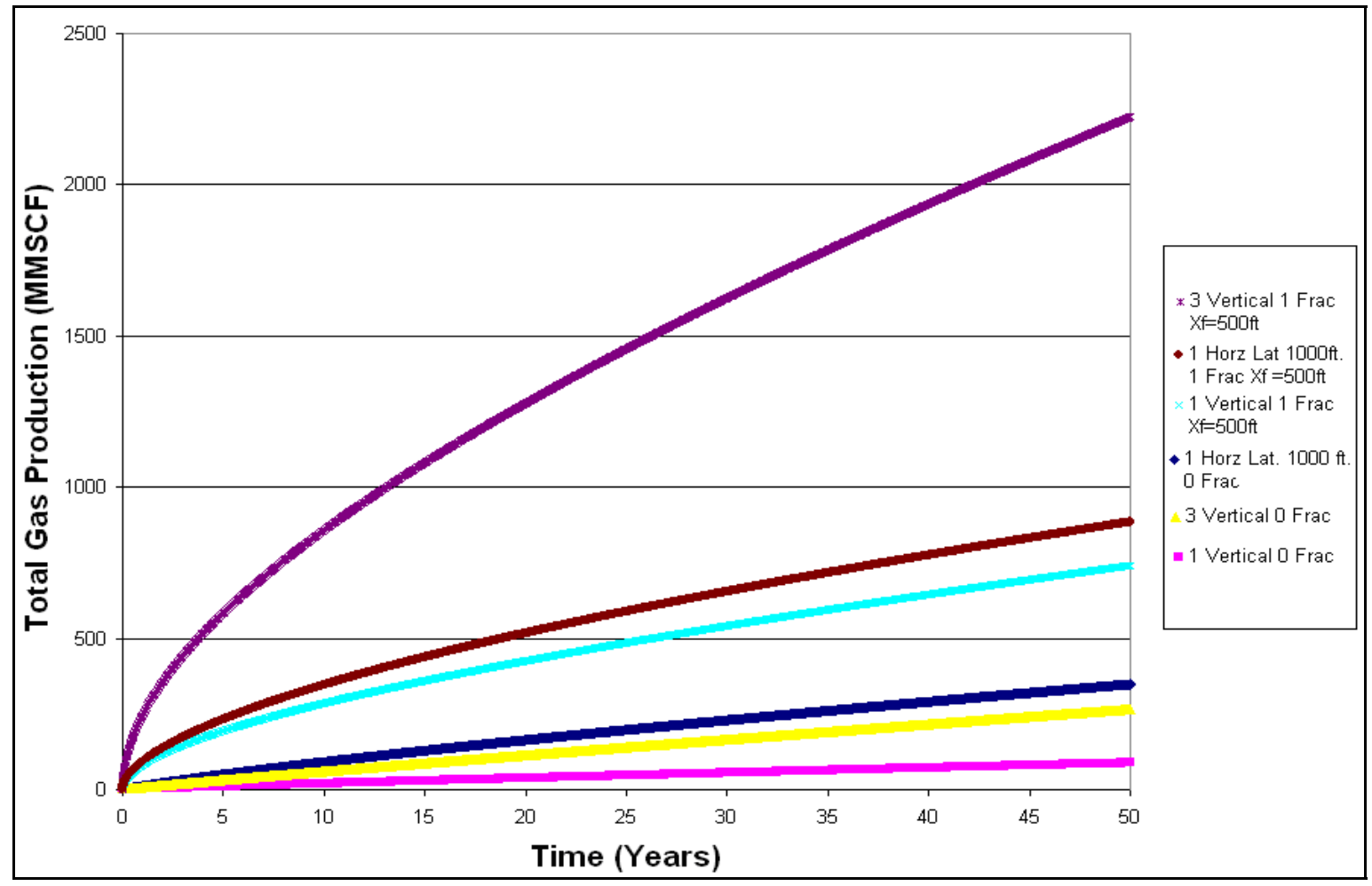

Figure IV-3 Effect of fracture treatment on total gas production for vertical and horizontal wells. 
Figure IV-4 shows the results for the single fracture runs conducted with a half length of 500 feet. This includes the single vertical wells. The other four plots on the graph shows the lateral lengths varying from 1000 feet to 4000 feet for the horizontal well designs. Similar to the case with no fracture the total gas production increases rather constantly about 250 MMSCF per 1000 feet of wellbore in the horizontal section. The three vertical well design produced a little over 500 MMCF more than the single fracture 4000 foot horizontal wellbore. The largest total gas production was obtained for the three vertical wells since there were three fracture treatment compared to a single treatments in horizontal wells.

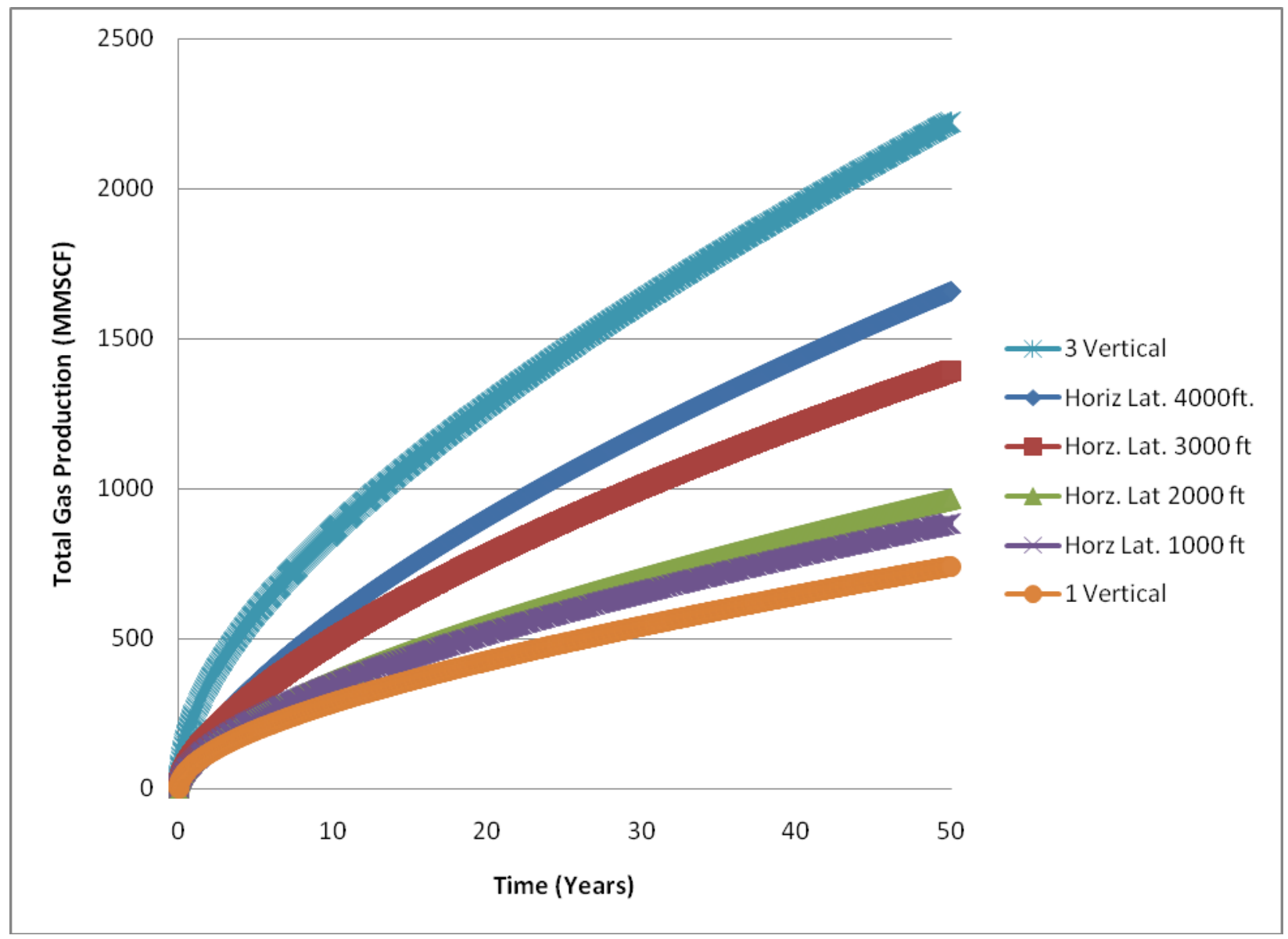

Figure IV-4 Comparison of total gas production for wells with one fracture treatment $(\mathrm{XF}=500$ $\mathrm{ft}$ ). 


\section{IV-4 Effect of Multiple Fractures in Horizontal Wellbore}

Figure IV-5 shows the total gas production trends for the horizontal wellbores with lateral sections ranging from 2000 to 4000 feet and with one and three stage fractures. Single stage fracture in real life for a horizontal well was unrealistic, but runs were conducted to compare the data and understand the effects of adding two more stages of fractures. The data suggests that by adding two fractures to any of the lateral lengths, approximately 750 MMCF of additional gas production over a 50 year period was achieved. This amount is approximately equal to the production from one vertical well. From these numbers it can be calculated that a horizontal well of approximately 3500 feet with 3 hydraulic fracture would be equal in total production to the 3 vertical wells each with one hydraulic fracture. It has been noted that vertical wells in the Marcellus would costs about one million per well so these three vertical wells would equal three million dollars in total. Compared to horizontal wells where one well cost about three million dollars to drill approximately 3000 feet lateral section with at least five to seven stages of hydraulic fracture treatments (Sumi 2008). The total production comparisons of vertical to horizontal wells are equal if only a three stage fracture job is utilized. Hence, horizontal wells would produce more gas and thus be more economical in the Marcellus shale. A more detailed economic analysis is presented in section IV-11. 


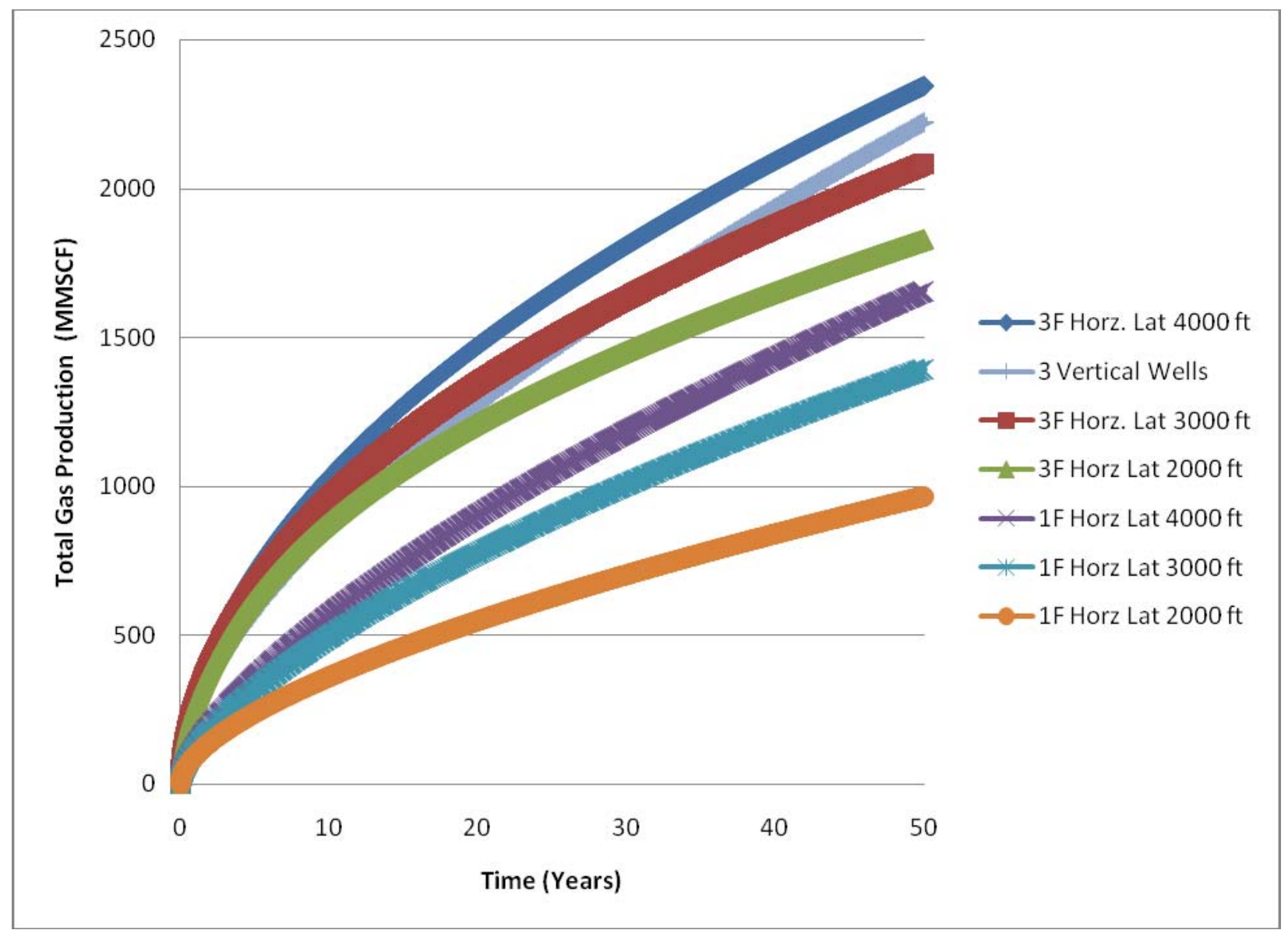

Figure IV-5 Comparison of total gas production for wells with one and three fracture treatments $(\mathrm{XF}=500 \mathrm{ft})$.

The total gas production values are plotted in Figure IV-6 for horizontal well designs with three and five fracture treatments and lateral lengths of 2000, 3000 and 4000 feet were used. As the amount of fractures are increased, the horizontal wells begin to produce much more gas over a long period of time. By adding two fractures an increase of approximately 750 MMCF of gas over the 50 year period or, a 375 MMCF increase per fracture stage was observed. 


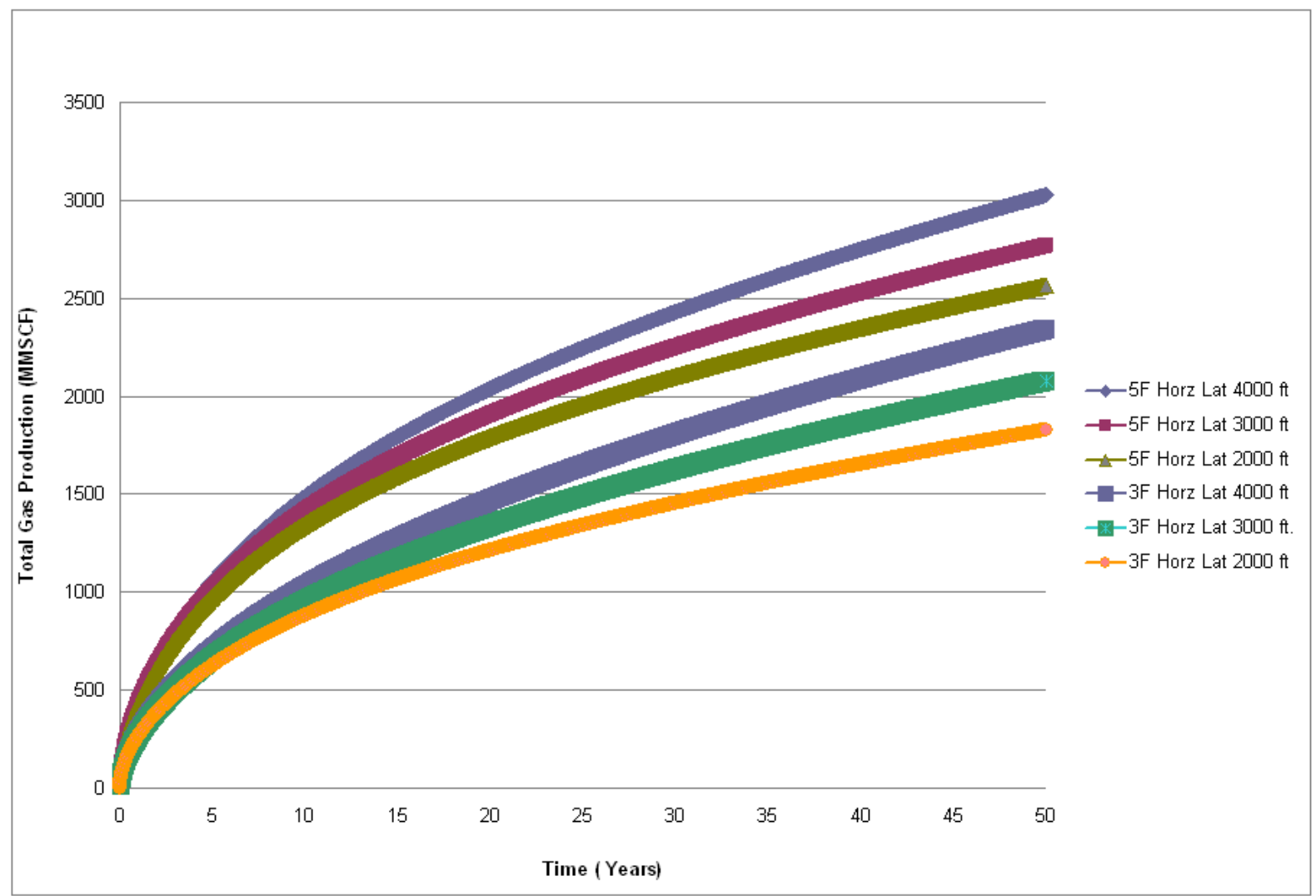

Figure IV-6 Comparison of total gas production for horizontal wells with three and five fracture treatments $(\mathrm{XF}=500 \mathrm{ft})$.

Figure IV-7 shows the comparison of the five stage fracture to the seven stage fracture treatment. Similar to results shown in Figure IV-6, a 750 MMCF jump in overall gas production or 375 MMCF additional gas per fracture treatment is observed. When compared to a 250 MMCF increase per 1000 feet of wellbore, it appears that the addition of fractures results in a favorable increase in gas production compared to the increase in production based on longer lateral lengths. In Figure IV-7, the top two lines represent the total gas production for the seven stage fractures followed by the lower two lines representing the five stage fracture. For all cases the total gas production from the 4000 foot wellbore is slighty higher then the 3000 foot wellbore. The well performance improves significantly with the increase of number of fracture treatments. 


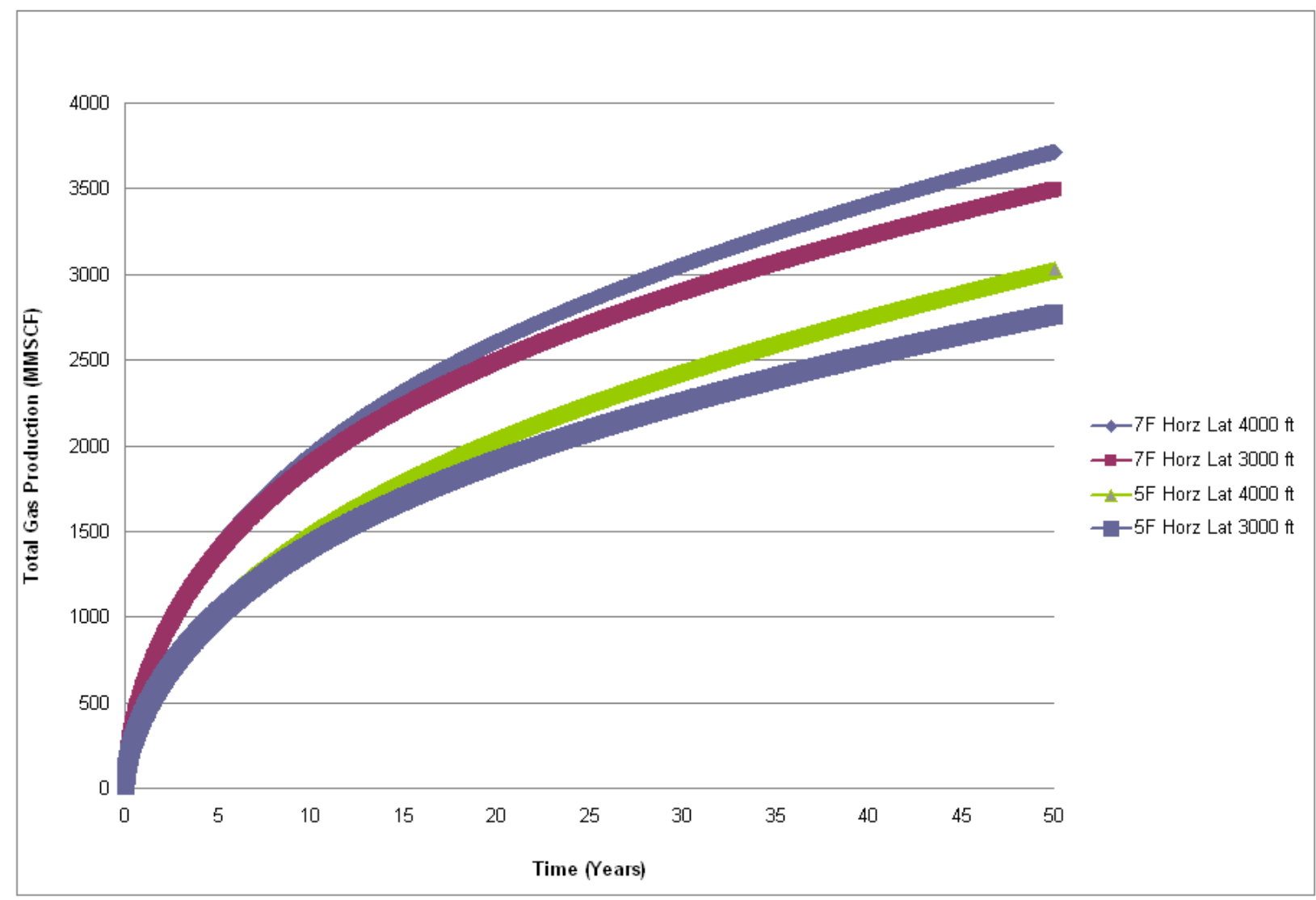

Figure IV-7 Comparison of total gas production for horizontal wells with five and seven fracture treatments $(\mathrm{Xf}=500 \mathrm{ft})$.

\section{IV-5 Multiple Fracture Comparisons}

Figure IV-8 shows the comparison of total gas production for five different fracture designs used in this research with a 500 foot propped half length. Additionally, the total production from the 3 vertical well design is added to the figure for the purpose of comparing to the horizontal well designs. The seven fracture stage design in a horizontal well would cost approximately three million dollars which would be about equal to the development cost of three vertical wells. These costs would vary due to the amount of proppant used, water used, length of wellbore, number of stages and number of problems that might have occurred with the well. 
Based on the results for the cumulative production obtained from the entire group of Marcellus wells, it is more beneficial to drill horizontally. The production trends can be used to estimate the outcome of new well designs. For example, when seven vertical wells are drilled, the expected production would be about 750 MMCF per well. Also, for an 11 stage fracture treatment completed in a slightly longer wellbore to maintain the equal 400 foot spacing, the approximate amount of production after 50 years would be approximately 5100 MMCF.

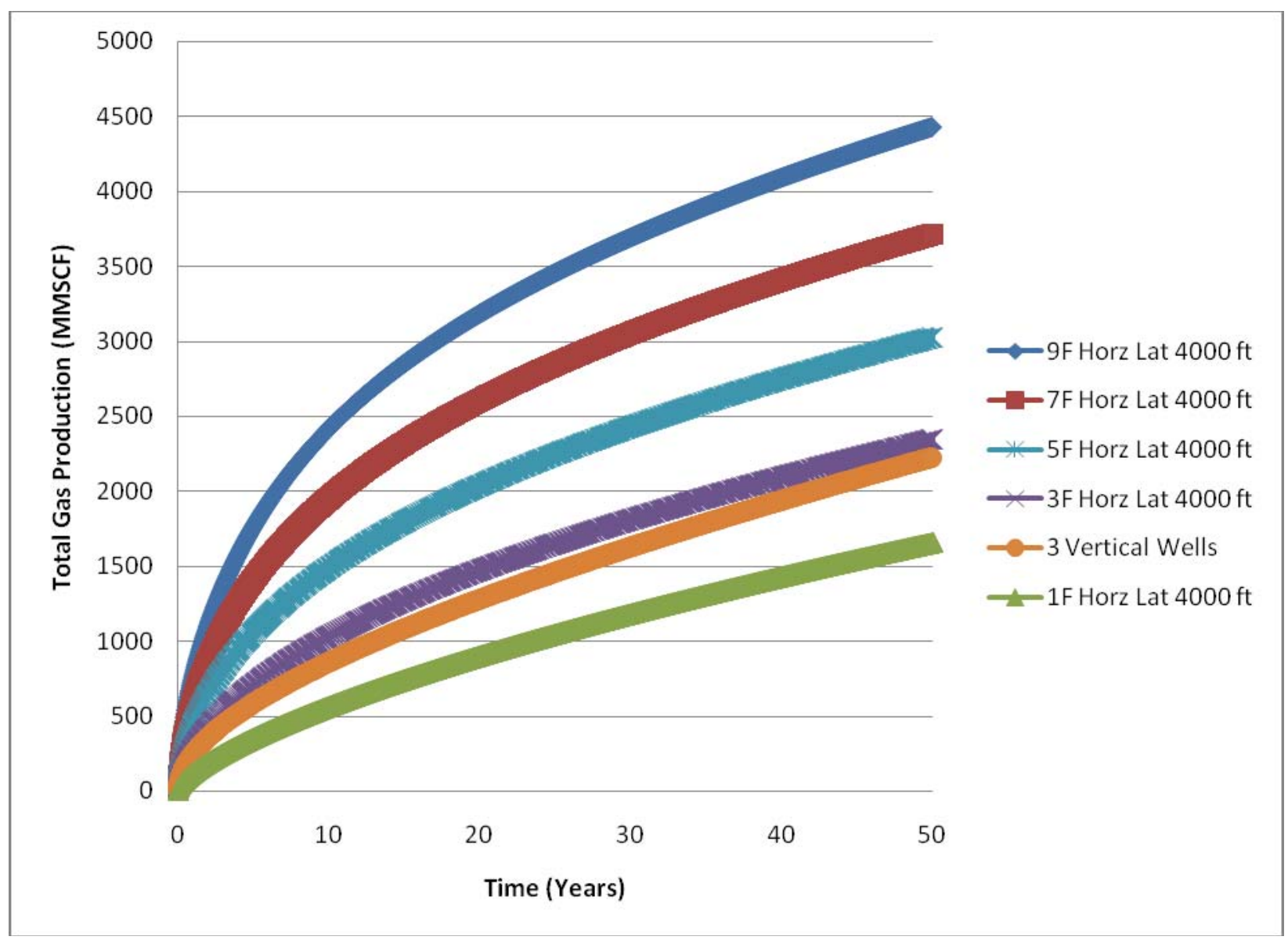

Figure IV-8 Comparison of total gas production for horizontal wells with $4000 \mathrm{ft}$ lateral length and different number of fracture treatments and three vertical well design (XF=500 ft). 


\section{IV-6 Effect of Fracture Spacing}

During this research, the fracture spacing of the wells was held constant in order to maintain verifiable results. To understand the effect of fracture spacing additional runs were conducted with increased fracture spacing. Figure IV-9 shows the comparison of total gas production with the $4000 \mathrm{ft}$ lateral well when three and five fracture treatments are conducted at $400 \mathrm{ft}$ and $800 \mathrm{ft}$ spacing's. The results are presented for the $4000 \mathrm{ft}$ horizontal well to allow the placement of fractures with $800 \mathrm{ft}$ spacing. The shorter horizontal length designs was limited in the number of possible fracture treatments. The results show the improved drainage with the 800 $\mathrm{ft}$ spacing for both three and five stage fracture treatments. This increase in gas production is more pronounced in the later life of the field. The early production data does not yield distinguishable gas production for both fracture spacing designs. 


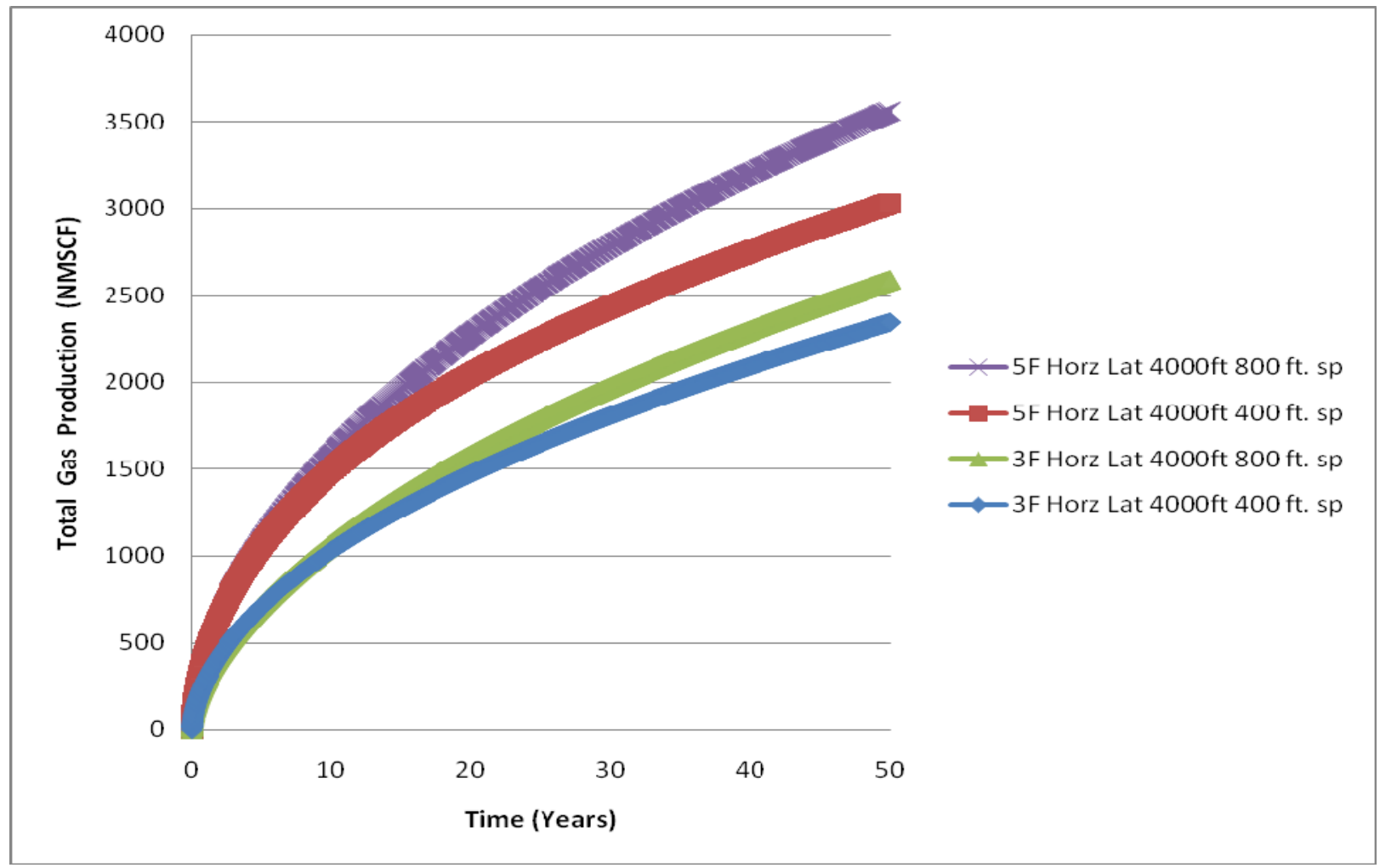

Figure IV-9 Comparison of total gas production for horizontal wells with different number of fracture treatments and spacing between treatments $(\mathrm{XF}=500 \mathrm{ft})$.

\section{IV-7 Effect of Fracture Half Length}

The effect of fracture half length on gas production with different well designs is presented for three cases. Figure IV-10, shows the total gas production for a vertical well with four different fracture half length designs. For every 250 foot increment there is an approximately 250 to 300 MMCF increase in total gas production over the 50 year period. There appears to be a linear relationship between the fracture half length and the increase in total gas production. 


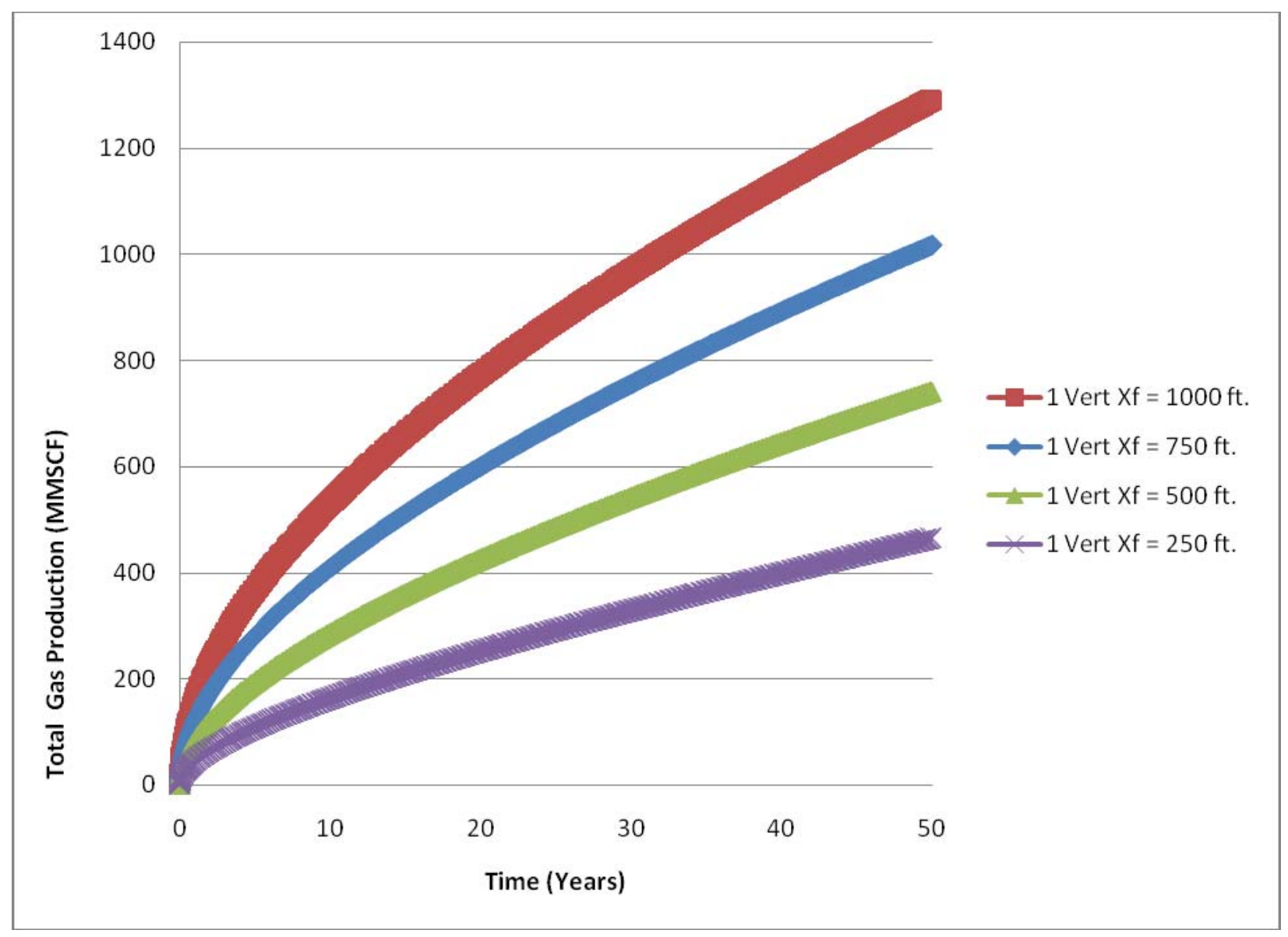

Figure IV-10 Comparison of total gas production from vertical wells with different fracture half lengths.

Fracture half length analysis is also conducted for the three vertical well designs (Figure IV-11). Similar to the single vertical well design, there was approximately 250 to 300 MMCF increase in total gas production over the 50 year period per $250 \mathrm{ft}$ increment in fracture half length. In the case of a 1000 foot fracture half length, the total gas produced was $3900 \mathrm{MMCF}$ with three vertical wells. When 250 foot fracture half length was used, approximately 1420 MMCF gas was produced in the 50 year period. A noticeable difference of over 500 MMCF of gas production was observed between the shortest and longest fracture half lengths in the first five years. 


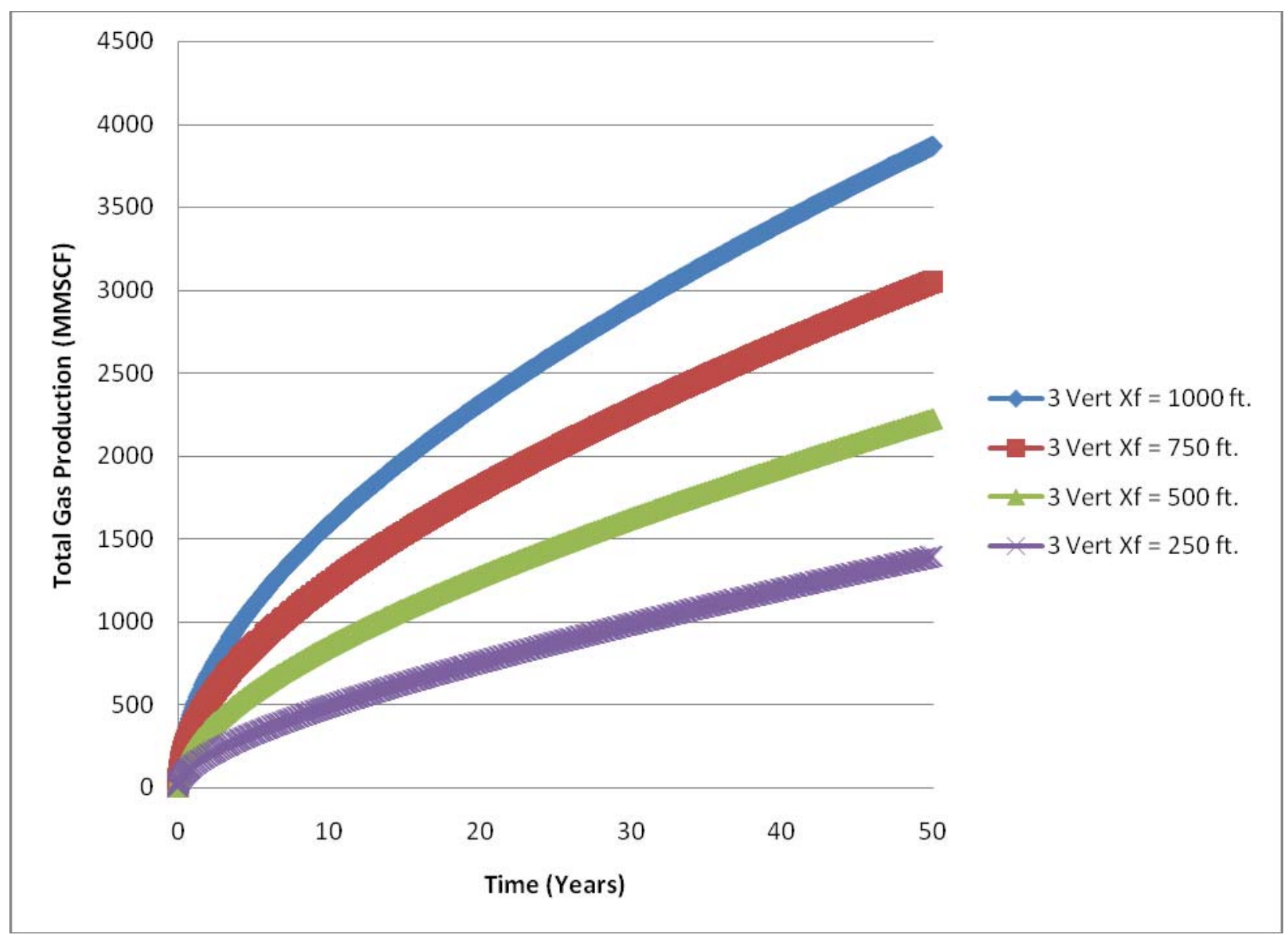

Figure IV-11 Comparison of total gas production from three vertical wells with different fracture half lengths.

Figure IV-12 shows the effect of fracture half length on gas production for a horizontal wellbore with nine fracture treatments. For every 250 foot increment in fracture treatment there was approximately 1250 MMCF increase in total gas production over the 50 year period. The three vertical wells with a 1000 foot half length fracture treatments produced more than a ninefracture treatments conducted for the 4000 foot lateral well with a 250 foot fracture half length. The single horizontal well with a 4000 foot lateral section and a 1000 foot fracture half length produced 7,400 MMCF, at the end of 50 years. This total production value was the largest 
production among the well design used in this study. However, the increased production achieved by longer fracture half lengths needs to be supported by economic decisions.

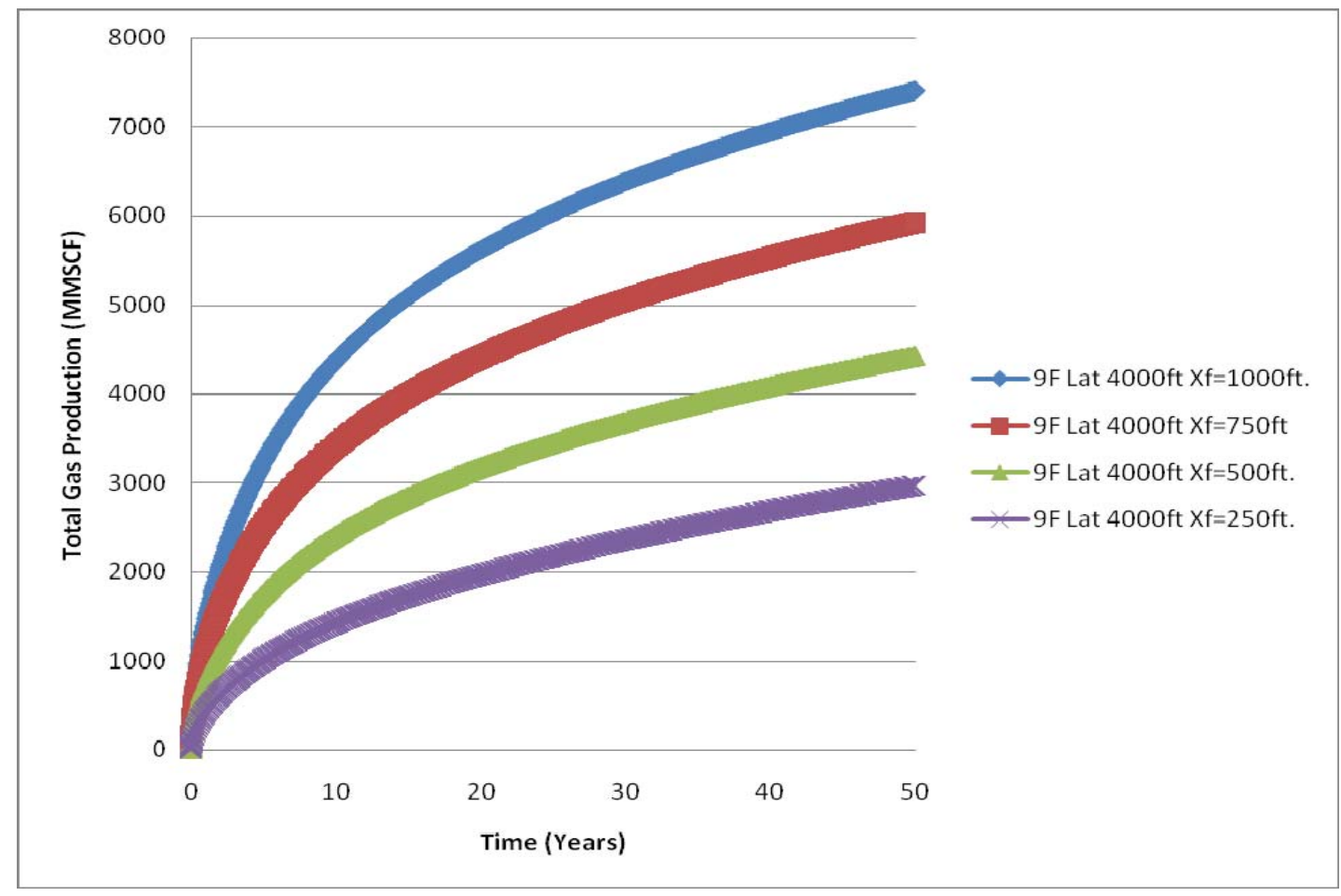

Figure IV-12 Comparison of total gas production from horizontal wells with $4000 \mathrm{ft}$ lateral lengths and nine fracture treatments with different fracture half lengths.

\section{IV-8 Effects of Fracture Half Length and Lateral Length}

Eight different well designs were considered to study the combined effects of fracture half length and lateral length of the wellbore. Figure IV-13, shows the total gas production for eight different well designs with four different fracture half lengths and two lateral wellbore lengths. There is approximately a $250 \mathrm{MMCF}$ increase in total gas production for every thousand feet of wellbore compared to approximately 1250 MMCF increase in total gas production per 
250 feet of propped half length. The impact of fracture half length on gas production is much greater than the lateral length of the wellbore.

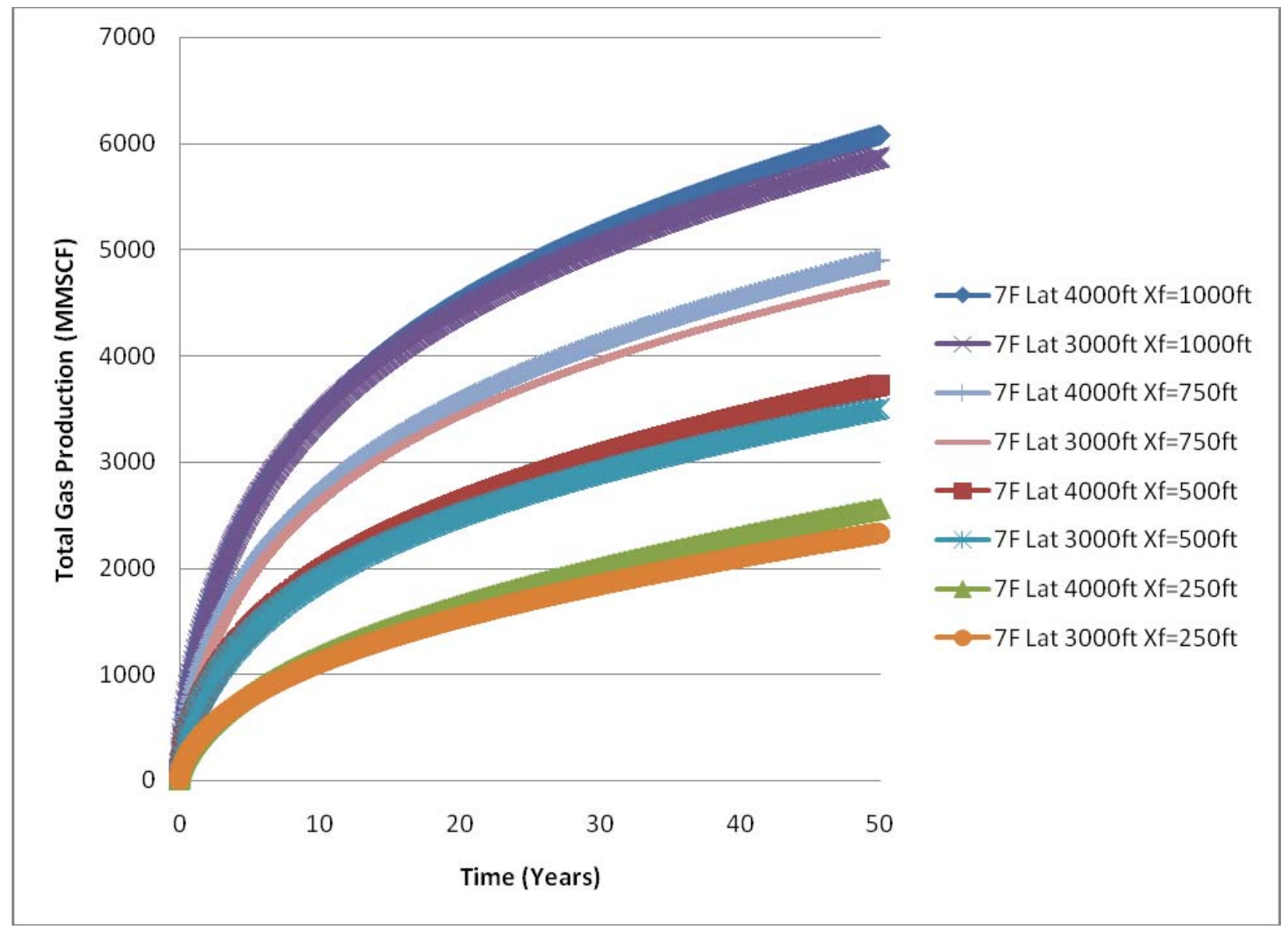

Figure IV-13 Comparison of total gas production from horizontal wells with 3000 and $4000 \mathrm{ft}$ lateral lengths and seven fracture treatments with different fracture half lengths.

\section{IV-9 Comparison of Fracture Half Length and Lateral Length through SRV}

In order to understand the combined effects of fracture half length and length of the lateral section for horizontal wells, a new approach was used to compare the drainage areas. Table IV-1 shows the combination of fracture half lengths and lateral lengths used in the study. 
The fracture half lengths are placed in the x-direction and the lateral sections are placed in the $y$ direction and their product is defined as the stimulated rock volume (SRV). The SRV values presented in Table IV-1 have identical values for different pairs of fracture half length and lateral length combinations. The SRV value of 3,000,000 representing either $1000 \mathrm{ft}$ fracture half length with a $3000 \mathrm{ft}$ lateral wellbore or $750 \mathrm{ft}$ fracture half length with a $4000 \mathrm{ft}$ lateral wellbore is used to determine and compare the total gas production for both designs. Figure IV-14 shows the total gas production for an SRV value of 3,000,000 with both designs and seven fracture treatments. The design with a longer fracture half length yields approximately 1,000 MMSCF more gas production over the 50 year period.

Table IV-1 SRV values used in this study.

\begin{tabular}{|l|r|r|r|r|r|}
\hline & \multicolumn{5}{|c|}{ Half Lengths } \\
\hline \multirow{4}{*}{$\begin{array}{l}\text { Lateral } \\
\text { Lengths }\end{array}$} & $\mathbf{1 0 0 0}$ & $\mathbf{2 5 0}$ & $\mathbf{5 0 0}$ & $\mathbf{7 5 0}$ & $\mathbf{1 0 0 0}$ \\
\cline { 2 - 6 } & $\mathbf{2 0 0 0}$ & $\mathbf{5 0 0 , 0 0 0}$ & 500,000 & 750,000 & $1,000,000$ \\
\cline { 2 - 7 } & $\mathbf{4 0 0 0}$ & 750,000 & $1,000,000$ & $1,500,000$ & $2,000,000$ \\
\hline
\end{tabular}




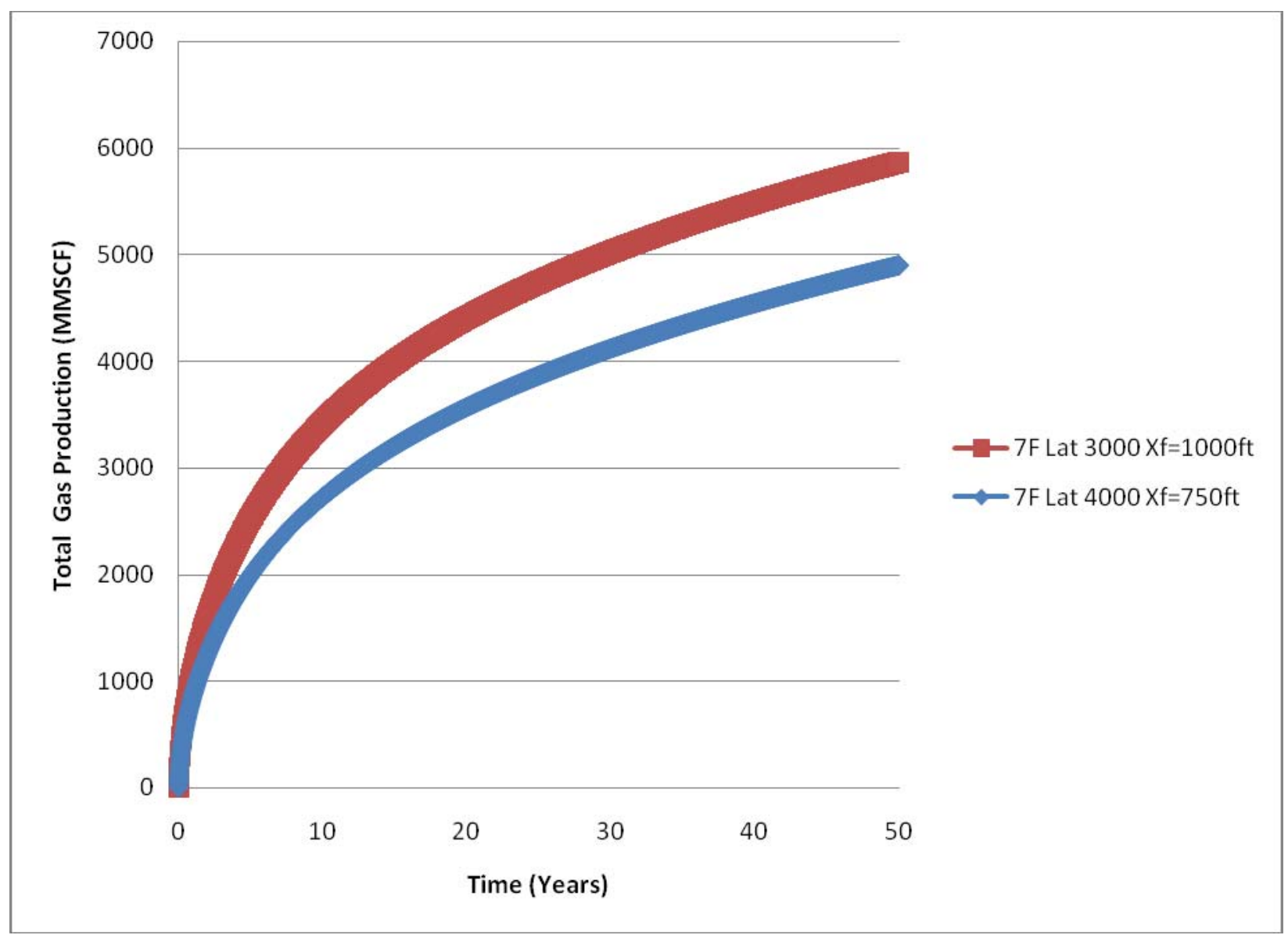

Figure IV-14 Comparison of total gas production for two well designs with same SRV and seven fracture treatments.

Additional runs were used to compare the total gas production values with the design representing a two million and a three million SRV's. Figure IV-15 shows the total gas production for four different well designs with five fracture treatments. Increase in SRV values increases the total gas production and this production increase is more significant if a longer fracture half length is used. The well design with a three million SRV represented by a 2000 foot lateral length and a 750 foot fracture half length out performs the well designed with a 3000 foot long lateral and a 500 foot fracture half length by approximately 750 MMSCF over the 50 year period. 


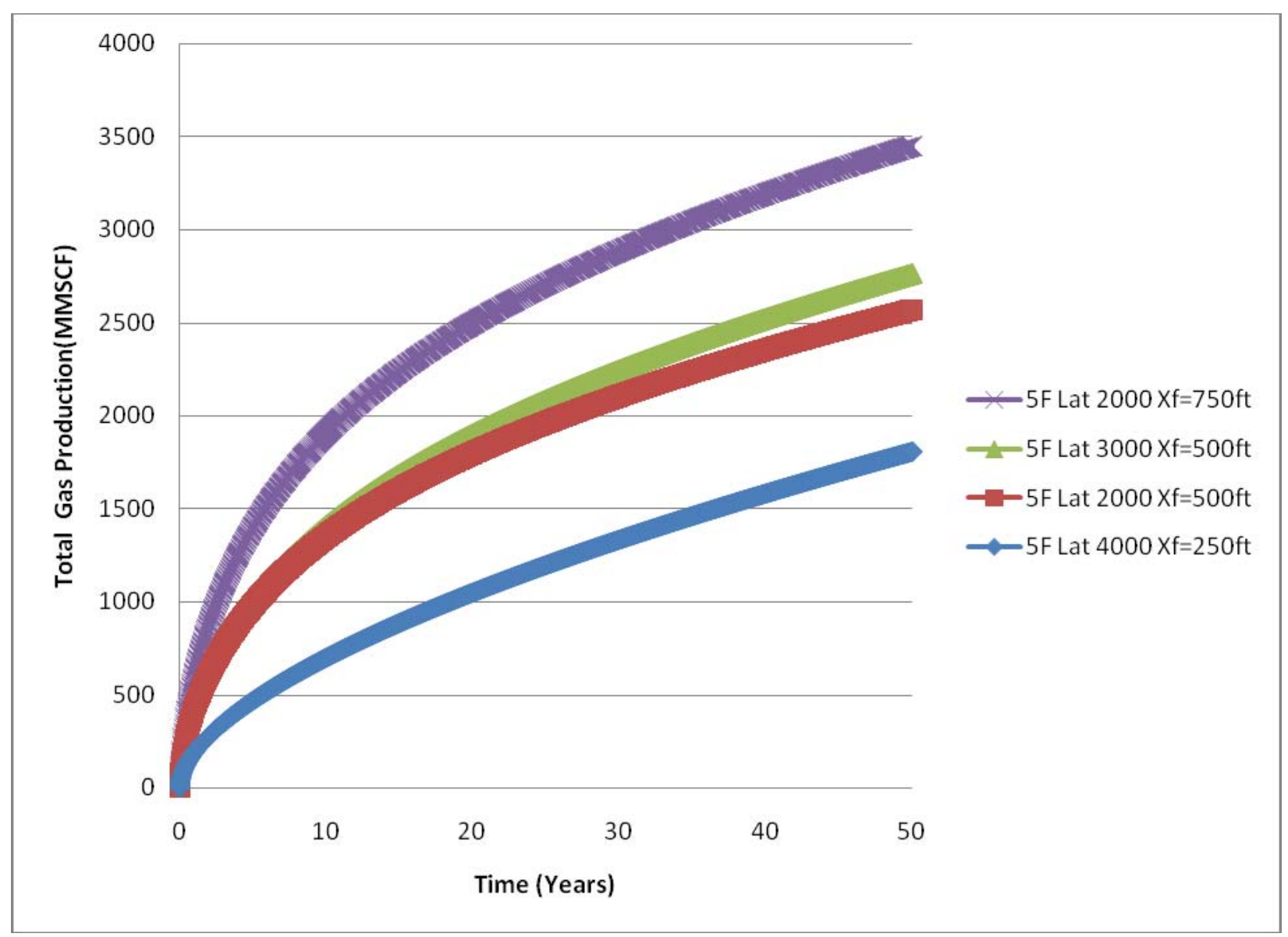

Figure IV-15 Comparison of total gas production for one and one and a half million stimulated rock volume with five fracture treatment designs.

Figure IV-16 compares the total gas production for four different well designs with five fracture treatments and two different SRV values. When the 4000 feet lateral with a 500 foot fracture half length is compared against the 2000 foot lateral length with a 1000 foot fracture half length, the 2000 foot lateral with the 1000 foot half length outperforms the 4000 foot well by producing more than $1400 \mathrm{MMCF}$ gas at the end of the 50 year period. This increase between the two different wells with the same SRV values is attributed to the two fold increase in fracture half length. In the case of well design with three million SRV values, a 250 foot increase in fracture half length produced approximately 700 MMCF more gas over the 50 year period. 


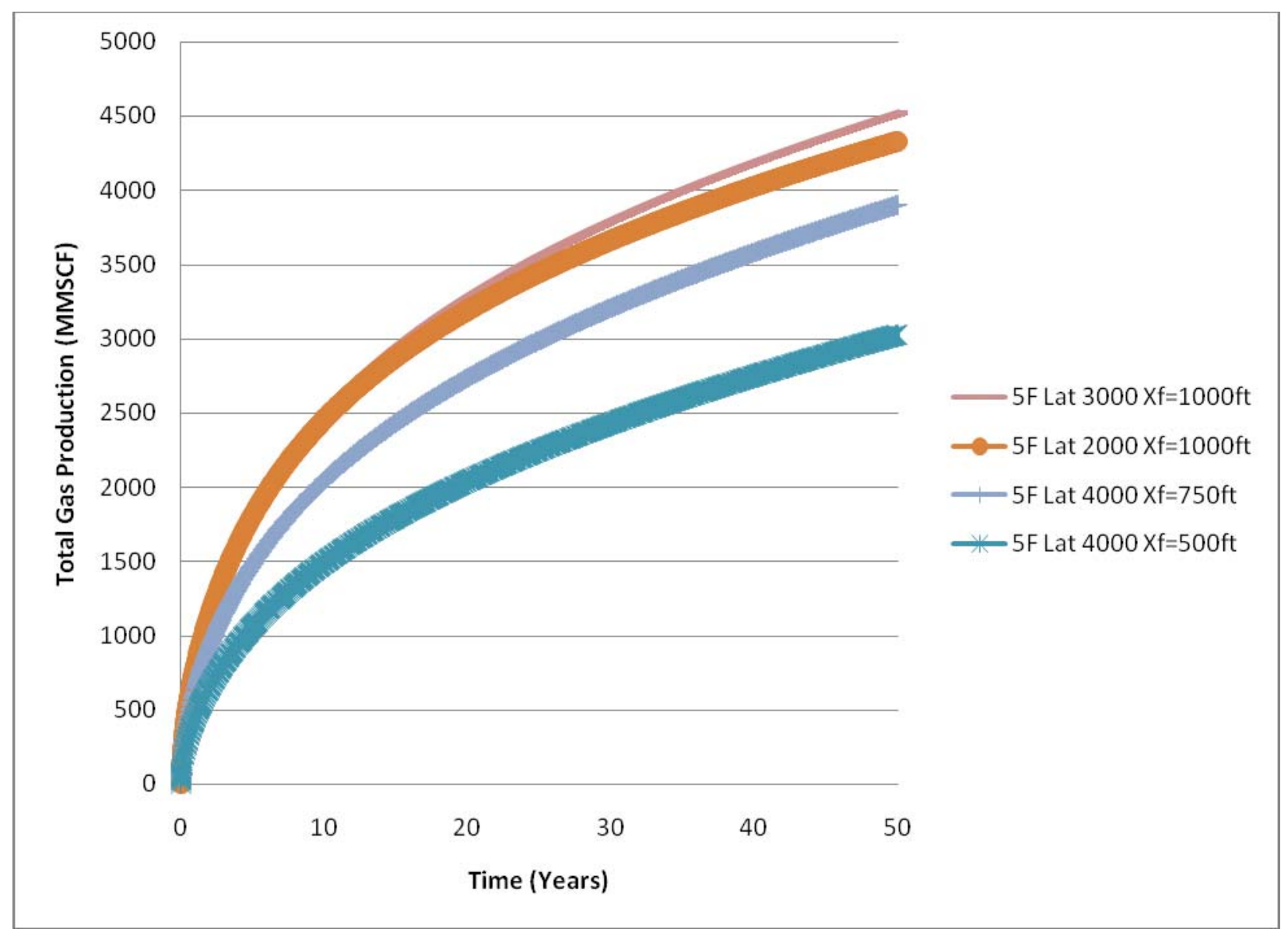

Figure IV-16 Comparison of total gas production for two and three million stimulated rock volume with five fracture treatment design.

The total gas production values are also compared for designs with three fracture treatments represented by two million and a three million SRV values as shown in Figure IV-17. The comparison between a 4000 feet lateral with a 500 foot fracture half length and a 2000 foot lateral length with a 1000 foot fracture half length shows an approximately 1300 MMCF increase in total production over the fifty year period. It should also be noted that as the number of fracture treatments decreased the total gas production difference between two designs with the same SRV values decreased. Also, the well design with a 2000 foot lateral length and a 1000 foot fracture half length design produces more gas than the well design with a 4000 foot lateral 
and a 500 foot fracture half length even with a lower SRV value. It appears that the increase in fracture length results in a more efficient drainage area.

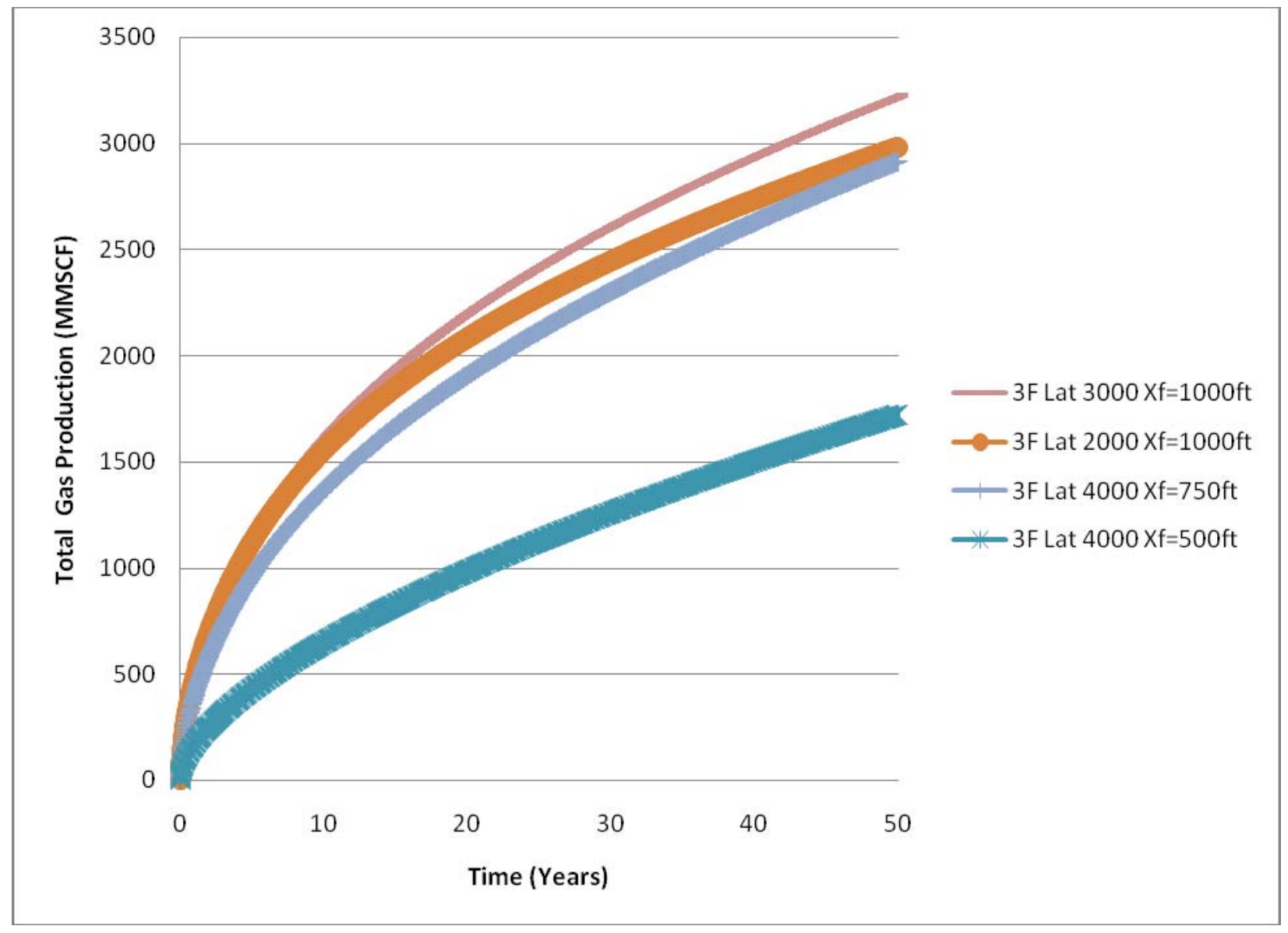

Figure IV-17 Comparison of total gas production for two and three million stimulated rock volume with three fracture treatment designs.

Runs conducted with one fracture design are given in Figure IV-18 for five different well designs. All designs have similar production trends with the exception of the well design with a 2000 foot lateral length and a 500 foot fracture half length representing a SRV value of one million. The SRV values vary between one and one and a half million, however, the shape of the total production graphs are close to each other and do not result in distinguishable production 
values. When a closer look is presented for the last ten years the differences amount to approximately 50 MMCSF at the end of 50 years for designs with an SRV value of one and a half million and the design with 1000 foot lateral length and a 1000 foot fracture half length (Figure IV-19).

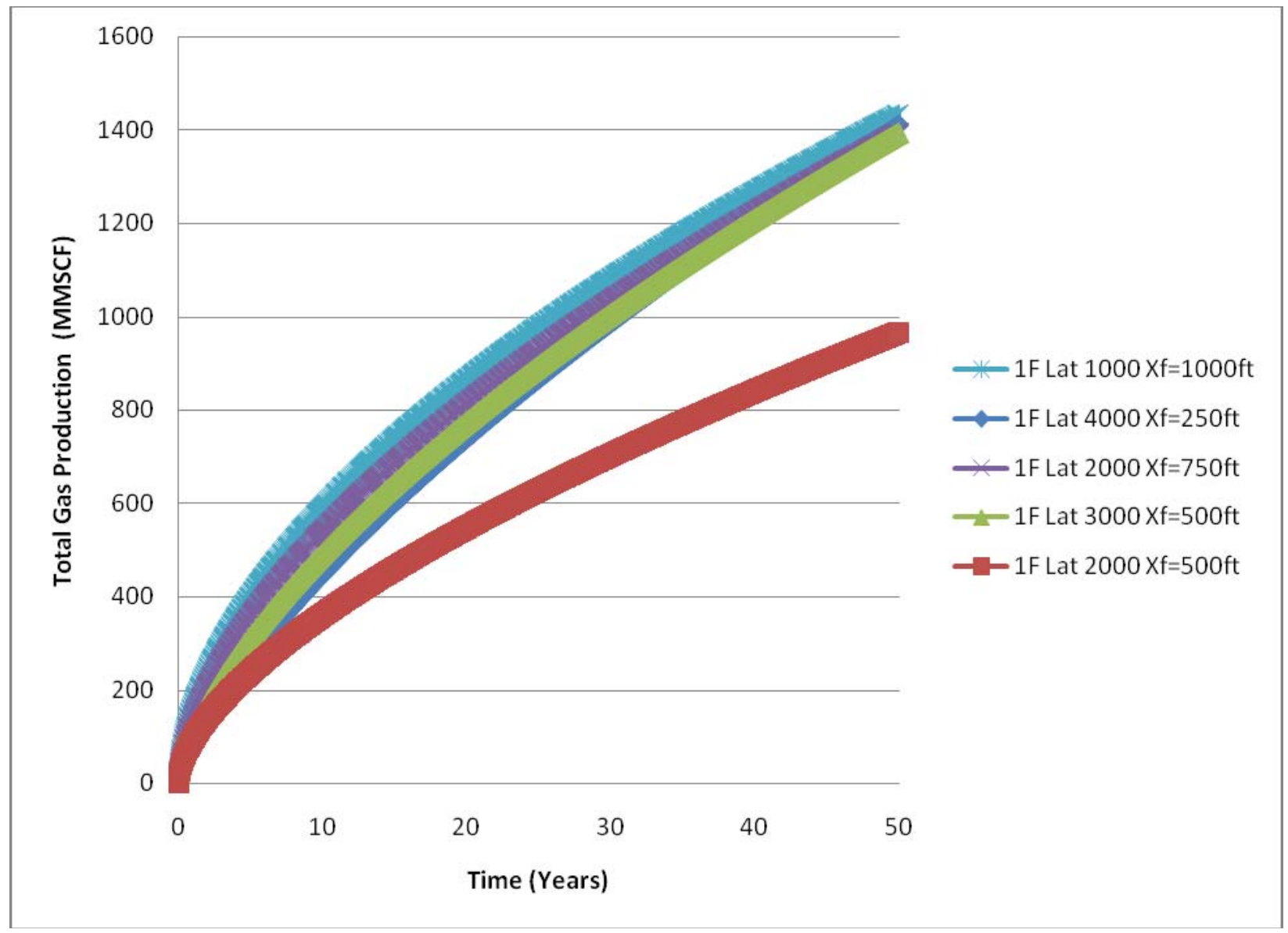

Figure IV-18 Comparison of total gas production for one and one and a half million stimulated rock volume with one fracture treatment design. 


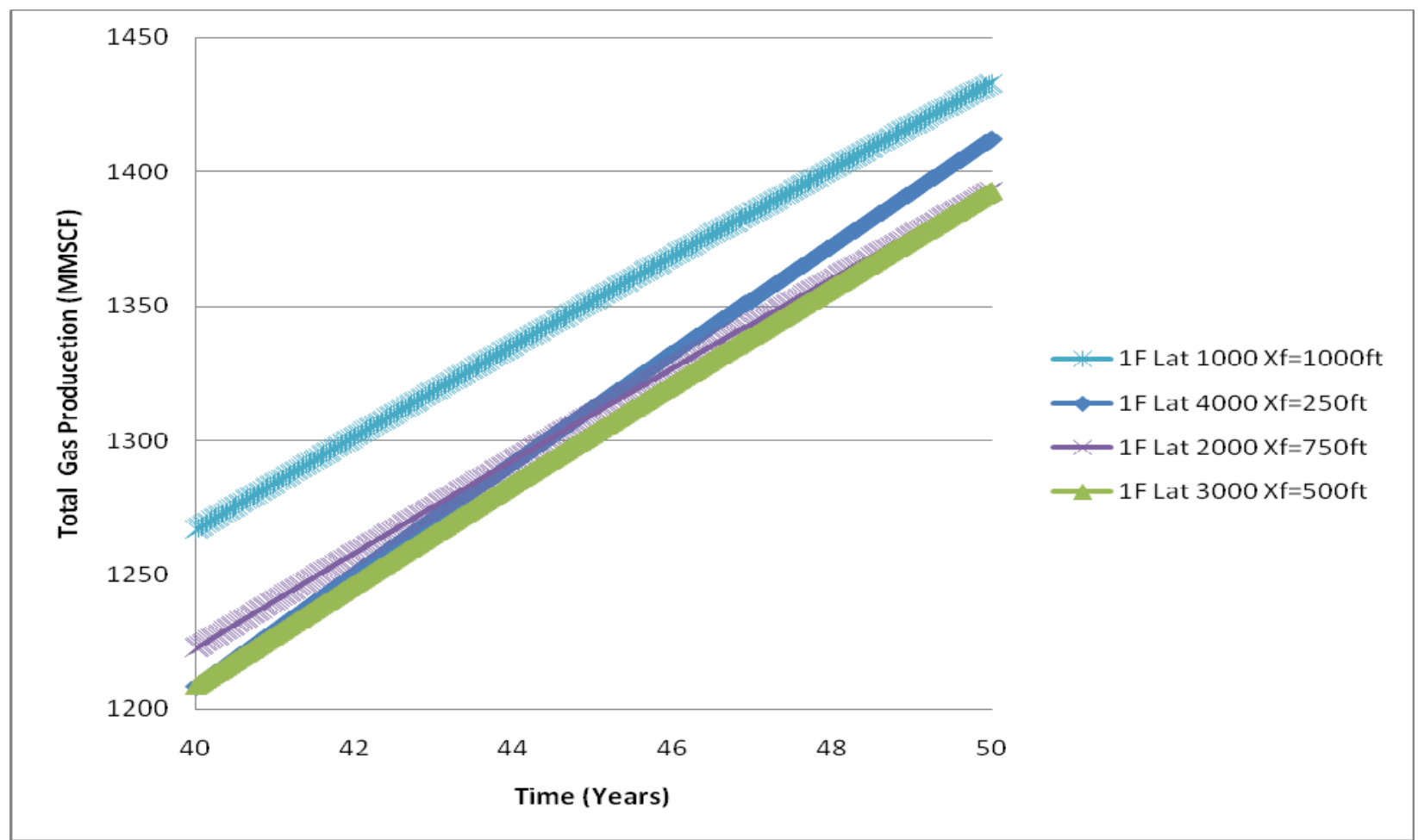

Figure IV-19 Comparison of total gas production for one and one and a half million stimulated rock volume for the last ten years.

\section{IV-10 Effect of Gas Production on Field Pressure}

The total initial gas in place (GIP) for all cases studied is approximately 248 MMMSCF and the recovered total gas at the end of 50 years makes a small portion of the GIP. For example, there was 243,250.62 MMSCF gas was in the reservoir after 50 years of production for a seven fracture treated 4000 foot long wellbore with a $750 \mathrm{ft}$ fracture half length. This results in the recovery of $1.97 \%$ of the total GIP (Figure IV-20). This number was lower than expected due to the large size of the simulated reservoir. This recovery value was the highest among the designs considered in the study. Figure IV-21 shows the variation of reservoir pressure with time for the 
same well design. All runs showed a similar trend for the reservoir pressure during the 50 year production period.

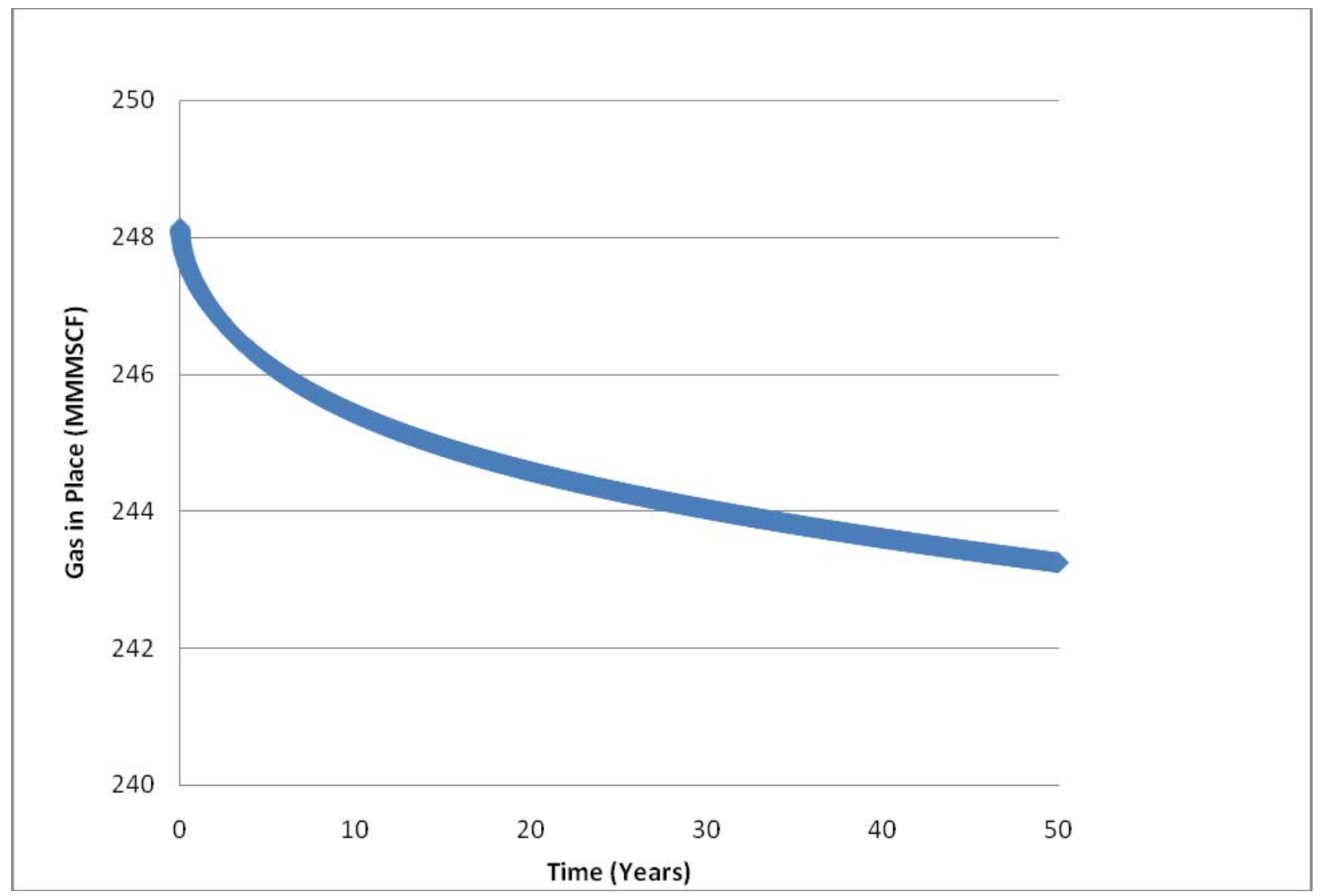

Figure IV-20 Variation of GIP for the horizontal well with seven fracture treatments and 4000 foot lateral section and $750 \mathrm{ft}$ fracture half length. 


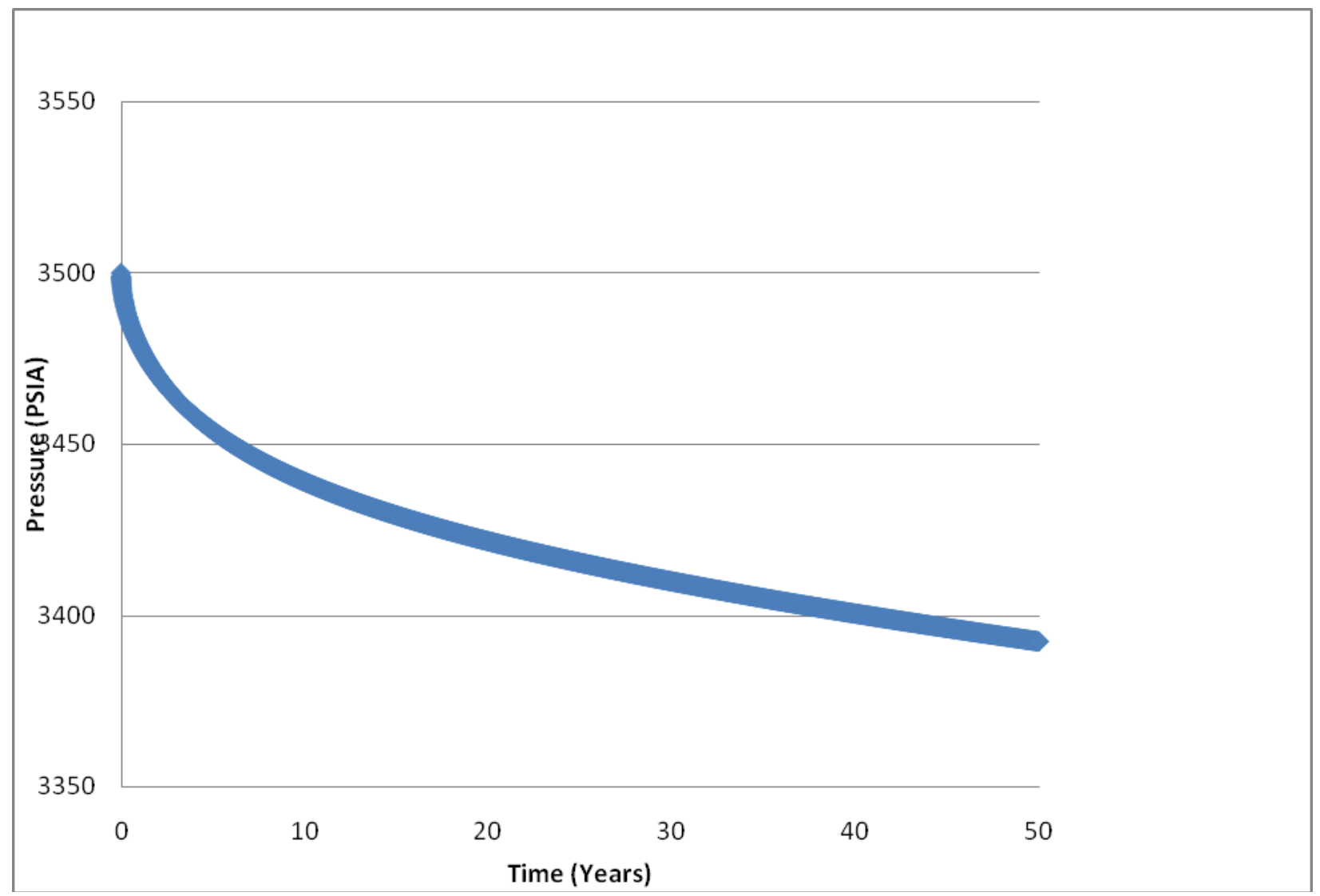

Figure IV-21 Variation of reservoir pressure for the horizontal well with seven fracture treatments and 4000 foot lateral section and $750 \mathrm{ft}$ fracture half length.

To visualize the pressure distributions in the reservoir, new plots are presented in Figure IV-22 through Figure IV-24. Figure IV-22 shows the pressure distribution for a horizontal well with a 2000 foot lateral section and a 500 foot fracture half length with one fracture treatment. In this case, only a small fraction of the overall reservoir experiences pressure drop after 50 years of production. The total area, used in this study can be developed with additional wells without the comingling of the gas to increase the recovery rate in the reservoir. The number of wells will vary depending on the length of the horizontal lateral section. 


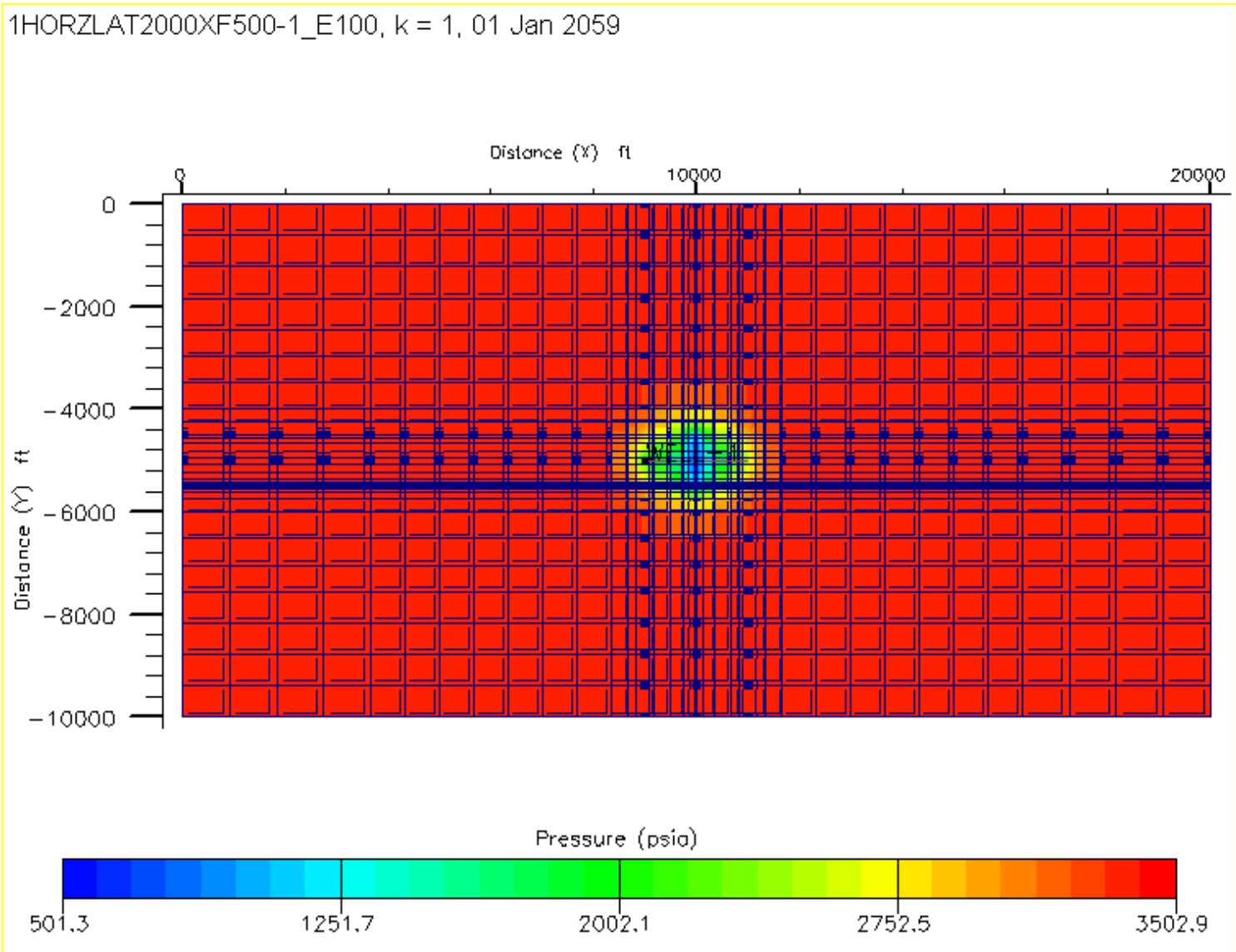

Figure IV-22 Reservoir pressure distribution at the end of 50 years (horizontal well with one fracture treatments).

Figure IV-23 shows the pressure distribution for a horizontal well with a 2000 foot lateral section and 500 foot fracture half length with three fracture treatments. Similar to Figure IV-22, the pressure depleted area is a small fraction of the study area even with the addition of two fracture treatments. However, the pressure drop starts to expand out to a greater distance as the amount of fractures increase. Thus, less number of horizontal wells would be needed in the reservoir when more fracture treatments are designed. 


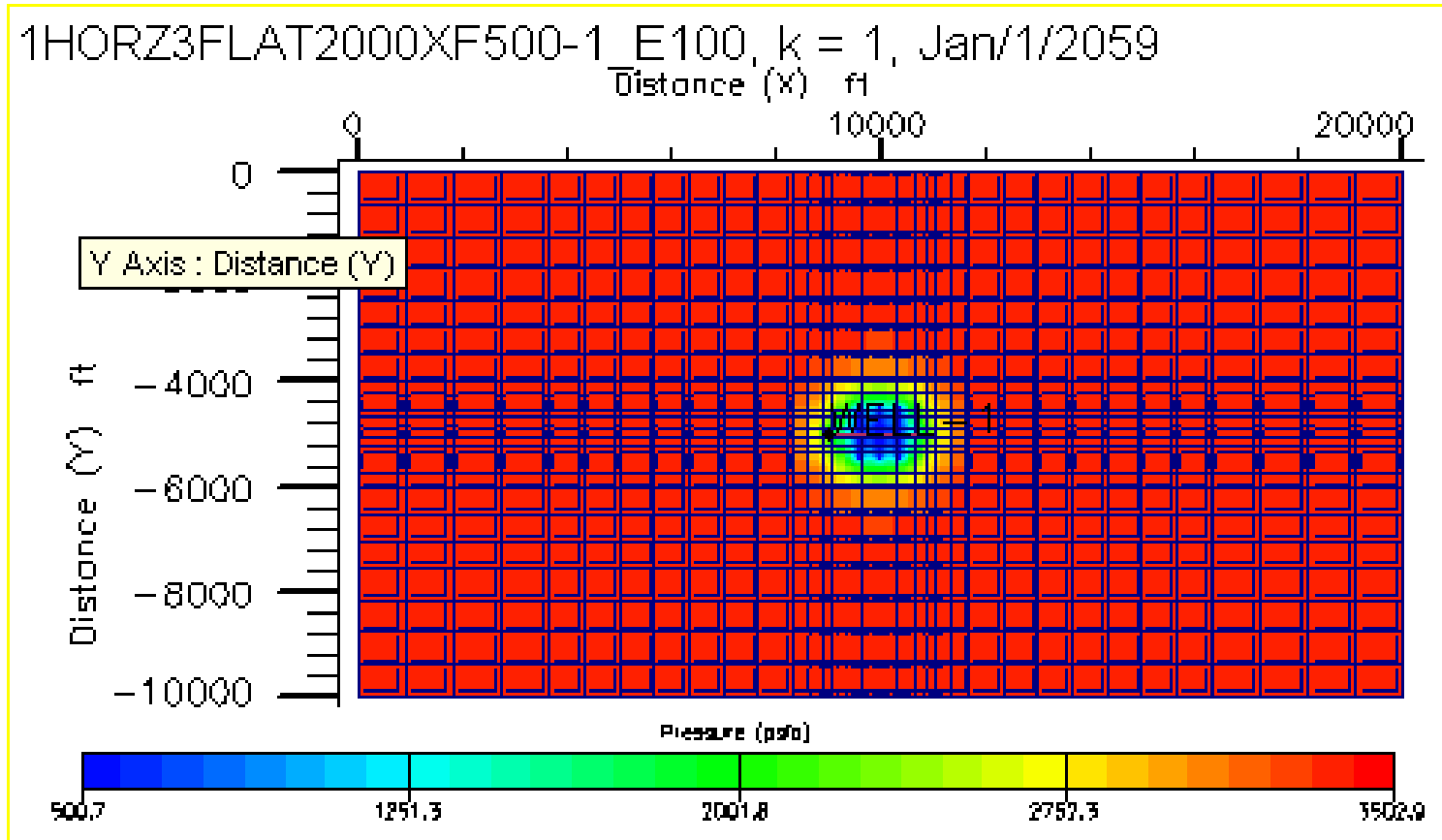

Figure IV-23 Reservoir pressure distribution at the end of 50 years (horizontal well with three fracture treatments).

Figure IV-24 shows the pressure distribution in the reservoir at the end of a 50 year production period for three vertical well design with one fracture treatment. It appears that the wells can be evenly spaced and also more vertical wells than horizontal wells can be drilled in the reservoir resulting in the increase of recoverable reserves in the given time period. 


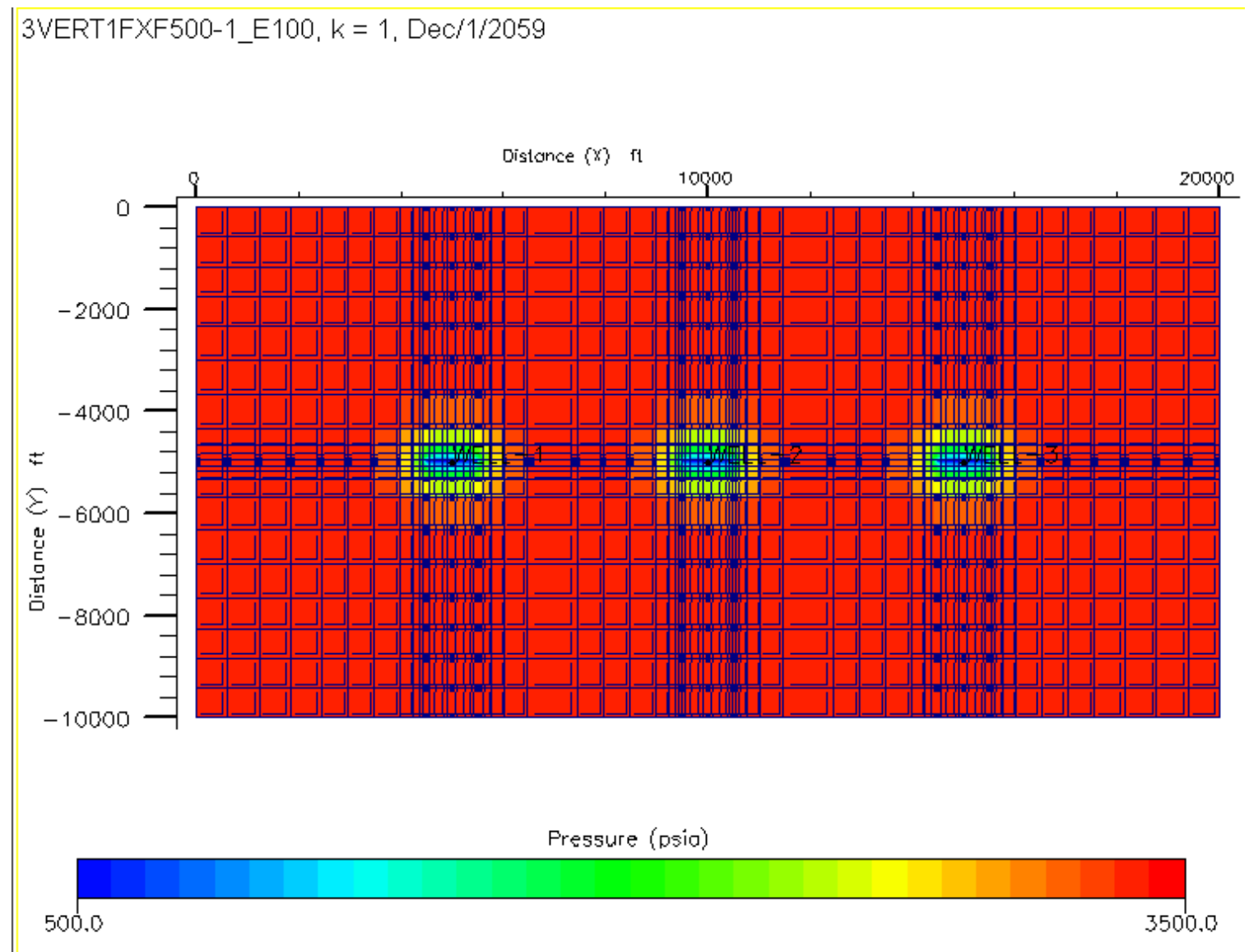

Figure IV-24 Reservoir pressure distribution at the end of 50 years (three vertical wells with one fracture treatments). 


\section{IV-11 Economics Analysis}

In order to determine economic feasibility, first a cash flow model was constructed for all seventy-four simulated runs. Once the cash flow charts were constructed net present values (NPV)'s can be calculated along with internal rates of return (IRR)'s. These two values are used to analysis the economic feasibility of these design parameters considered in this study. All equations used in the economic analysis came from (Newman and Ikoku).

Our model is a common cash flow model. Its main parameters are:

- Capital Expenses or Investment

- Operating Expenses

- Interest rate

- Gas price

In a cash flow model, investment is defined as the sum of all costs. The capital expenses used in the economic analysis for drilling a horizontal well of varying lateral lengths along with the cost associated with drilling the vertical wells are given in Table IV-2. The costs of fracture treatment per stage depending on the fracture half length employed in this study are shown in Table IV-3. All cost values used are general averages from personal communications with different operators.

Table IV-2 Drilling cost values used in the economics study.

\begin{tabular}{|l|r|}
\hline Well Design - (Drilling Only) & \multicolumn{1}{c|}{ Cost, $\mathbf{~}$} \\
\hline Horizontal with $1000 \mathrm{ft}$ Lateral & $2,000,000$ \\
\hline Horizontal with $2000 \mathrm{ft}$ Lateral & $2,100,000$ \\
\hline Horizontal with $3000 \mathrm{ft}$ Lateral & $2,200,000$ \\
\hline Horizontal with $4000 \mathrm{ft}$ Lateral & $2,300,000$ \\
\hline Vertical Drilling Cost & 800,000 \\
\hline
\end{tabular}


Table IV-3 Completion costs used in the economic study.

\begin{tabular}{|l|r|}
\hline \multicolumn{1}{|c|}{ Well Design - (Completions Only) } & Cost, $\mathbf{\$}$ \\
\hline Frac Half Length per Stage $(250 \mathrm{ft})$ & 100,000 \\
\hline Frac Half Length per Stage $(500 \mathrm{ft})$ & 125,000 \\
\hline Frac Half Length per Stage $(750 \mathrm{ft})$ & 150,000 \\
\hline Frac Half Length per Stage $(1000 \mathrm{ft})$ & 175,000 \\
\hline
\end{tabular}

Operating costs were assumed to remain constant at thirty dollars a day per well. A fixed interest rate of $15 \%$ is used throughout the economic study. A constant gas price of 3 dollars per MSCF was also used in this study. This may be very conservative number for gas price considering today's gas price is 3.75 dollars per MSCF. Along with the fact that the price of gas is projected to increase at some point in the next ten years, however, a conservative economic analysis is used to prevent overestimation of costs for the project. In addition, a $12.5 \%$ royalty tax was taken out of the total gas revenue. For all cases, the same parameters were used and these economic results were calculated for the first ten years of the wells life. Table IV-4 below lists the economic parameters used in the economic analysis.

Table IV-4 Parameters used in the economics analysis.

\begin{tabular}{|l|r|}
\hline \multicolumn{1}{|c|}{ Parameter } & \multicolumn{1}{c|}{ Value } \\
\hline Operating Cost, \$/Month & 900 \\
\hline Gas Price, \$/MSCF & 3 \\
\hline Royalty, \% & 12.5 \\
\hline Interest Rate,\% & 15 \\
\hline
\end{tabular}

The results of economic analysis for all cases are given in Table-B1, Appendix B. Two cases with one vertical well and one horizontal well are presented to give the details of the economic analysis. The results are color coded in light blue for uneconomical results and color coded in dark blue for economical designs. 


\section{IV-11-I Vertical Wells}

The economic analysis for one vertical well with a 750 foot half length is given in Table IV-5. The payout time was determined as 9.7 years with a NPV of -0.344 million dollars and an IRR of $0.32 \%$. This shows that with the $15 \%$ interest rate this well would be uneconomical. If the interest rate was less than $0.32 \%$ then this well would become economical. In all of the vertical well cases regardless of the number of wells or fracture half length the results showed that there were not economical with a three dollars per MSCF gas price used in this study.

\section{IV-11-II Horizontal Wells}

The economic analysis for a horizontal well with nine fractures, a four thousand foot lateral length and a fracture half length of one thousand feet is presented in Table IV-6. The gas production per year, gas revenue after the royalty’s, the expenses including the drilling, completion and operating costs, cash flow, are given on a yearly basis for ten years. For the horizontal well design considered in the economic analysis, a NPV value of 3.425 million dollars with an IRR of $54 \%$ were obtained. The payback time on the investment was calculated as 1.2 years. 


\section{Vertical Well}

Table IV-5 Standard cash flow model run for a vertical well.

Actual Development Plan - Economic Evaluation

1 Vertical Well with $750 \mathrm{ft}$ Half Length

$\begin{array}{lc}\text { Interest Rate }= & 15 \% \\ \text { Gas Price }= & 3 \$ / \mathrm{MSCF}\end{array}$

\begin{tabular}{|c|c|c|c|c|c|c|c|c|c|c|c|c|c|}
\hline Time & (Years) & 0 & 1 & 2 & 3 & 4 & 5 & 6 & 7 & 8 & 9 & 10 & Total \\
\hline Gas Production & (MSCF/Y) & & 122508 & 52974 & 39945 & 35781 & 30656 & 29308 & 26127 & 25647 & 24292 & 22217 & 409456 \\
\hline Gas Revenue & $\$ M$ & & 0.322 & 0.139 & 0.105 & 0.094 & 0.080 & 0.077 & 0.069 & 0.067 & 0.064 & 0.058 & 1.075 \\
\hline Drilling Cost & $\$ M$ & 0.800 & & & & & & & & & & & 0.800 \\
\hline Completion Cost & $\$ M$ & 0.150 & & & & & & & & & & & 0.150 \\
\hline Operating Cost & $\$ M / Y$ & & 0.011 & 0.011 & 0.011 & 0.011 & 0.011 & 0.011 & 0.011 & 0.011 & 0.011 & 0.011 & 0.110 \\
\hline Total Expenses/Y & & 0.950 & 0.011 & 0.011 & 0.011 & 0.011 & 0.011 & 0.011 & 0.011 & 0.011 & 0.011 & 0.011 & 1.060 \\
\hline Cashflow & & -0.950 & 0.311 & 0.128 & 0.094 & 0.083 & 0.070 & 0.066 & 0.058 & 0.056 & 0.053 & 0.047 & \\
\hline NPV Project @ 15\% & $\$ M$ & & & & & & & & & & & & -0.344 \\
\hline Discount Factor & & 1.000 & 0.870 & 0.756 & 0.658 & 0.572 & 0.497 & 0.432 & 0.376 & 0.327 & 0.284 & 0.247 & \\
\hline Discount Cash Flow & & -0.950 & 0.270 & 0.097 & 0.062 & 0.047 & 0.035 & 0.029 & 0.022 & 0.018 & 0.015 & 0.012 & -0.344 \\
\hline IRR & & & & & & & & & & & & & $0.32 \%$ \\
\hline Cashflow Project Cum & & -0.950 & -0.639 & -0.511 & -0.417 & -0.334 & -0.265 & -0.199 & -0.141 & -0.085 & -0.032 & 0.015 & \\
\hline Project Payout & 9.7 & & & & & & & & & & & & \\
\hline
\end{tabular}




\section{Horizontal Well}

Table IV-6 Standard cash flow model run for a horizontal well.

Actual Development Plan - Economic Evaluation

1 Horizontal Well 9 Fractures $4000 \mathrm{ft}$ Lateral Length and $1000 \mathrm{ft}$ Half Length

Interest Rate $=\quad 15 \%$

Gas Price $=\quad 3 \$$ MSCF

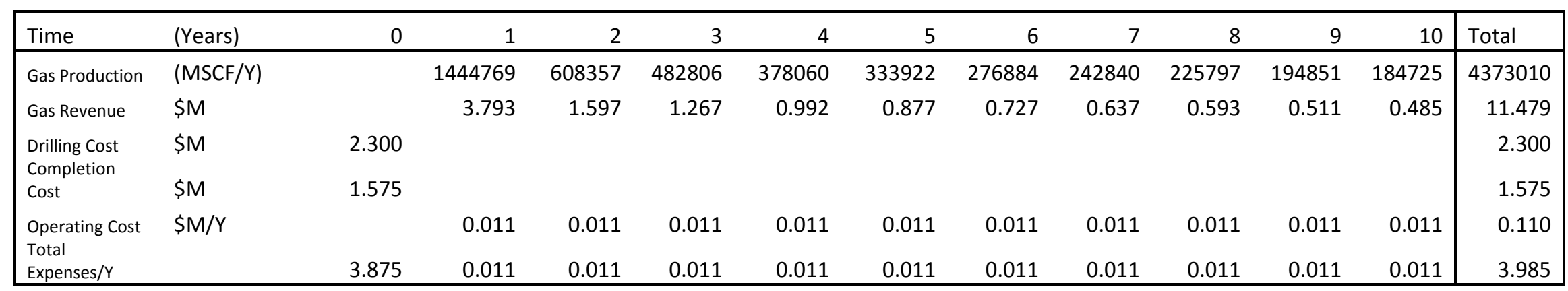

\begin{tabular}{|c|c|c|c|c|c|c|c|c|c|c|c|c|c|c|}
\hline $\begin{array}{l}\text { Cashflow } \\
\text { NPV Project @ }\end{array}$ & & & -3.875 & 3.782 & 1.586 & 1.256 & 0.981 & 0.866 & 0.716 & 0.627 & 0.582 & 0.501 & 0.474 & \\
\hline & $\$ M$ & & & & & & & & & & & & & 3.425 \\
\hline $\begin{array}{l}\text { Discount Factor } \\
\text { Discount Cash }\end{array}$ & & & 1.000 & 0.870 & 0.756 & 0.658 & 0.572 & 0.497 & 0.432 & 0.376 & 0.327 & 0.284 & 0.247 & \\
\hline Flow & & & -3.875 & 3.288 & 1.199 & 0.826 & 0.561 & 0.430 & 0.309 & 0.236 & 0.190 & 0.142 & 0.117 & 3.425 \\
\hline $\begin{array}{l}\text { IRR } \\
\text { Cashflow }\end{array}$ & & & & & & & & & & & & & & $54.00 \%$ \\
\hline Project Cum & & & -3.875 & -0.093 & 1.493 & 2.749 & 3.730 & 4.596 & 5.312 & 5.938 & 6.520 & 7.021 & 7.495 & \\
\hline Project Payout & & 1.2 & & & & & & & & & & & & \\
\hline
\end{tabular}


Figure IV-25 shows varying IRR values for a seven fracture horizontal well with a lateral length of 3000 feet and a 1000 foot half length. An IRR is calculated by where the NPV value would equal zero. Thus, in this case the IRR is calculated as $43.31 \%$. Therefore, the well could be drilled and completed with up to a $43.31 \%$ interest rate. In the economic analysis, an interest rate of $15 \%$ was used yielding a better NPV for the ten year evaluation period.

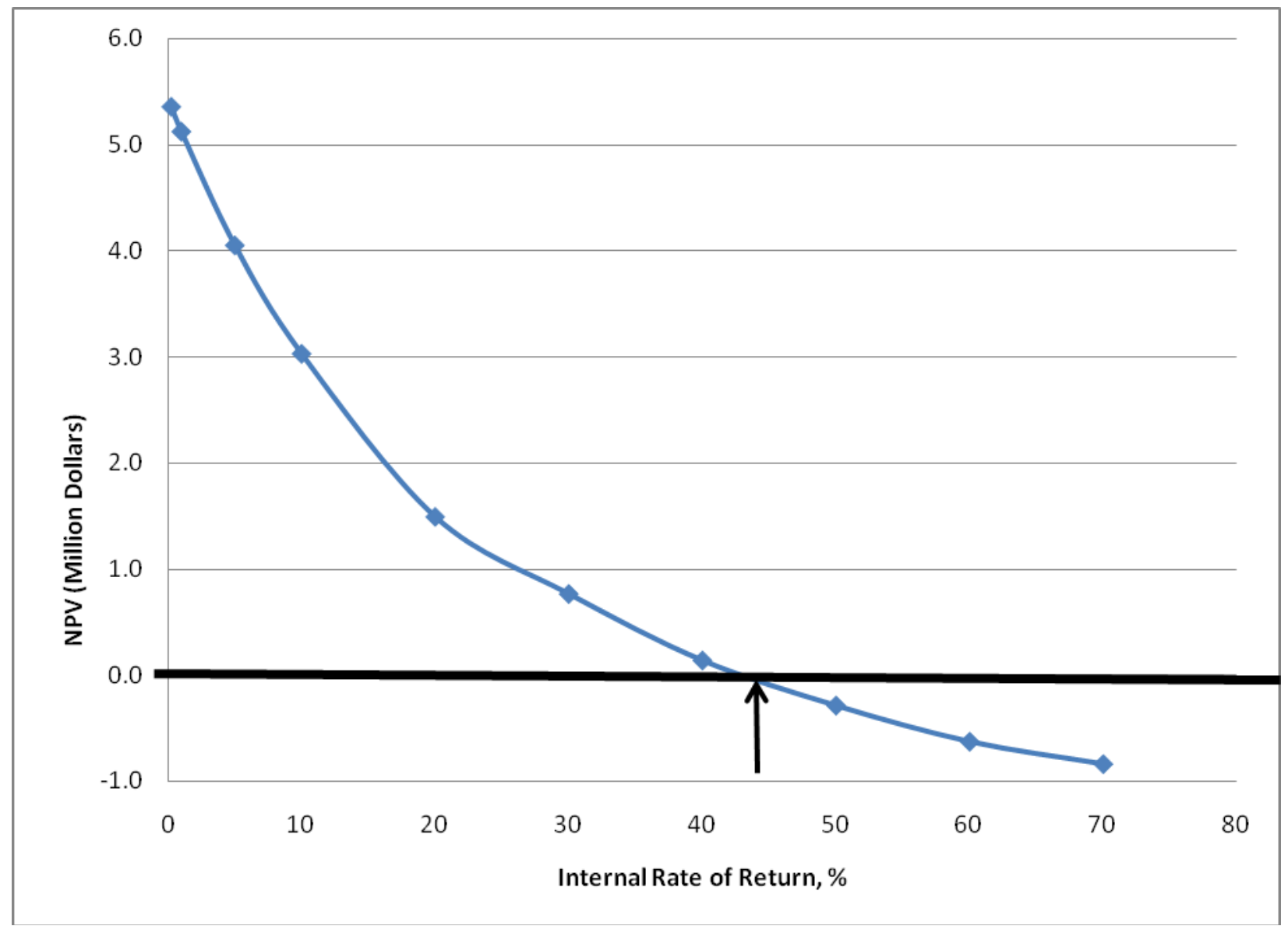

Figure IV-25 IRR of 7 Fracture 3000 foot lateral and 1000 foot half length well design.

Figure IV-26, summarizes all the simulated economics calculated. NPV values are shown for all of the cases and for an IRR of 15\%. A negative NPV or an IRR below 15\% was considered as uneconomical. 


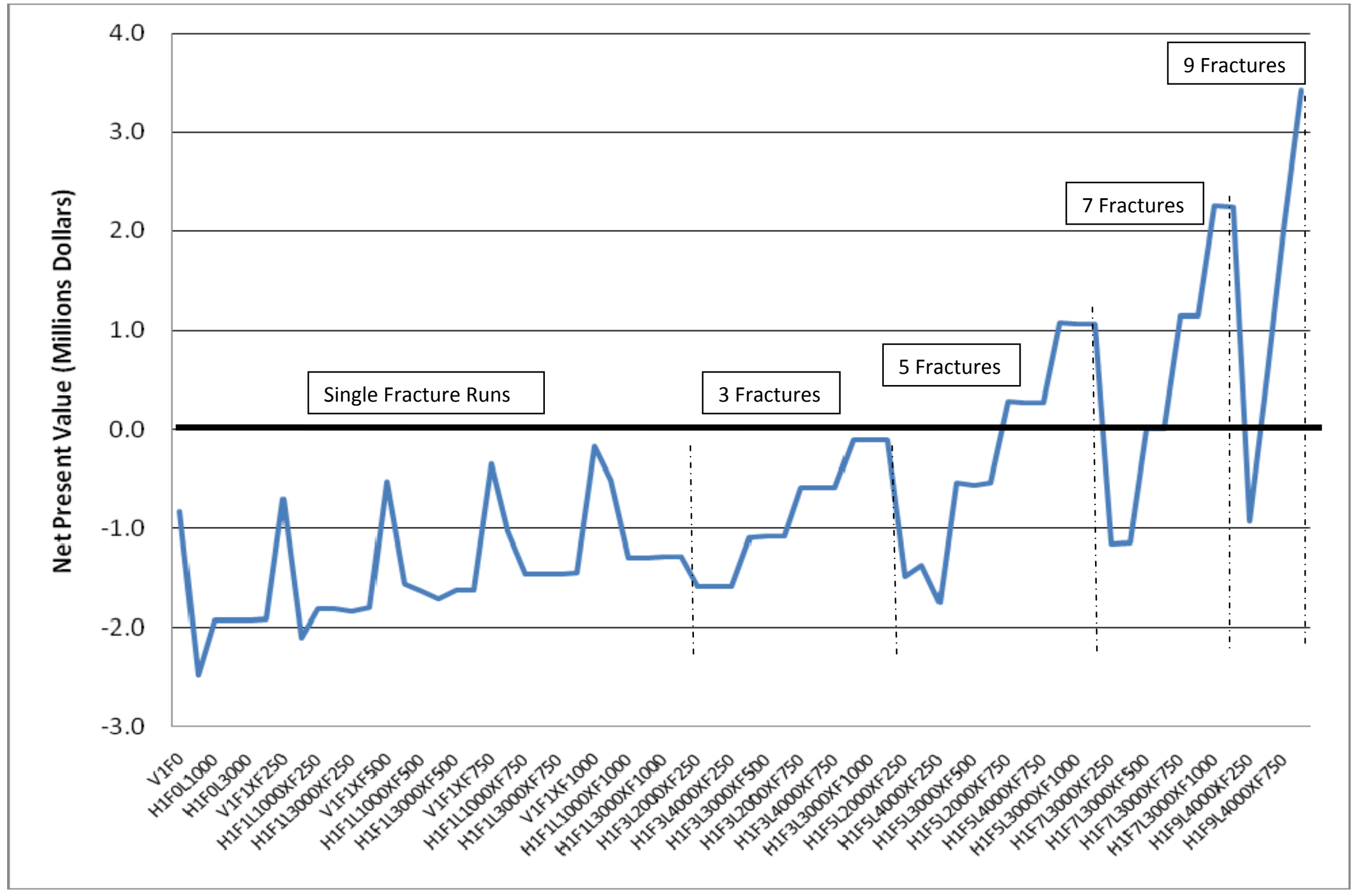

Figure IV-26 Comparison of NPV at 15\% interest rate for well designs used in this study. 
In Figure IV-26 ,the graphic representation of the economic evaluation shows from the left to right the amount of fractures increasing, and in those fracture sections the half length increases from left to right as well. In Figure IV-26, it can easily be seen that the larger the amount of fractures and the higher the half length, the larger the profit and more economical the wells will be. Lastly, the short straight lines are the changes between the lateral lengths. It can be noted that there is not much of a change between the lateral length sections.

In Figure IV-26, the well designs are described with abbreviations given in Table IV-7. The first letter "H" represents a horizontal well or "V" represents a vertical well followed by a number for the number of wells in the field. Next, the letter "F" is used for fractures followed by a number, for the amount of stages of fractures. The third part of the abbreviation is the lateral length of the horizontal wellbore represented by the letter "L" and a length of 1000, 2000, 3000 or 4000 feet. After that, the fracture half length is described by the letters "XF" followed by the distance of 250, 500, 750 or 1000 feet. Lastly, if the fracture spacing was changed there will be a "SP800" end of the acronym. An example would be H1F5L4000Xf750SP800, representing one horizontal well with five fractures and a lateral length of 4000 feet. Along with a 750 feet fracture half length at 800 foot spacing. 
Table IV-7 Description of abbreviations used in figures.

\begin{tabular}{|c|l|}
\hline Abbreviations & \multicolumn{1}{|c|}{ Descriptions } \\
\hline 1H & 1 Horizontal Well \\
\hline 1V & 1 Vertical Well \\
\hline 3V & 3 Verticals Wells \\
\hline OF & 0 Fractures \\
\hline 1F & 1 Fracture Stage \\
\hline 3F & 3 Fracture Stage \\
\hline 5F & 5 Fracture Stage \\
\hline 7F & 7 Fracture Stage \\
\hline 9F & 9 Fracture Stage \\
\hline L1 & 1000 Foot Lateral Length \\
\hline L2 & 2000 Foot Lateral Length \\
\hline L3 & 3000 Foot Lateral Length \\
\hline L4 & 4000 Foot Lateral Length \\
\hline XF250 & 250 Foot Half Length \\
\hline XF500 & 500 Foot Half Length \\
\hline XF750 & 750 Foot Half Length \\
\hline XF1000 & 1000 Foot Half Length \\
\hline $8 S P$ & 800 Foot Fracture Spacing \\
\hline
\end{tabular}

The color coding used for Table B-1 is also used for the results shown in Table IV-8 through Table IV-12. The final results from the data calculated showed that no single fractured horizontal or vertical wells were economical. The horizontal well with a minimum of three fractures was economical with the 1000 foot fracture half length when an 800 foot spacing was used. The horizontal wells with five fractures of 750 foot and 1000 foot half lengths were economical regardless of lateral length and spacing. The cases for seven and nine fractures with 500, 750, and 1000 foot half lengths were economical regardless of lateral lengths. Based on the IRR results, larger the number and length of fractures higher the IRR values. Also when looking at the same amount of fractures higher IRR's were found with longer fracture half lengths yet when looking at the different lateral lengths the shorter lateral lengths actually had higher IRR's. This is believed to be due to the fact the spacing was held constant. 


\section{IV-11-III Wells with a Single or No Fractures}

As discussed previously, the results for the zero and single fractures are uneconomical. The results are shown below in Table IV-8, are the NPV values at the $15 \%$ interest rate and the expected IRR for the well designs with single fractures and non-fractured wells. As it can be see the non fractured wells were very uneconomical especially the vertical wells which had a $-277 \%$ IRR. The single fractured horizontal and vertical wells were not much better varying from a 86.1 to a $9.8 \%$ IRR. All of these wells had a negative NPV values. The best well out of these cases was the single fractured vertical well with a 1000 feet fracture half length. If gas prices were higher, this well would be the first to become economical with a current IRR at 9.8\%. 
Table IV-8 Comparison of NPV and \% IRR for different designs for horizontal and vertical wells with zero and one fractures.

\begin{tabular}{|c|c|c|}
\hline Well Design & NPV (\$) & $\%, I R R$ \\
\hline No Fractures 1 Vertical Well & $-827,667.5$ & -277.67 \\
\hline No Fractures 3 Vertical Well & $-2,482,998.3$ & -277.70 \\
\hline No Fractures 1 Horz Well Lat $=1000 \mathrm{ft}$ & $-1,927,489.4$ & -308.91 \\
\hline No Fractures 1 Horz Well Lat $=2000 f t$ & $-1,924,197.2$ & -114.22 \\
\hline No Fractures 1 Horz Well Lat $=3000 \mathrm{ft}$ & $-1,920,905.4$ & -67.13 \\
\hline No Fractures 1 Horz Well Lat $=4000 \mathrm{ft}$ & $-1,917,612.8$ & -45.93 \\
\hline 1 Fracture 1 Vertical Well $X f=250 f t$ & $-699,273.6$ & -50.37 \\
\hline 1 Fracture 3 Vertical Well Xf=250ft & $-2,097,901.6$ & -50.40 \\
\hline 1 Fracture 1 Horz Well Lat $=1000 \mathrm{ft} X f=250 \mathrm{ft}$ & $-1,809,381.1$ & -86.10 \\
\hline 1 Fracture 1 Horz Well Lat $=2000 f t X f=250 f t$ & $-1,806,292.4$ & -54.18 \\
\hline 1 Fracture 1 Horz Well Lat $=3000 \mathrm{ft} X f=250 \mathrm{ft}$ & $-1,840,887.2$ & -43.23 \\
\hline 1 Fracture 1 Horz Well Lat $=4000 \mathrm{ft} X f=250 \mathrm{ft}$ & $-1,797,506.1$ & -28.14 \\
\hline 1 Fracture 1 Vertical Well $X f=500 f t$ & $-520,339.6$ & -11.94 \\
\hline 1 Fracture 3 Vertical Well $\mathrm{Xf}=500 \mathrm{ft}$ & $-1,561,018.3$ & -11.94 \\
\hline 1 Fracture 1 Horz Well Lat $=1000 \mathrm{ft} X f=500 \mathrm{ft}$ & $-1,633,537.6$ & -43.06 \\
\hline 1 Fracture 1 Horz Well Lat $=2000 \mathrm{ft} X f=500 \mathrm{ft}$ & $-1,713,199.8$ & -42.30 \\
\hline 1 Fracture 1 Horz Well Lat $=3000 \mathrm{ft} X f=500 \mathrm{ft}$ & $-1,626,996.8$ & -23.01 \\
\hline 1 Fracture 1 Horz Well Lat $=4000 \mathrm{ft} X f=500 \mathrm{ft}$ & $-1,624,603.0$ & -17.82 \\
\hline 1 Fracture 1 Vertical Well $X f=750 f t$ & $-343,913.2$ & 0.32 \\
\hline 1 Fracture 3 Vertical Well Xf=750ft & $-1,031,889.0$ & 8.88 \\
\hline 1 Fracture 1 Horz Well Lat $=1000 \mathrm{ft} X f=750 \mathrm{ft}$ & $-1,458,591.4$ & -23.96 \\
\hline 1 Fracture 1 Horz Well Lat $=2000 f t$ Xf $=750 \mathrm{ft}$ & $-1,459,318.6$ & -18.33 \\
\hline 1 Fracture 1 Horz Well Lat $=3000 \mathrm{ft} X \mathrm{f}=750 \mathrm{ft}$ & $-1,452,104.6$ & -11.52 \\
\hline 1 Fracture 1 Horz Well Lat $=4000 \mathrm{ft} X f=750 \mathrm{ft}$ & $-1,450,541.9$ & -8.45 \\
\hline 1 Fracture 1 Vertical Well $X f=1000 f t$ & $-171,209.4$ & 9.77 \\
\hline 1 Fracture 3 Vertical Well $X f=1000 \mathrm{ft}$ & $-513,628.1$ & 9.77 \\
\hline 1 Fracture 1 Horz Well Lat $=1000 \mathrm{ft} X f=1000 \mathrm{ft}$ & $-1,288,124.1$ & -13.37 \\
\hline 1 Fracture 1 Horz Well Lat $=2000 \mathrm{ft} X f=1000 \mathrm{ft}$ & $-1,290,298.9$ & -10.35 \\
\hline 1 Fracture 1 Horz Well Lat $=3000 \mathrm{ft} X f=1000 \mathrm{ft}$ & $-1,281,807.2$ & -7.55 \\
\hline 1 Fracture 1 Horz Well Lat $=4000 \mathrm{ft} X f=1000 \mathrm{ft}$ & $-1,280,827.2$ & -5.65 \\
\hline
\end{tabular}




\section{IV-11-IV Wells with Three Fractures}

Along with the single fractured well all of the regular spaced three fractured wells were also uneconomical. The IRR for the three fracture wells ranged from $-25.5 \%$ to $13.7 \%$ and the NPV values were negative. The best well in this group was the 4000 foot lateral with a 1000 foot half length although the 2000 and 3000 foot laterals were nearly identical in IRR values. There is a trend appearing that shows the cost of the extra 1000 feet of lateral may not be worth the investment. Table IV-9 summarizes the results for wells with three fractures.

Table IV-9 Comparison of NPV and \% IRR for different designs for the single horizontal well with three fractures.

\begin{tabular}{|c|c|c|}
\hline Well Design & $\mathrm{NPV}(\$)$ & $\%$, IRR \\
\hline 3 Fractures 1 Horz Well Lat $=2000 \mathrm{ft} X f=250 \mathrm{ft}$ & $-1,588,289.91$ & -25.48 \\
\hline 3 Fractures 1 Horz Well Lat $=3000 f t x f=250 f t$ & $-1,584,448.86$ & -19.61 \\
\hline 3 Fractures 1 Horz Well Lat $=4000 \mathrm{ft} X f=250 f t$ & $-1,580,783.03$ & -15.34 \\
\hline 3 Fractures 1 Horz Well Lat $=2000 f t x f=500 f t$ & $-1,086,213.36$ & -4.02 \\
\hline 3 Fractures 1 Horz Well Lat $=3000 \mathrm{ft} X f=500 f t$ & $-1,083,461.31$ & -2.42 \\
\hline 3 Fractures 1 Horz Well Lat $=4000 f t x f=500 f t$ & $-1,080,524.80$ & -1.12 \\
\hline 3 Fractures 1 Horz Well Lat $=2000 \mathrm{ft} X f=750 f t$ & $-589,201.42$ & 5.70 \\
\hline 3 Fractures 1 Horz Well Lat $=3000 \mathrm{ft} X f=750 \mathrm{ft}$ & $-586,657.30$ & 6.30 \\
\hline 3 Fractures 1 Horz Well Lat $=4000 f t X f=750 f t$ & $-584,461.85$ & 6.82 \\
\hline 3 Fractures 1 Horz Well Lat $=2000 \mathrm{ft} X f=1000 \mathrm{ft}$ & $-104,300.60$ & 13.52 \\
\hline 3 Fractures 1 Horz Well Lat $=3000 \mathrm{ft} X f=1000 \mathrm{ft}$ & $-102,027.81$ & 13.63 \\
\hline 3 Fractures 1 Horz Well Lat $=4000 \mathrm{ft} X f=1000 \mathrm{ft}$ & $-100,170.99$ & 13.73 \\
\hline
\end{tabular}

\section{IV-11-V Wells with Five Fractures}

The five fractured wells yielded favorable economical designs. The results are summarized in Table IV- 10. The economical wells were those with a 750 or 1000 foot half length regardless of the lateral length. The IRR values ranged from -15.7 \% to $29 \%$. It appeared 
that the fracture half length is the key factor in the economical analysis; the smaller the fracture half length the lower the IRR value compared to the larger fracture half lengths. As for the lateral length it appears that the shorter half length are actually starting to be more cost efficient.

Table IV-10 Comparison of NPV and \% IRR for different designs for the single horizontal well with five fractures.

\begin{tabular}{|c|c|c|}
\hline Well Design & NPV $(\$)$ & $\%$, IRR \\
\hline 5 Fractures 1 Horz Well Lat $=2000 \mathrm{ft} X f=250 \mathrm{ft}$ & $-1,487,343.31$ & -13.50 \\
\hline 5 Fractures 1 Horz Well Lat $=3000 \mathrm{ft} X f=250 \mathrm{ft}$ & $-1,370,334.11$ & -6.80 \\
\hline 5 Fractures 1 Horz Well Lat $=4000 \mathrm{ft} X f=250 \mathrm{ft}$ & $-1,744,018.88$ & -15.71 \\
\hline 5 Fractures 1 Horz Well Lat $=2000 \mathrm{ft} X f=500 \mathrm{ft}$ & $-536,626.42$ & 7.07 \\
\hline 5 Fractures 1 Horz Well Lat $=3000 \mathrm{ft} X f=500 \mathrm{ft}$ & $-562,307.33$ & 7.09 \\
\hline 5 Fractures 1 Horz Well Lat $=4000 \mathrm{ft} X f=500 \mathrm{ft}$ & $-538,034.05$ & 7.85 \\
\hline 5 Fractures 1 Horz Well Lat $=2000 \mathrm{ft} X f=750 \mathrm{ft}$ & $284,670.10$ & 18.37 \\
\hline 5 Fractures 1 Horz Well Lat $=3000 \mathrm{ft} X f=750 \mathrm{ft}$ & $271,065.00$ & 18.09 \\
\hline 5 Fractures 1 Horz Well Lat $=4000 \mathrm{ft} X f=750 \mathrm{ft}$ & $280,050.99$ & 18.05 \\
\hline 5 Fractures 1 Horz Well Lat $=2000 \mathrm{ft} X f=1000 \mathrm{ft}$ & $1,086,222.62$ & 30.53 \\
\hline 5 Fractures 1 Horz Well Lat $=3000 \mathrm{ft} X f=1000 \mathrm{ft}$ & $1,067,551.61$ & 29.56 \\
\hline 5 Fractures 1 Horz Well Lat $=4000 \mathrm{ft}$ Xf=1000ft & $1,077,325.35$ & 29.03 \\
\hline
\end{tabular}

Figure IV-27 is a graphically representation of the five fracture wells and the NPV values that were discussed in Table IV-10. This graph presents the economical analysis, for the wells with a 250 and 500 foot half length in the negative direction and the wells with a 750 and 1000 foot half lengths in a positive direction. 


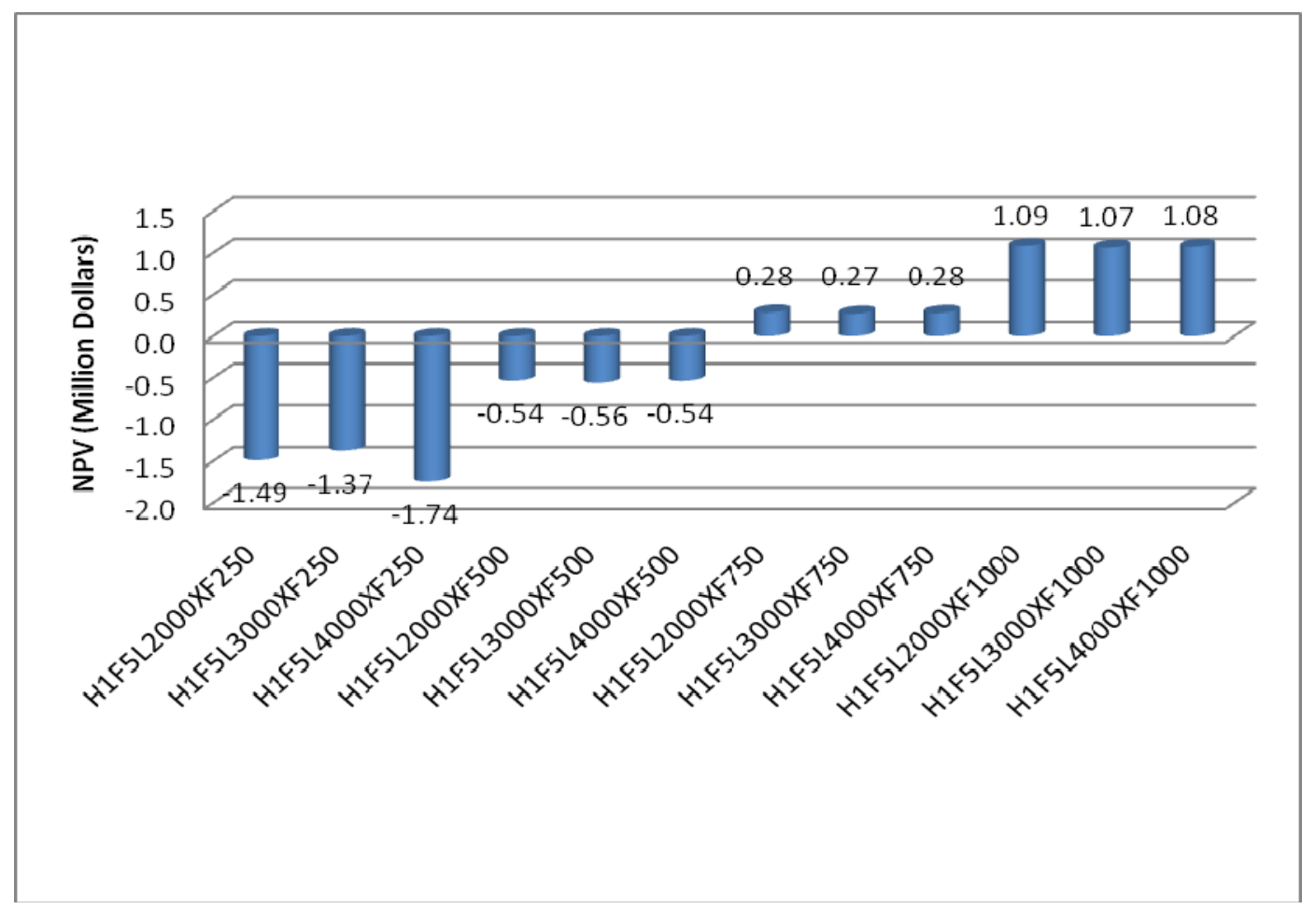

Figure IV-27 Comparison of NPV values for different designs for the single horizontal well with five fractures.

\section{IV-11-VI Wells with Seven Fractures}

The results for horizontal wells with seven fractures are shown in Table IV-10. As discussed earlier, with seven fractures, the only economical results are with half lengths of either 500, 750 or 1000 feet regardless of lateral length. Table IV-11 shows that as the amount of fractures and half length distance increases the IRR and NPV value increases. The difference in lateral length does not yield much difference in the economic analysis. It appears uneconomical to drill the extra 1000 feet of wellbore if the same amount of fracture treatment can be conducted in the shorter wellbore. The shorter wellbores are actually more cost efficient over this time period. In this case even completing the 500 foot half length would be risky at a $15 \%$ return on your investment. 
Table IV-11 Comparison of NPV and \% IRR for different designs for the single horizontal well with seven fractures.

\begin{tabular}{|c|c|c|}
\hline Well Design & NPV (\$) & $\%$, IRR \\
\hline 7 Fractures 1 Horz Well Lat $=3000 \mathrm{ft} X f=250 \mathrm{ft}$ & $-1,151,786.40$ & -1.34 \\
\hline 7 Fractures 1 Horz Well Lat $=4000 \mathrm{ft} X f=250 \mathrm{ft}$ & $-1,147,901.55$ & -0.30 \\
\hline 7 Fractures 1 Horz Well Lat $=3000 f t$ Xf=500ft & $6,973.93$ & 15.08 \\
\hline 7 Fractures 1 Horz Well Lat $=4000 f t$ Xf=500ft & $5,482.96$ & 15.06 \\
\hline 7 Fractures 1 Horz Well Lat =3000ft Xf=750ft & $1,149,244.52$ & 29.96 \\
\hline 7 Fractures 1 Horz Well Lat $=4000 \mathrm{ft} X f=750 \mathrm{ft}$ & $1,145,489.16$ & 29.31 \\
\hline 7 Fractures 1 Horz Well Lat $=3000 \mathrm{ft} X f=1000 \mathrm{ft}$ & $2,254,821.78$ & 43.31 \\
\hline 7 Fractures 1 Horz Well Lat $=4000 \mathrm{ft} X \mathrm{Xf}=1000 \mathrm{ft}$ & $2,248,598.53$ & 48.84 \\
\hline
\end{tabular}

Figure IV-28 compares the results for horizontal wells with the seven fractures. The results indicate a negative NPV for the 250 half length wells and positive NPV for the wells with 500, 750 and 1000 foot half lengths. The difference in NPV's for wells with different lateral lengths are not significant. This shows that it's not economical to drill longer laterally.

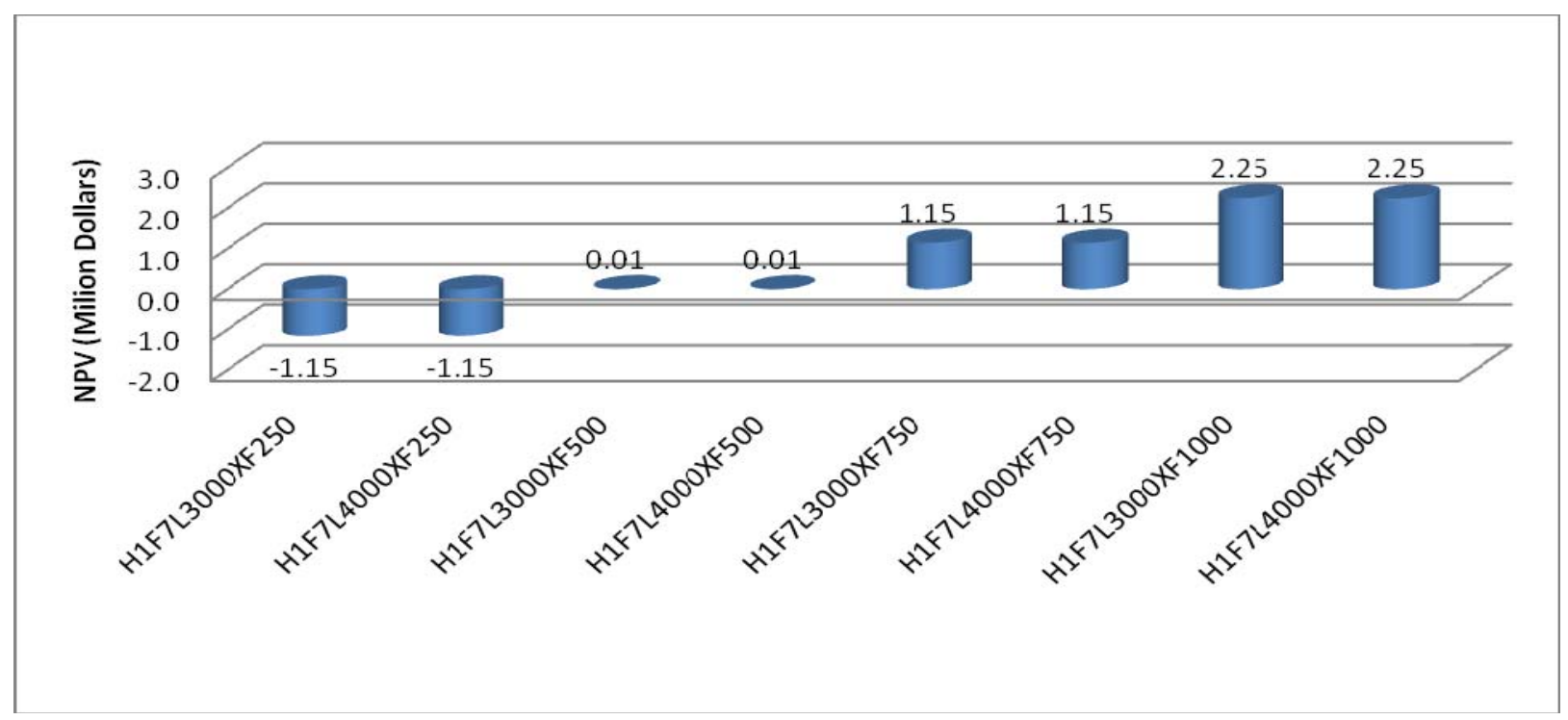

Figure IV-28 Comparison of NPV values for different designs for the single horizontal well with seven fractures. 


\section{IV-11-VII Wells with Nine Fractures}

For a horizontal well with nine fractures, the 250 foot half length is determined to be uneconomical with an IRR of 3.56\%. In the case of wells with 500, 750 and 1000 foot half lengths, the results were economical ranging from a $20.24 \%$ to a $54.0 \%$ IRR. The nine fracture 4000 foot lateral wellbore with a 1000 foot fracture half length had the highest IRR out of all of the well designs considered in this study. In wells with nine fractures there are no other lateral lengths to compare due to the spacing of the fractures, thus the only comparison is the fracture half length. Like the previous examples the larger the fracture half length the more economical is the well.

Table IV-12 Comparison of NPV and \% IRR for different designs for the single horizontal well with nine fractures.

\begin{tabular}{|l|r|r|}
\hline \multicolumn{1}{|c|}{ Well Design } & NPV (\$) & $\%$, IRR \\
\hline 9 Fractures 1 Horz Well Lat $=4000 \mathrm{ft} X f=250 \mathrm{ft}$ & $-930,412.51$ & 3.56 \\
\hline 9 Fractures 1 Horz Well Lat $=4000 \mathrm{ft}$ Xf $=500 \mathrm{ft}$ & $552,554.48$ & 20.24 \\
\hline 9 Fractures 1 Horz Well Lat $=4000 \mathrm{ft}$ Xf $=750 \mathrm{ft}$ & $2,008,661.38$ & 38.44 \\
\hline 9 Fractures 1 Horz Well Lat $=4000 \mathrm{ft}$ Xf $=1000 \mathrm{ft}$ & $3,424,897.21$ & 54.00 \\
\hline
\end{tabular}

Figure IV-29 compares the results for horizontal wells with nine fractures. The results indicate a negative NPV for the 250 foot half length wells and positive NPV for the wells with 500, 750 and 1000 foot fracture half lengths. The large difference between the NPV values for each 250 foot fracture half length increases can also be noted. It would definitely be worth adding longer fracture half lengths at $\$ 25,000$ per 250 feet at initial cost to increase the NPV to about 1.5 million dollars per 250 feet of fracture half length. 


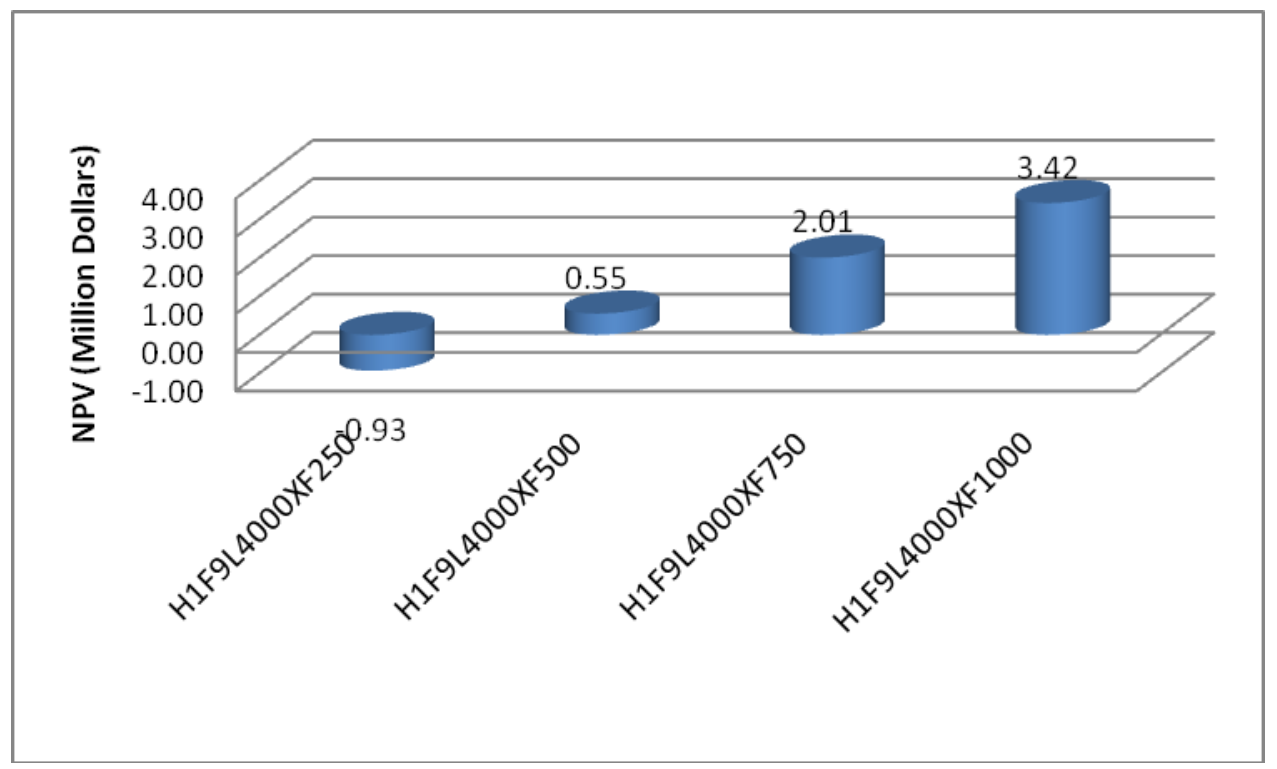

Figure IV-29 Comparison of NPV values for different fracture half length designs for the single horizontal well with $4000 \mathrm{ft}$ lateral length and nine fractures. 


\section{Chapter V. Conclusions}

Based on the runs conducted in this study, the following conclusions are presented:

- The production of the horizontal wells greatly outperforms the production from a vertical well. Thus horizontal well design overall appears to be the best as far gas production from Marcellus shale is considered. Horizontal wells were also found to be more cost efficient in the economic analysis study conducted.

- When economics were considered, it was shown that the longer fractured half length of 1000 feet and maximizing the number of fractures, nine in this study, were the most optimal designs. As far as the lateral length was concerned, it was not cost efficient to drill longer laterals if the number of fractures placed in the lateral are equal.

- Maximizing the fracture spacing in the lateral section of the wellbore, increased total gas production. Evenly spacing and increasing the number of fracture maximizes the total volume subject to drainage, thus reducing the amount of overlapped fractures and increasing the total production with a result of early recovery times.

- The fracture half length parameter was found to have much more influence on gas production than the lateral length. In this study, there was approximately a 250 MMCF increase in total gas production for every thousand feet of lateral wellbore length compared to approximately 1250 MMCF per 250 feet of propped half length increase in a fifty year period. In addition, there was a 375 MMCF per fracture increase in total gas production over the fifty-year period. The results indicate that fracture half length is the most important parameter followed by number of fractures and lateral wellbore length. 
- The use of SRV as a design criteria for horizontal wellbore length and fracture half length selection should consider the impact of fracture half length on gas production. The total gas production was higher when a longer fracture half length us usedin the well design with the same SRV value but with a short fracture half length. 


\section{Chapter VI. Recommendations}

The following recommendations are presented for further study of gas production from Marcellus shale:

- To use a heterogeneous formation properties such as porosity and permeability and determine their effects on gas production from Marcellus shale.

- To expand this study by adding different fracture half lengths and different amounts of fractures near the optimal designs found in this study.

- To expand this study with multi horizontal well field studies and or multi vertical well field studies. 


\section{Chapter VII. References}

“Area Drilling.” Oil \& Gas Journal. 106.10 (10 Mar. 2008).

Armas, Genaro C. “Appalachia tantalizes natural gas drillers.” USA Today. 3 Feb. 2008.

Atlas America, Inc. “Atlas America, Inc. Q1 2008 Earnings Call Transcript.” Seeking Alpha. 26 May 2008.

Chernoff, Harry. “Investing in the Marcellus Shale.” Seeking Alpha. 17 Mar. 2008.

“Company News.” Oil \& Gas Journal. 106.9 (3 Mar. 2008).

Contrarian Profits. “Pennsylvania’s Marcellus Shale: Welcome to America’s Next Great Energy Boom.” 13 Jul. 2008.

Devon Energy Production Co, L.P. "Railroad Commission of Texas” Drilling and Completion Reports. 27 Dec 2007. Production Data.

Drake, Steve. “Unconventional Gas Plays SPEE.” Marsh Operating Company. 6 Dec. 2007.

EIA, “Energy Information Administration Data” Aug 2007.

http://tonto.eia.doe.gov/dnav/ng/hist/n9010us2m.htm.

EIA, Energy Information Administration. “Natural Gas- Year in Review.” Mar. 2008. 6 Oct. 2008.<http://www.eia.doe.gov/pub/oil_gas/natural_gas/feature_articles/2008/ngyir2007/ngyir20 07.pdf $>$.

Engelder T., and Lash, G.G., "Systematic joints in Devonian black shale: A target for horizontal drilling in the Appalachian Basin:,” American Association of Petroleum Geologists Bulletin, Oct. 2007.

Falchek, David. “Legislators Look to Protect Water During the Drilling for Natural Gas.” CitizensVoice.com. 26 Aug. 2008.

Fontaine, J., Johnson, N. Schoen, D. "Design, Execution, and Evaluation of a "Typical” Marcellus Shale Slickwater Stimulation: A Case History, SPE 117772-MS, SPE Eastern Regional Meeting 2008

Harper, John A. "The Marcellus Shale- An Old "New” Gas Reservoir in Pennsylvania.” Pennsylvania Geology. 38.1 (Spring 2008).

Ikoku, Chi U., “Economic Analysis and Investment Decisions”, John Wiley \& Sons, 1985. 
“Jacobs Energy Seeks to Begin Producing Marcellus Shale.” NewswireToday. 15 Jul. 2008.

Lash G., Stratigraphy and Fracture History of the Middle and Upper Devonian succession, Western New York - Significance to Basin Evolution and Hydrocarbon Exploration: AAPG, 2008.

Lane H.S. and A. T. Watson, and D.E. Lancaster, "Identifying and Estimating Desorption from Devonian Shale Gas Production Data”, SPE 19794, 1989.

Lane H.S., Texas A\&M u., D.E. Lancaster, S.A. Holditch \& Assoc.Inc:, and A.T. Watson, Texas A\&M U., "Estimating Gas Desorption Parameters from Devonian Shale Well Test Data”, SPE 21272, 1990.

Miller, Mike "Marcellus Shale.” Marshall Miller \& Associates, Inc. Oil \& Gas Division Presentation. Fall 2008.

Newman, Donald G., "Engineering Economic Analysis” Third Edition, Engineering Press, Inc. 1988.

Nome, Shannon. "From Shale to Shining Shale- A Primer on North American Natural Gas Shale Plays.” Deutsche Bank, RedOrbit News. 7 Jul. 2008.

Perkins, C.K. "Logistics of Marcellus Shale Stimulation: Changing the face of Completions in Appalachia”, SPE 117754-MS, (2008).

Pickering, Hayden, J.; Pursell, D. "The Barnett Shale - Visitors Guide to the Hottest Gas Play in the U.S.” Presentation, October 2005.

Pinkhouse J.A., Paktinat, J., Johnson, N., Williams, C., Lash, Gary, Penny, G.S. and Goff, D.A."Case Study: Optimizing Hydraulic Fracturing Performance in Northeastern United States Fractured Shale Formations” SPE Paper 104306, 2006.

Range Resources Corporation. “Range Provides Marcellus Shale Update.” Jul. 142008.

Range Resources Corporation. Range Resources Press Release. Nov 2008

Range Resources Corporation. Range Resources Press Release. Feb. 242009

Soeder, D.J. "Porosity and Permeability of Eastern Devonian Gas Shale,” SPE 15213-PA, March 1988.

Suhy, T.E. "Uncovering and Exploiting Existing Marcellus Shale Opportunities in the Appalachian Basin”, SPE 117751-MS, SPE Eastern Regional Meeting Oct 11-15 2008.

Sumi, Lisa. "Shale Gas: Focus on the Marcellus Shale." Oil \& Gas Accountability Project/Earthworks. May 2008. 


\section{Appendix A}

Appendix A shows the Schlumberger Eclipse software was used to model the Marcellus shale. A coal bed methane template was used to enter shale properties for all cases. A procedure to run the software and enter data through the template shown below:

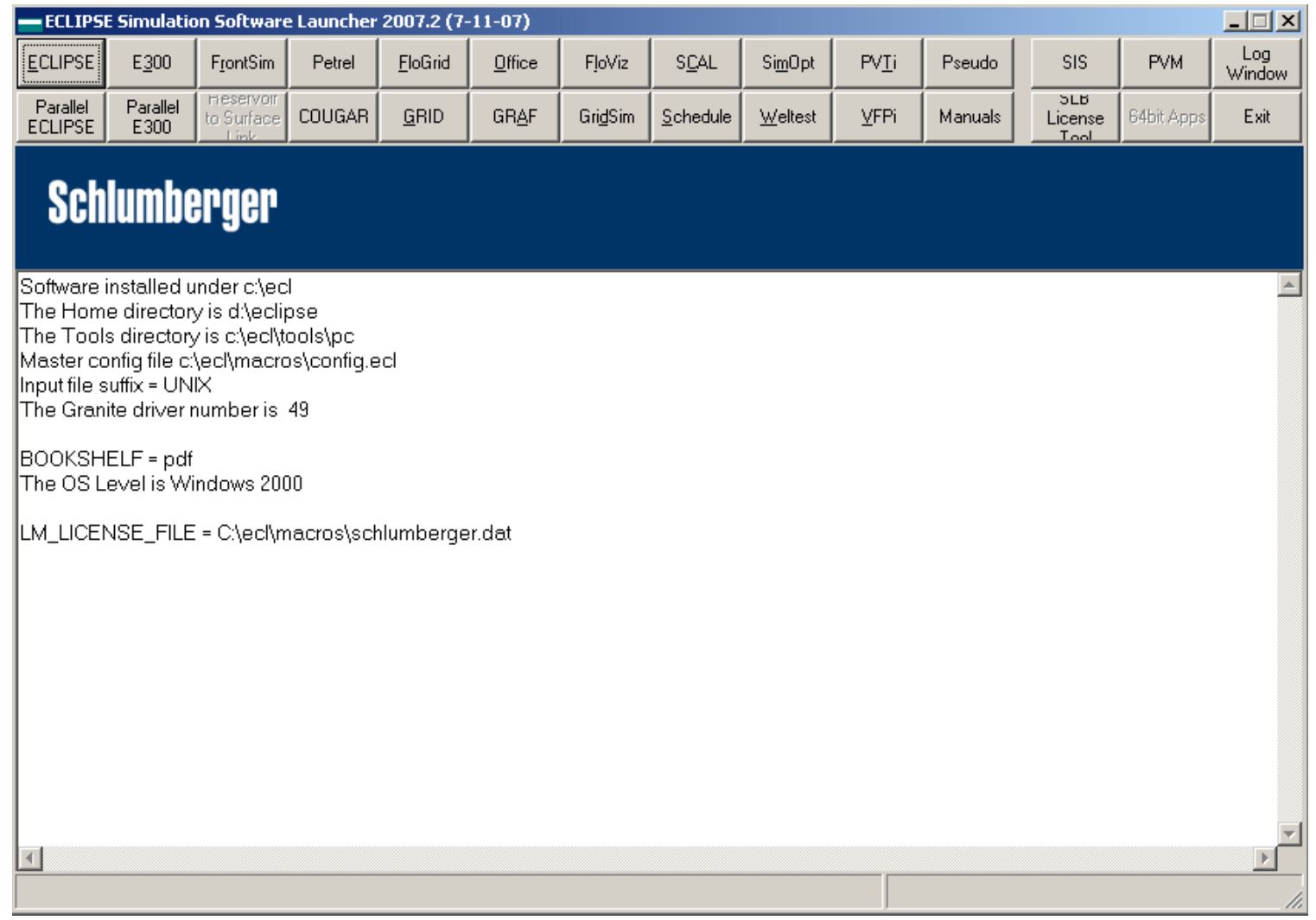

Figure A-1 Eclipse launcher screen.

Figure A-1 is the Eclipse launcher, once here the "Office "tab at the top of the screen was selected and used for the modeling simulation. The "Startup Directory" tab would appear next and the user can select the location of files to be saved. In this example, the file was saved in the "g” directory, under thesis, final runs, and a horizontal well with nine fractures in a four thousand foot wellbore with a one thousand foot propped half length folder. In addition, the user 
can select the version of the software program to run in this screen. The 2007.2 version of Eclipse was used for this research (Figure A-2).

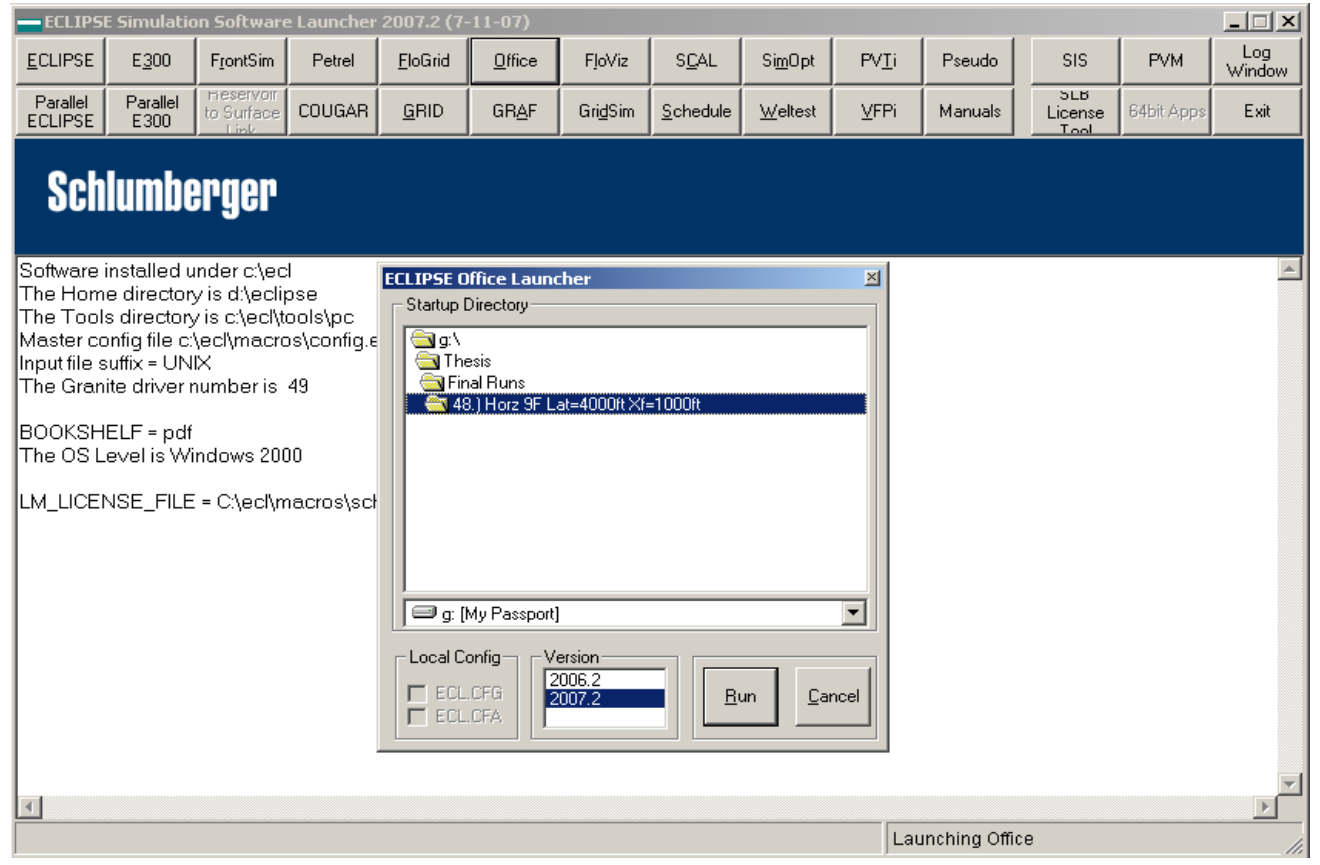

Figure A-2 Eclipse office launcher screen.

Once office screen is open, the user needs to select the new project ( Figure A-3).

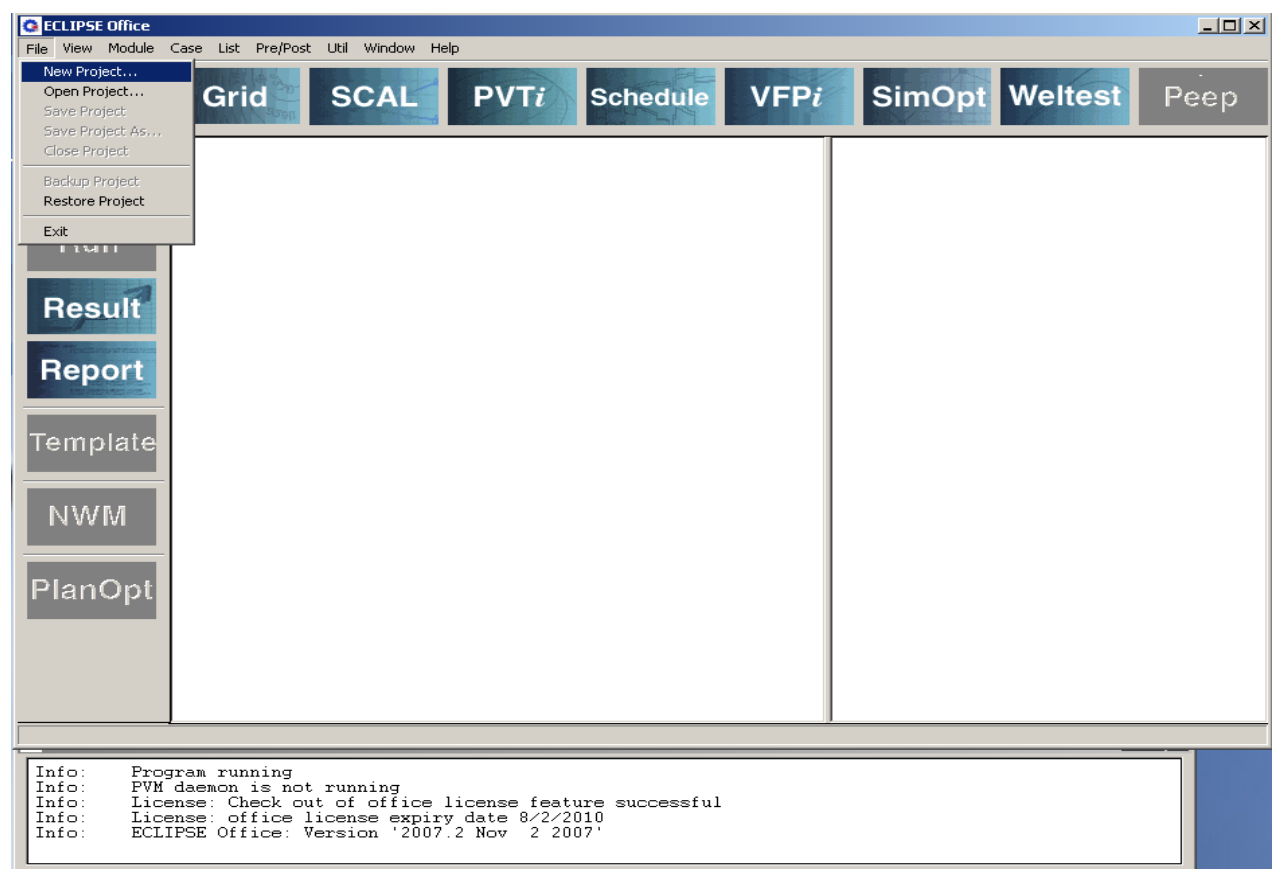

Figure A-3 Eclipse office screen. 
Once the new project is open, the file name is entered and saved in the directory selected earlier. The file named has a default extension type of “.off” for the office program (Figure A-4).

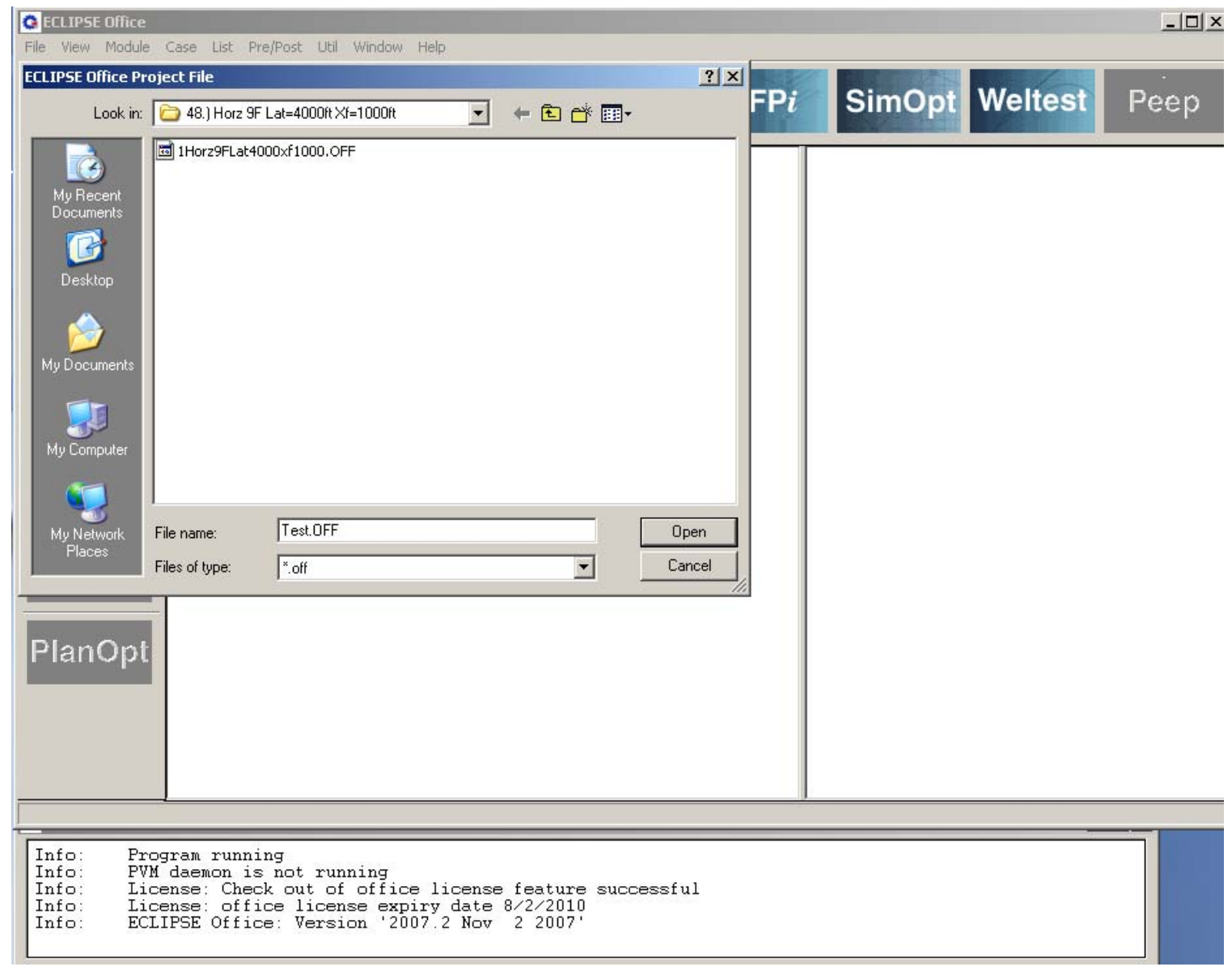

Figure A-4 Eclipse file directory screen.

Once Eclipse office is open and the file is selected, a template case can be added. This feature will allow the user to select from different types of reservoirs to model the cases desired (Figure A-5). 


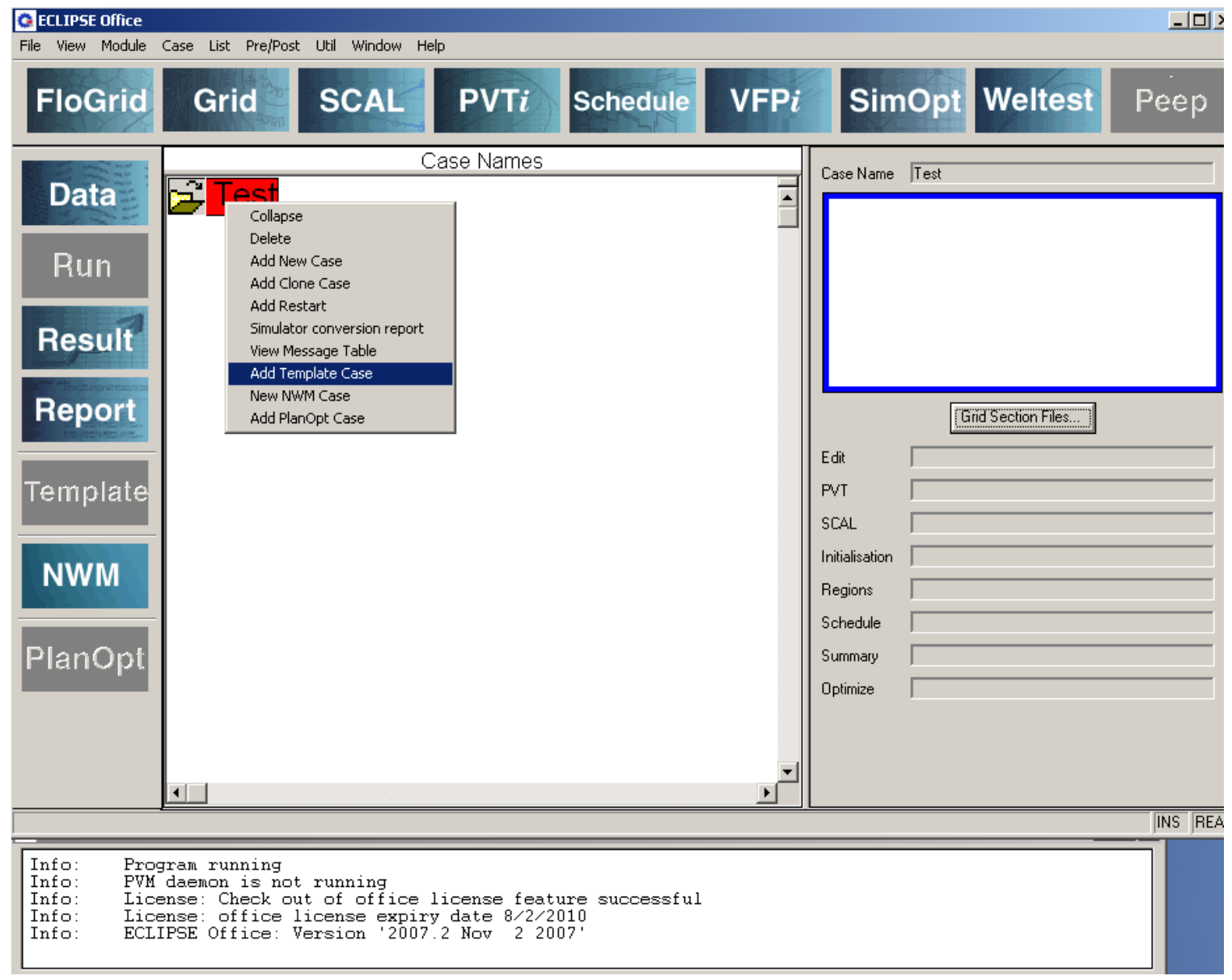

Figure A-5 Eclipse add template case screen.

Figure A-6 shows the four templates available in the program namely, single well radial, completions modeling tool, coal bed methane and CO2 sequestration. Along with that the case, name and type of unit that are to be used can also be selected.

Based on discussions with programming experts, the use of parameters in the coal bed methane template was recommended to correctly model shale gas reservoirs. This is because shale has the two forms of flow, both the conventional "free" gas and as adsorbed gas. Field units and the coal bed methane template were selected for this project. 


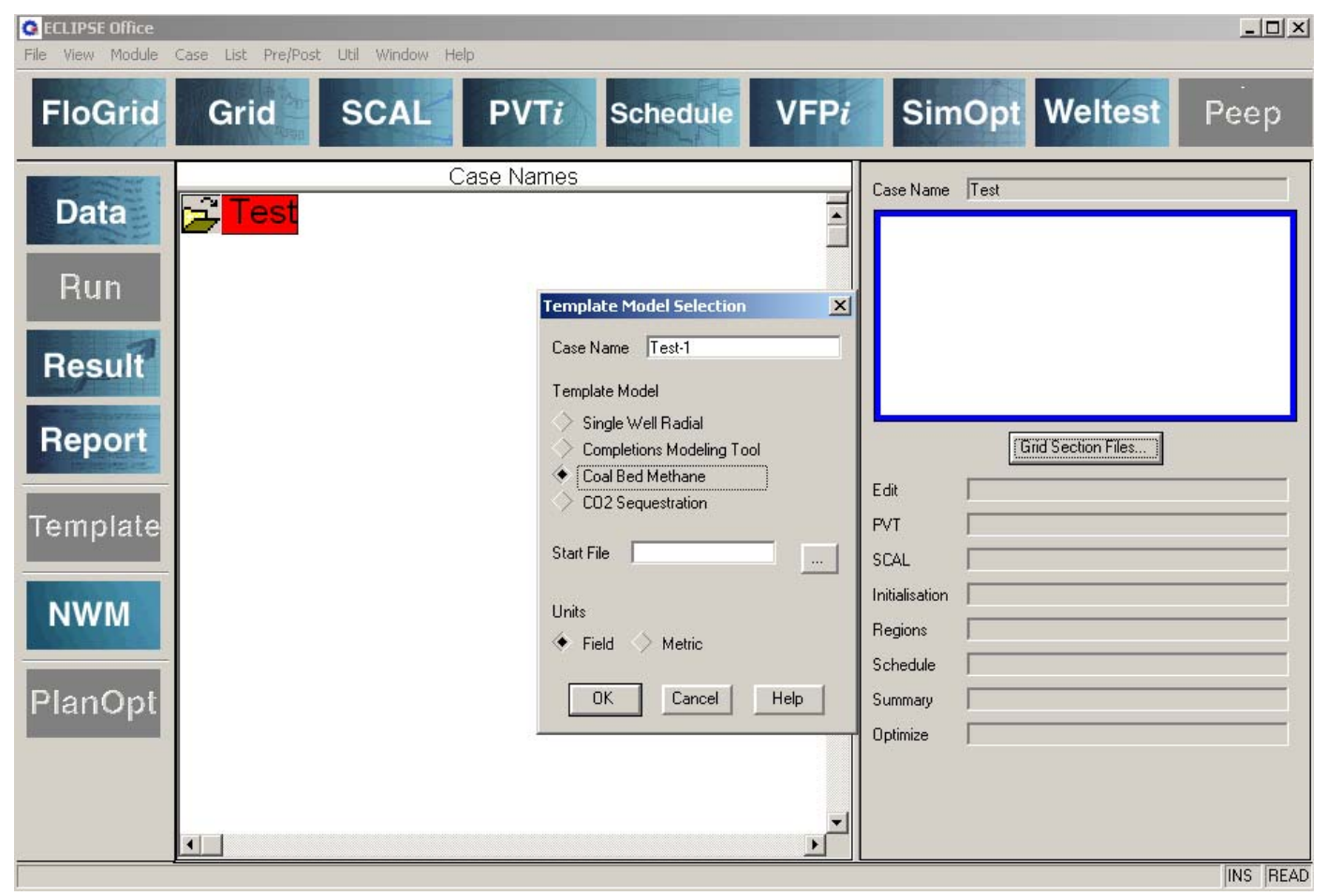

Figure A-6 Coal bed methane template selection screen.

Once the coal bed methane template is open, the model can be edited by selecting and working on the tasks presented under the workflow sections. The first selection is tabbed model definition and in this section changes can be made to the simulation time and reporting intervals along with basic model parameter selections (Figure A-7). For the simulation length and recording, the starting day for all runs was selected as January 1, 2009 and the end date was selected was January 1, 2059. A reporting interval of 31 days was used for the total simulation time of 50 years. In the model parameters section, the gas and water phases were selected. Other parameters selected were the "model employs a non-equilibrium initialization” and "coal defined on unit weight basis with ash and moisture content”. Instant adsorption model is automatically selected and there is no gas injection. 


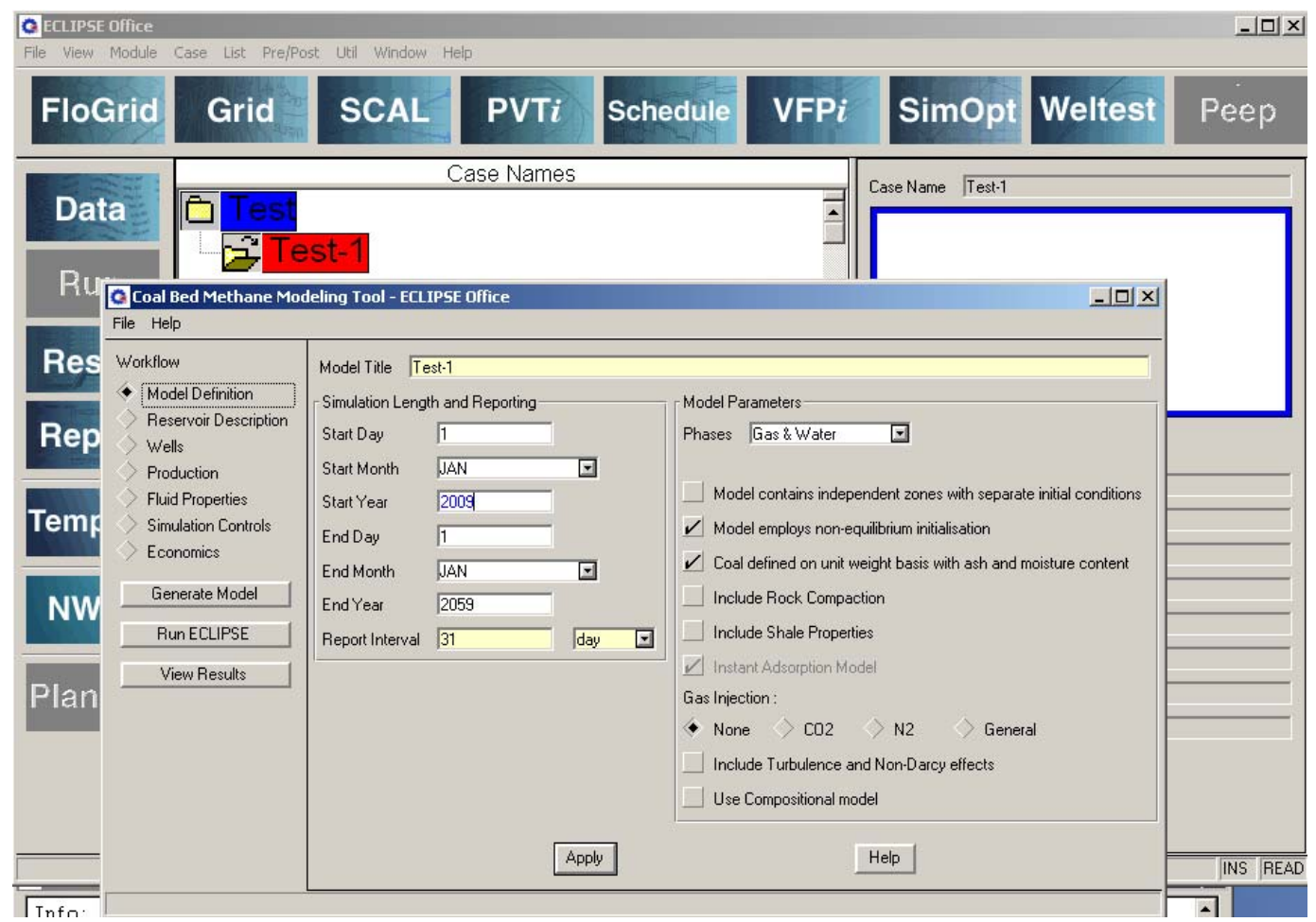

Figure A-7 Model definition screen.

The second selection of the workflow section is the reservoir description. There are five different tabs in this section; namely, layers, rock properties, non-equilibrium initial conditions, aquifers and fractures (Figure A-8). In the layers tab, the layer name is entered as the Marcellus and the rock name is simply called the reservoir. For top depth left and right values in feet, were taken from typical southwestern Pennsylvania location with an approximate depth of 6000 feet and zero horizontal displacement due to the relative small size of the modeled reservoir (Sumi, 2008). The total thickness used was 90 feet (Harper, 2008). The reservoir used in the study was $20,000 \mathrm{ft}$. by $10,000 \mathrm{ft}$. with a rectangle drainage area to encompass the area of the largest well selected in this research. 


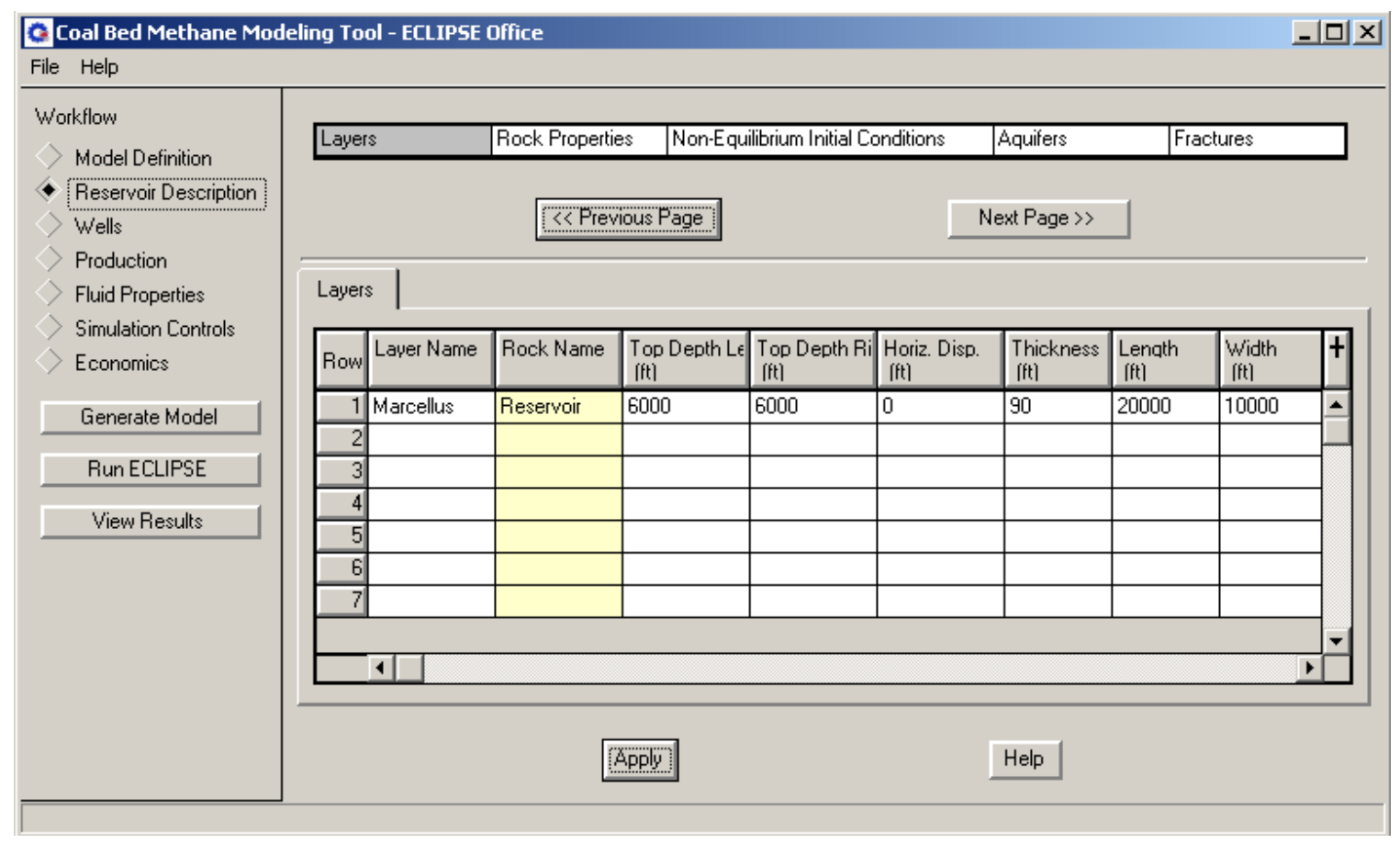

Figure A-8 Reservoir description for layers screen.

The layers tab is followed by the rock properties tab on the reservoir description workflow (Figure A-9). Permeability of the Marcellus shale was studied as earlier as 1988 by Soeder. He found the permeability in the Marcellus as $0.005909 \mathrm{mD}$. Also, researchers reported the permeability of the Marcellus to be in the micro Darcy’s (Soeder, 1988) (Miller, 2008). Based on personal discussions with company representatives, the permeability of Marcellus shale is reported as larger, smaller or about the same as the Barnett shale which is less than $0.0001 \mathrm{mD}$ (Pickering, 2005). Thus, a rather conservative number of $0.0004 \mathrm{mD}$ was used for the permeability of Marcellus shale. This number was used in both the $\mathrm{x}$ and $\mathrm{y}$ directions and the $\mathrm{z}$ direction is set on a default of $1 / 10^{\text {th }}$ of the horizontal direction. In terms of the porosity a four percent value was used (Nome, 2008) (Hayden, 2005). 


\begin{tabular}{|c|c|c|c|c|c|c|c|c|}
\hline \multicolumn{8}{|c|}{ C. Coal Bed Methane Modeling Tool - ECLIPSE Office } & $-|\square| x$ \\
\hline \multicolumn{9}{|l|}{ File Help } \\
\hline \multicolumn{9}{|l|}{ Workflow } \\
\hline Model Definition & \multicolumn{2}{|l|}{ Layers } & ock Properties & \multicolumn{2}{|c|}{ Non-Equilibrium Initial Conditions } & Aquifers & \multicolumn{2}{|l|}{ Fractures } \\
\hline - Reservoir Description & \multirow{2}{*}{\multicolumn{5}{|c|}{$\ll$ Previous Page }} & & & \\
\hline$>$ Wells & & & & & & Jext Page $\gg>$ & & \\
\hline$>$ Production & \multirow{2}{*}{\multicolumn{8}{|c|}{ Rock Properties }} \\
\hline Fluid Properties & & & & & & & & \\
\hline Simulation Controls & \multicolumn{8}{|c|}{ Define properties for individual coal types. } \\
\hline Genomics & Row ${ }^{F}$ & Rock Name & Fracture Porosity & $\begin{array}{l}\text { Bulk X-dir Perm. } \\
|\mathrm{mD}|\end{array}$ & $\begin{array}{l}\text { Bulk Y-dir Perm. } \\
{[\mathrm{mD}]}\end{array}$ & $\begin{array}{l}\text { Bulk Z-dir Perm. } \\
{[\mathrm{mD} \mid}\end{array}$ & $\begin{array}{l}\text { Coal Compress. } \\
\text { //Dsil }\end{array}$ & t \\
\hline Generate Model & $1 / F$ & RESERVOIR & 0.04 & 0.0004 & 0.0004 & $4 \mathrm{E}-5$ & $1 \mathrm{E}-6$ & $\Delta$ \\
\hline Run ECLIPSE & 2 & & & & & & & \\
\hline \multirow{7}{*}{ View Results } & 3 & & & & & & & \\
\hline & 4 & & & & & & & \\
\hline & 5 & & & & & & & \\
\hline & 6 & & & & & & & \\
\hline & \multicolumn{8}{|c|}{ - } \\
\hline & & 1 & & & & & & \\
\hline & & & Apply & & & Help & & \\
\hline
\end{tabular}

Figure A-9 Reservoir description for rock properties screen.

Figure A-10 shows the non-equilibrium initial conditions section of the reservoir description. Only two data values are inputted for the initial reservoir pressure and water saturation. These numbers are approximate and obtained from a number of undisclosed companies with operations in the Marcellus shale. 


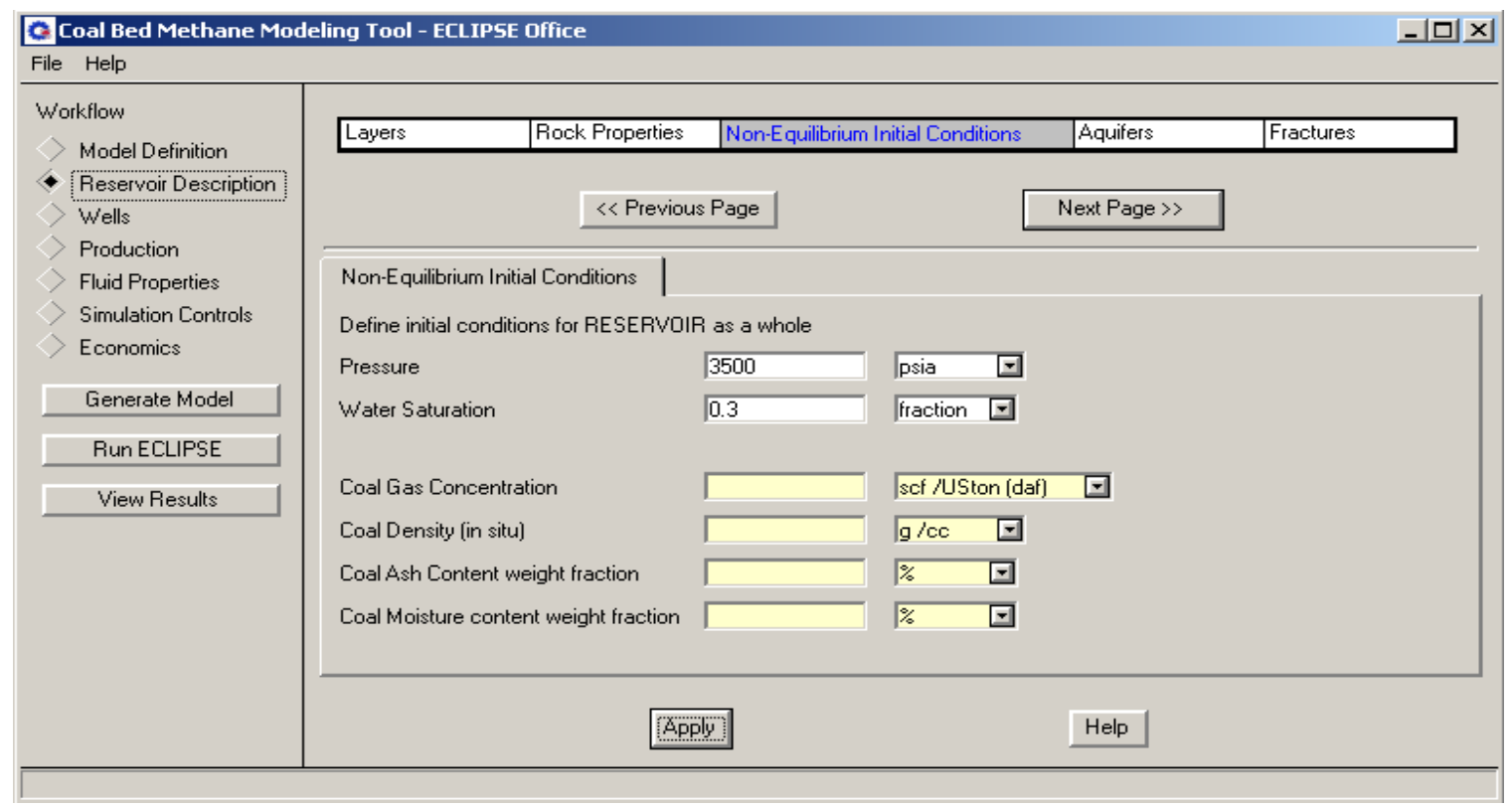

Figure A-10 Reservoir description for non-equilibrium initial conditions screen.

The aquifers section of the reservoir description is shown in Figure A-11. The aquifer section is not used but included here for a complete description of properties needed for reservoir description.

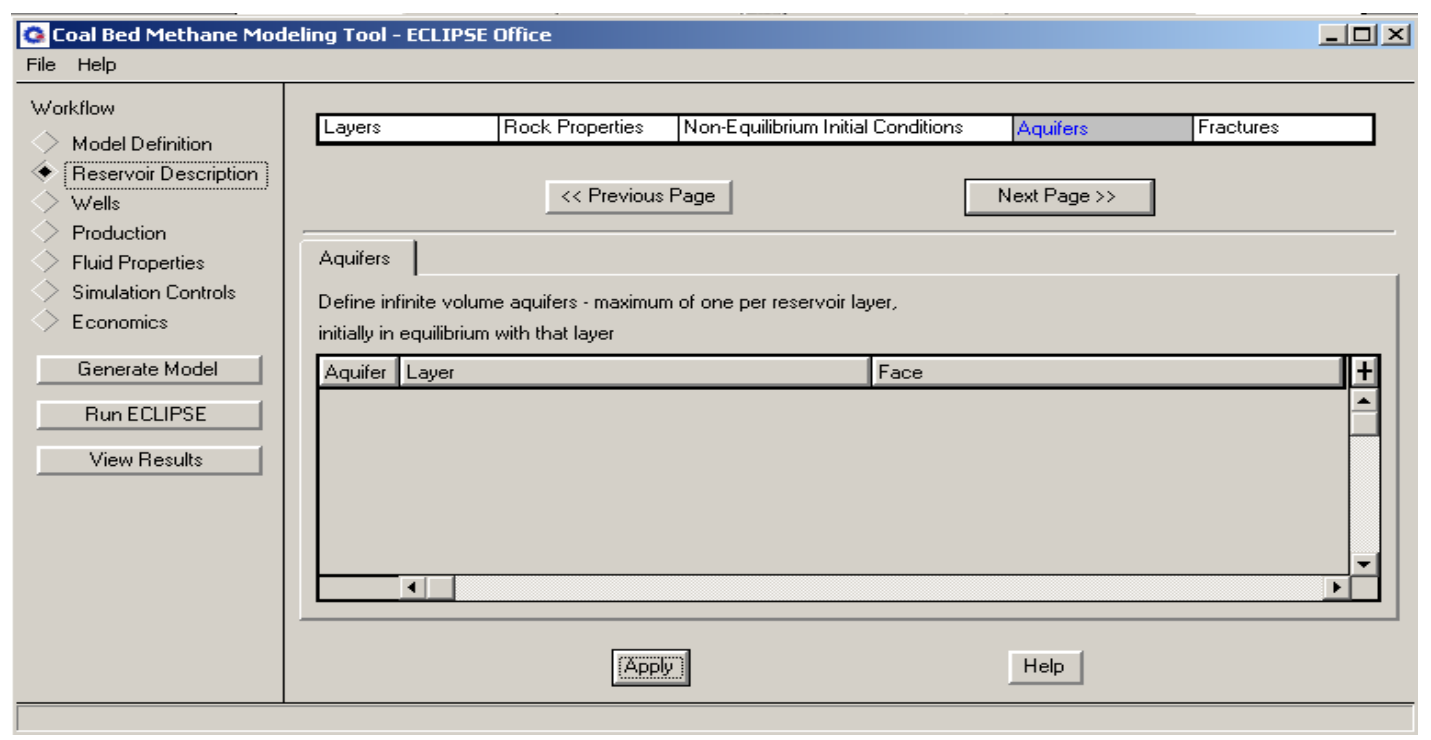

Figure A-11 Reservoir description for aquifers screen. 
Figure A-12 shows the fractures tab for reservoir description. For this example a three stage fracture is shown. First, a new fracture would be selected and enabled in the model. Since the well is drilled in the $\mathrm{x}$ direction, the fracture is placed in the $\mathrm{y}$ direction. The fracture half length is entered and the values used in this study were 250, 500, 750 and1000 feet. All fractures in the same well are assigned the same half lengths, thus if one fracture is 1000 feet of propped half length then all of the other stages are assigned with the same 100 foot value. 1000 feet was used as the maximum fracture half length based on published data (Pinkhouse, 2006). The top of the fracture was selected as 6000 feet and 6090 feet was used as the bottom of the fracture covering the 90 foot thickness in the reservoir. The $\mathrm{x}$ and $\mathrm{y}$ centre of the fracture, was always placed at the middle of the lateral section of the horizontal wellbore and midpoint of the formation. If there where additional fractures they were placed $400 \mathrm{ft}$. on each side of the center. This is because there are only odd amounts of frac stages, one, three, five, seven, and nine fractures were studied. Depending on the length of the wellbore, some runs used 800 foot fracture spacing and were specified in the results section. Table III-1 summarizes the runs conducted in detail. The fracture permeability value of $200 \mathrm{mD}$ and a porosity value of 10\% were used in all runs. 


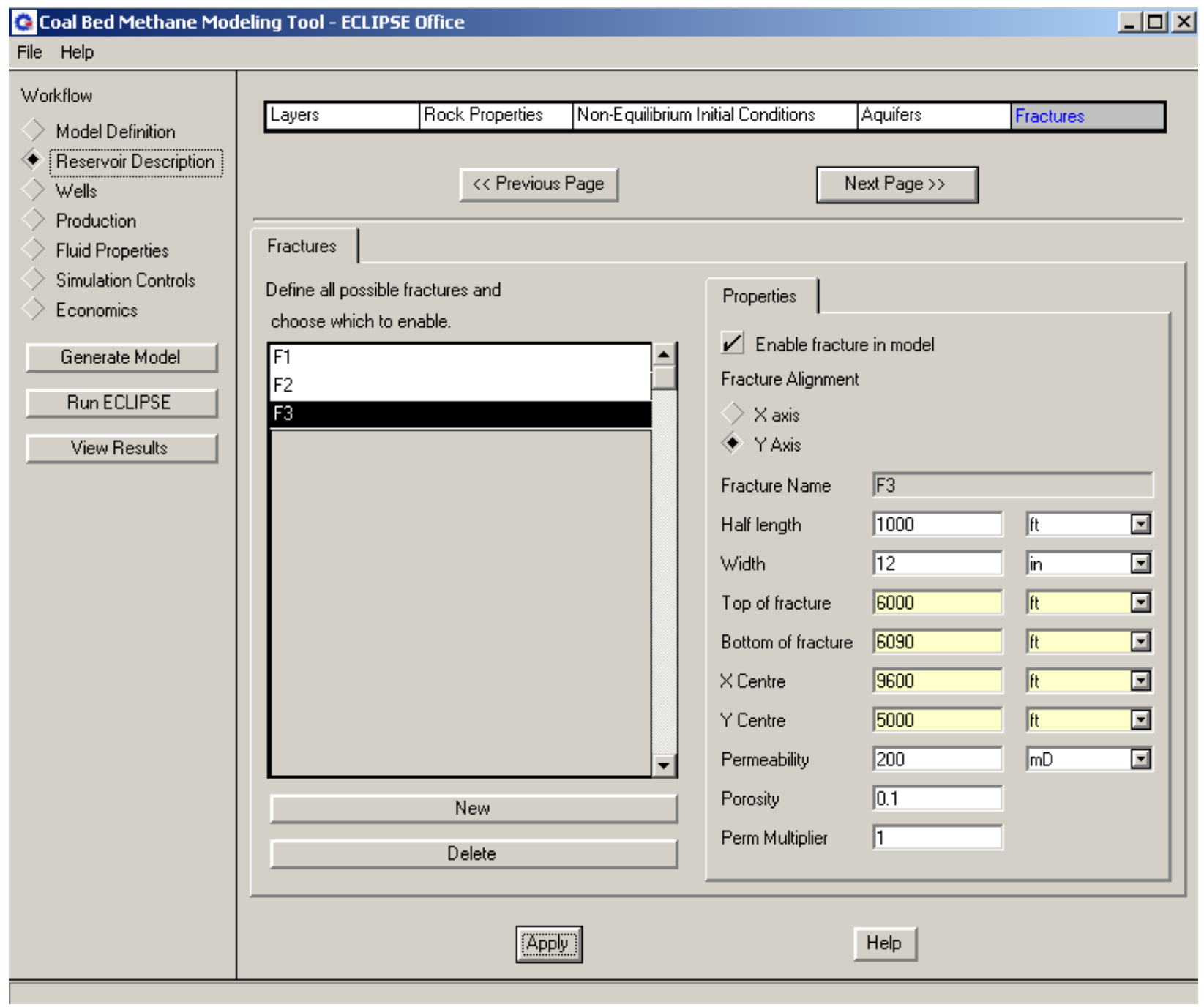

Figure A-12 Reservoir description for fractures screen.

Figure A-13 shows the wells section of the workflow where vertical and horizontal wells can be added to the reservoir. 


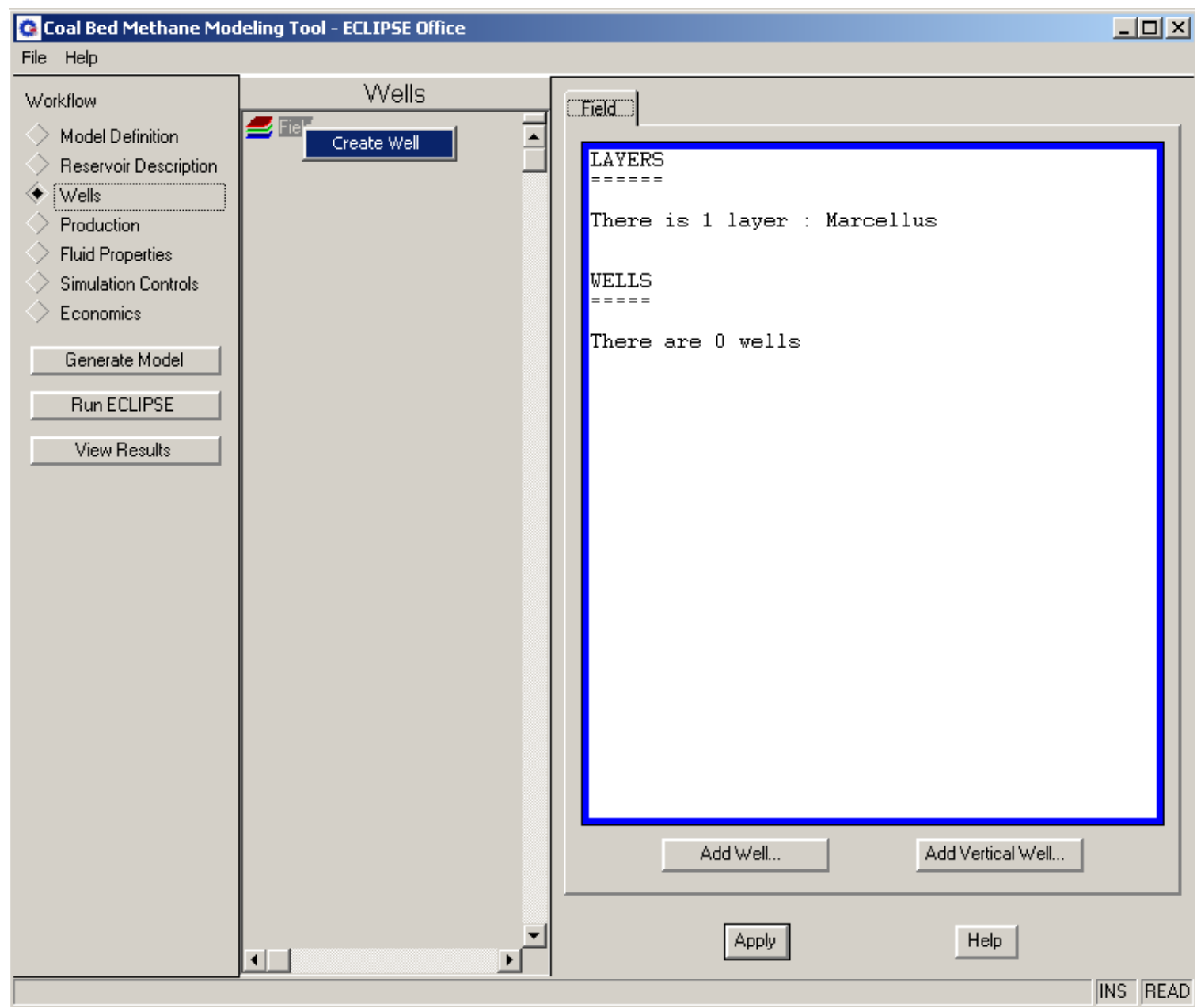

Figure A-13 Wells workflow for create well screen.

Once a well is created, the vertical deviation survey data can be entered. (Figure A-14). All wells aren’t truly straight but for simulation purposes they are assumed to be vertical with no deviation and horizontal with no undulations. The drilled hole diameter at the pay zone is selected as a $6 \frac{1}{1} / 4$ inch. The example well is vertical with the $\mathrm{x}$ direction is set at $8,000 \mathrm{ft}$. and the $\mathrm{y}$ direction is set at $5000 \mathrm{ft}$. The $\mathrm{z}$ values were set at the top and bottom of the formation. 


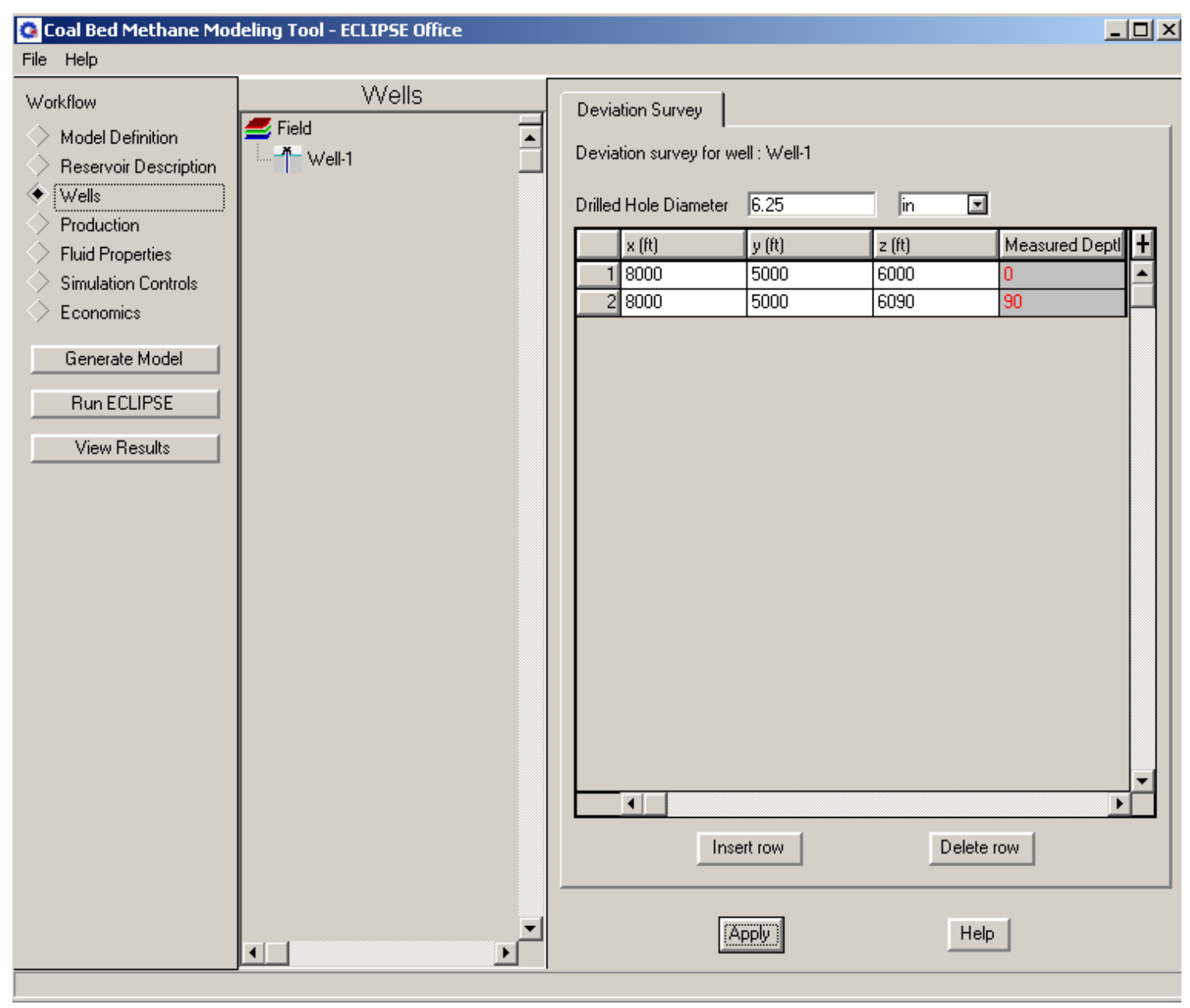

Figure A-14 Wells workflow for wells deviation survey screen.

In the case of a horizontal well, a lateral is added ( Figure A-15). The measured depth for the lateral section was the middle of the formation. 


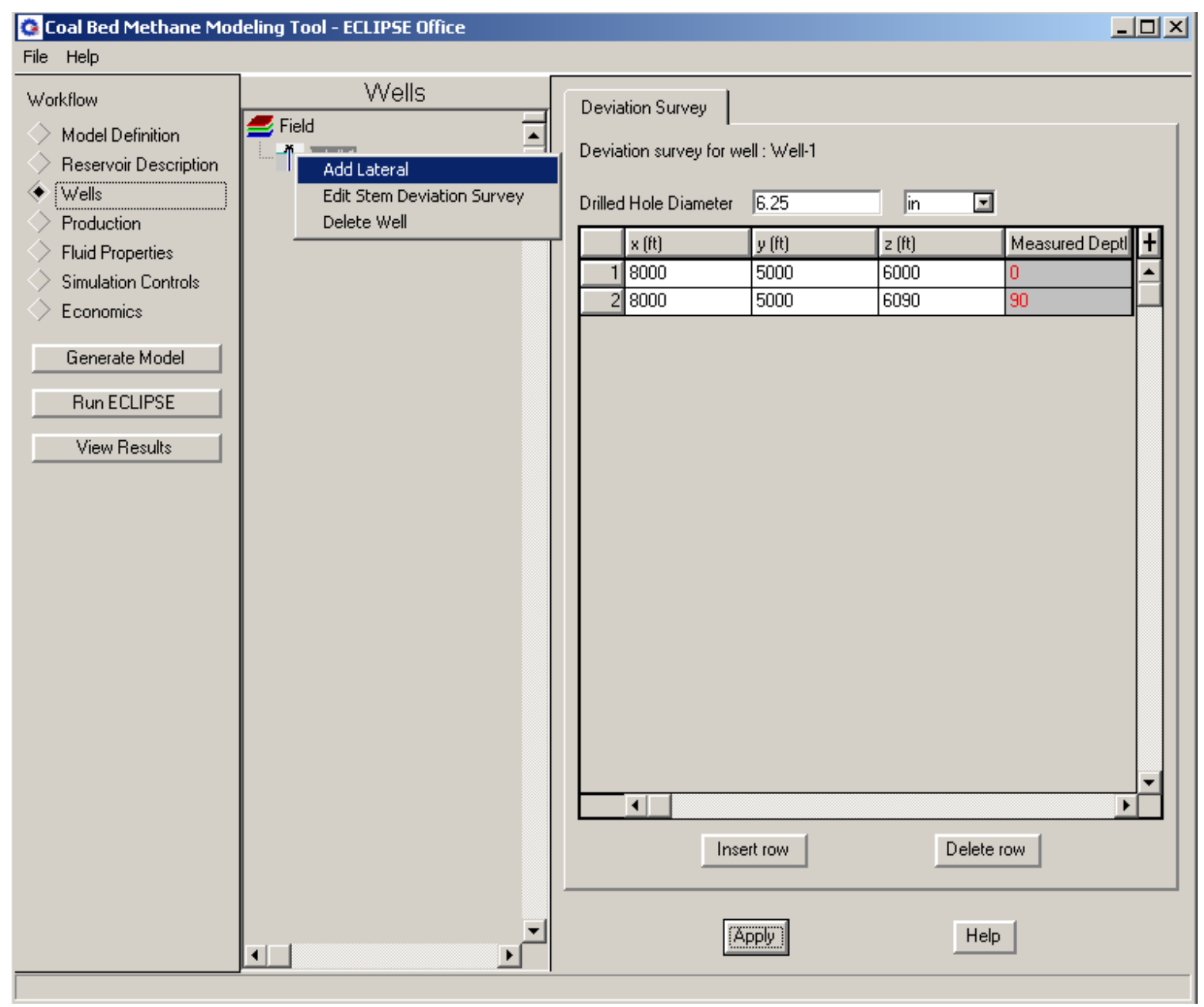

Figure A-15 Wells workflow for adding laterals screen.

Once the lateral section is added, a new deviation survey needs to be added for the lateral section (Figure A-16). For a well with a $4000 \mathrm{ft}$. lateral length the x-direction is set at 12,000 ft and the $y$-direction is kept the same (5,000 ft.) and the $\mathrm{z}$ direction is maintained in the center of the formation at $6,045 \mathrm{ft}$. 


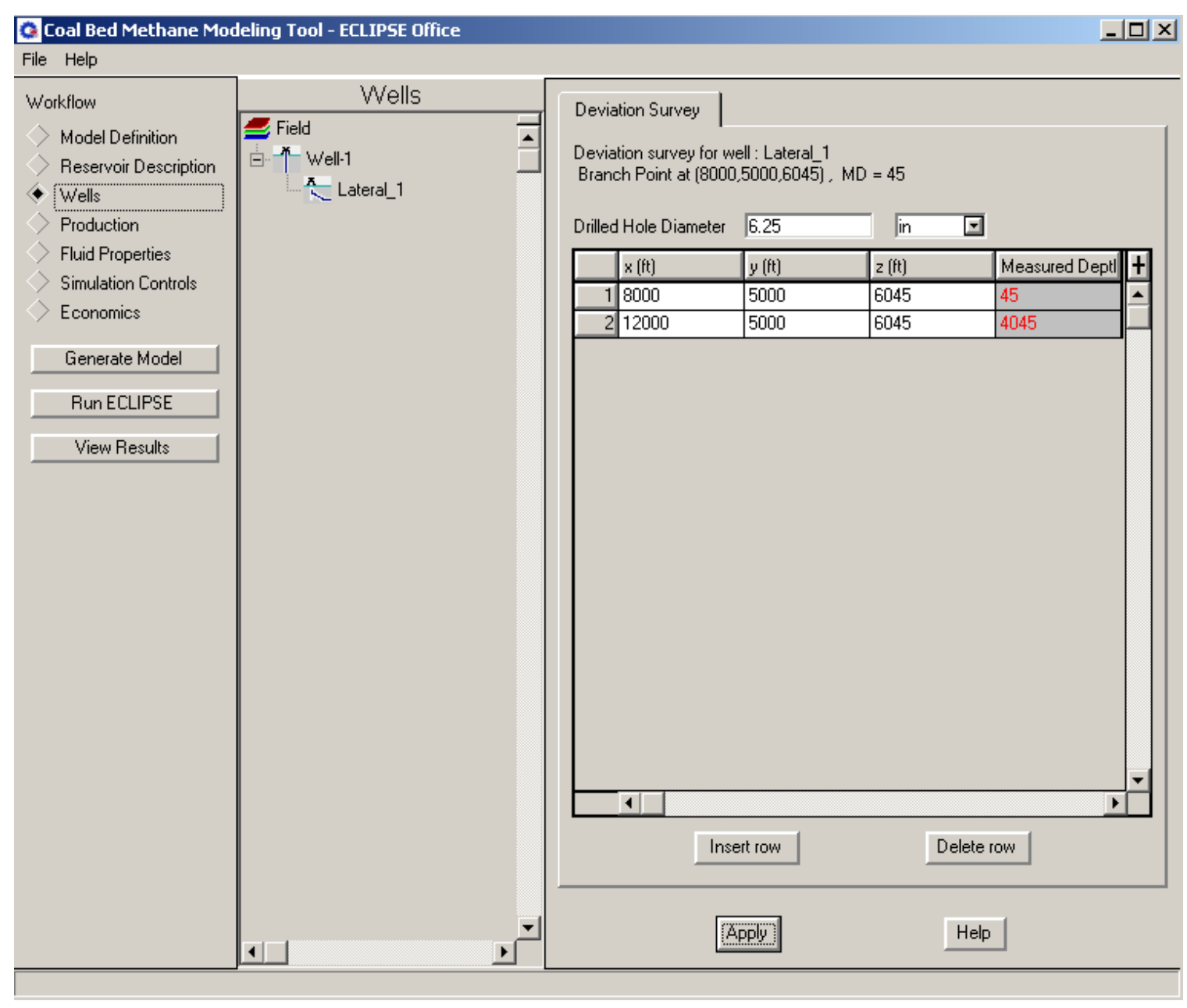

Figure A-16 Wells work flow for horizontal section deviation survey screen.

Figure A-17 shows the production section of workflow. Once the well is defined different types of events can be selected, production is one of the events that needs to be added. Once production is added, well controls can be set. In the production section, the user can select the starting date for producing the well. For all the runs, the well will start producing at the beginning of simulation and stays open. The well is controlled by the gas rate, although other controls such as bottomhole pressure is possible. The target gas rate was set at 2,000,000 Mscf/day for all of the well stimulated. This number needed to be kept constant and set at a 
rather high rate. This meant that the wells were being produced at the highest possible rate. This was done to achieve maximum initial production for all well designs.

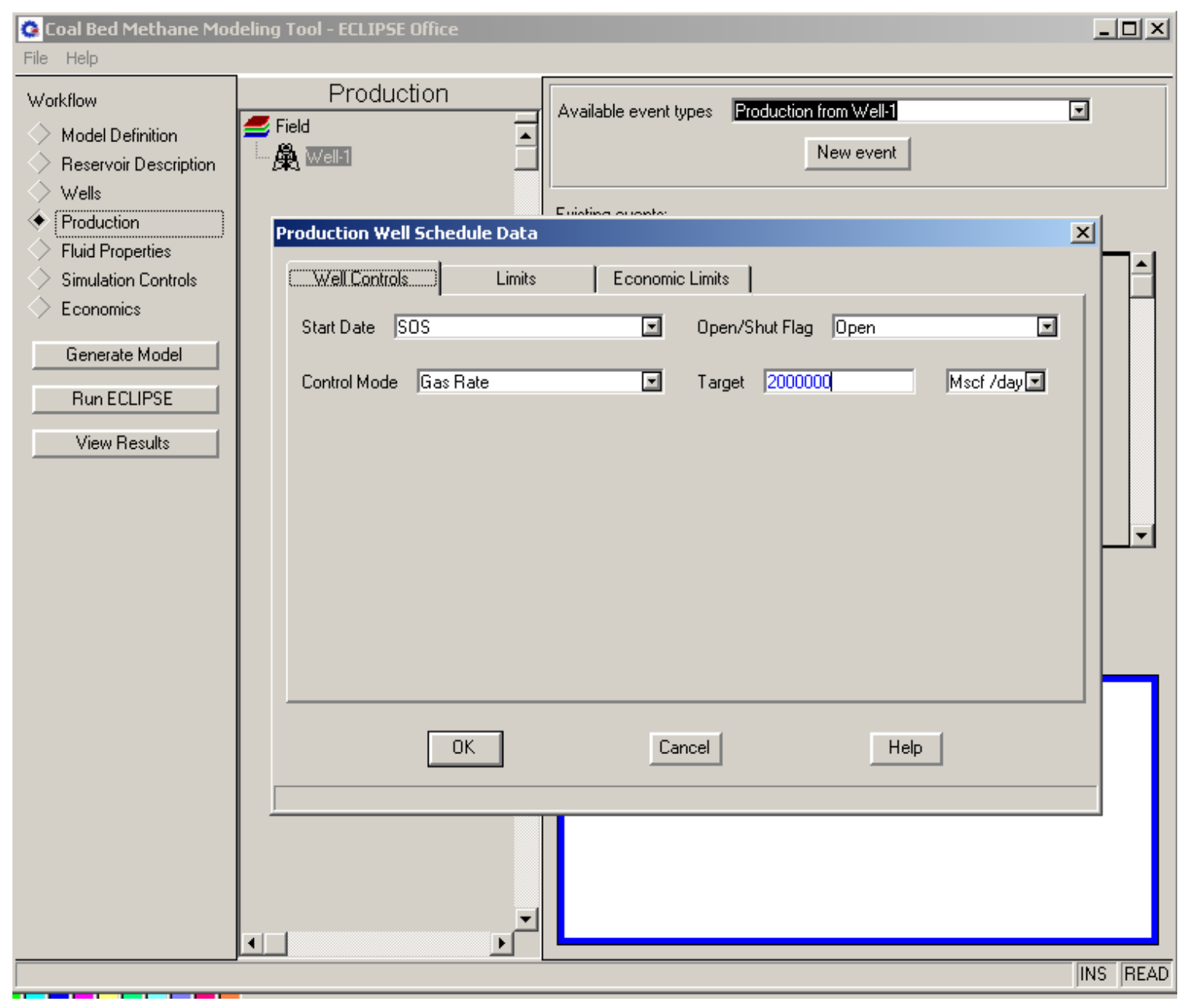

Figure A-17 Production well control options.

For all wells the bottomhole pressure limit was set at 500 psia (Figure A-18). 


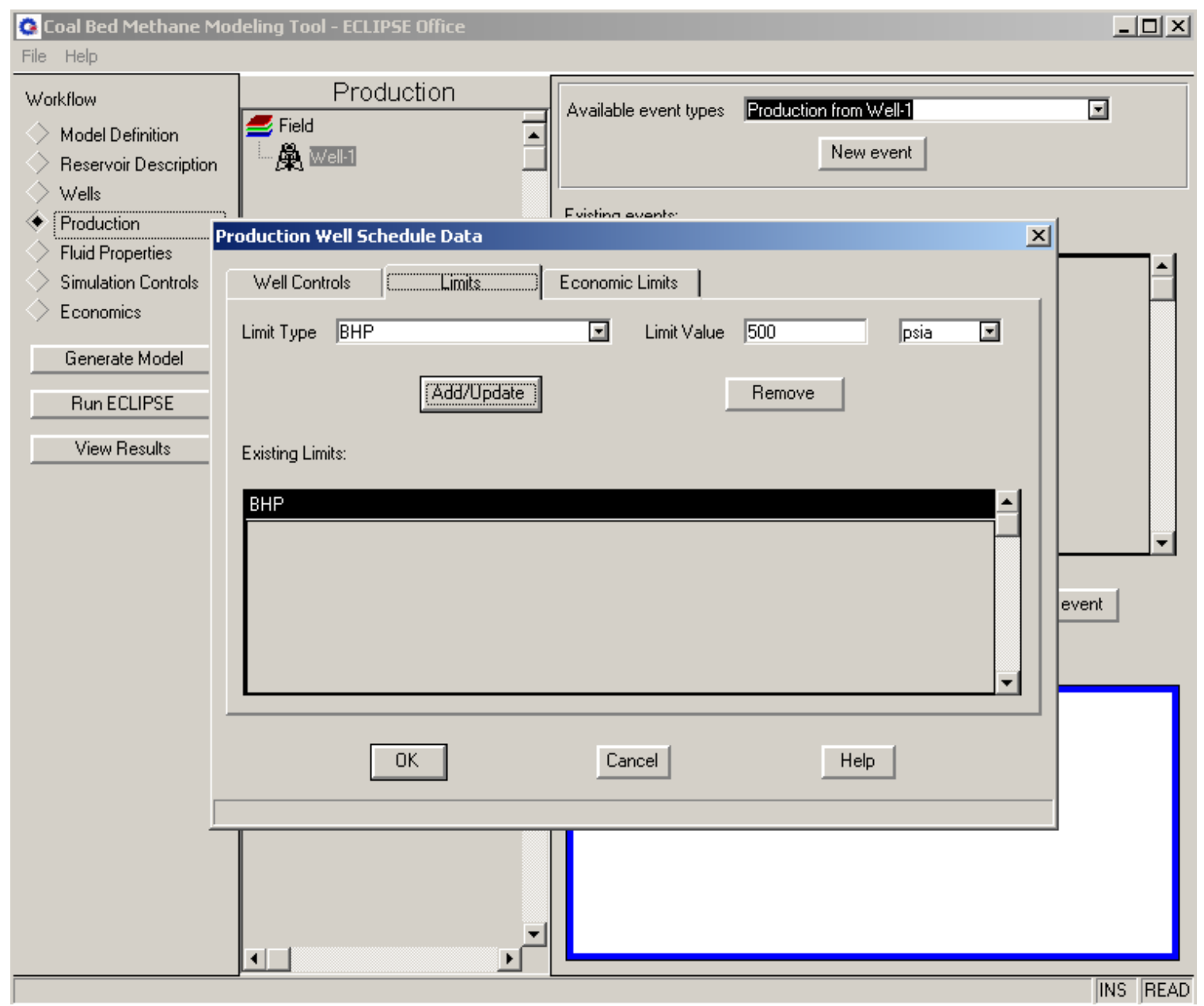

Figure A-18 Production well limit options.

The production well description is followed by entering the necessary properties for the perforations as shown in Figure A-19 for the vertical well. Figure A-20 shows the perforation properties needed for the horizontal segment of the well. In all cases a skin factor of zero was used. 


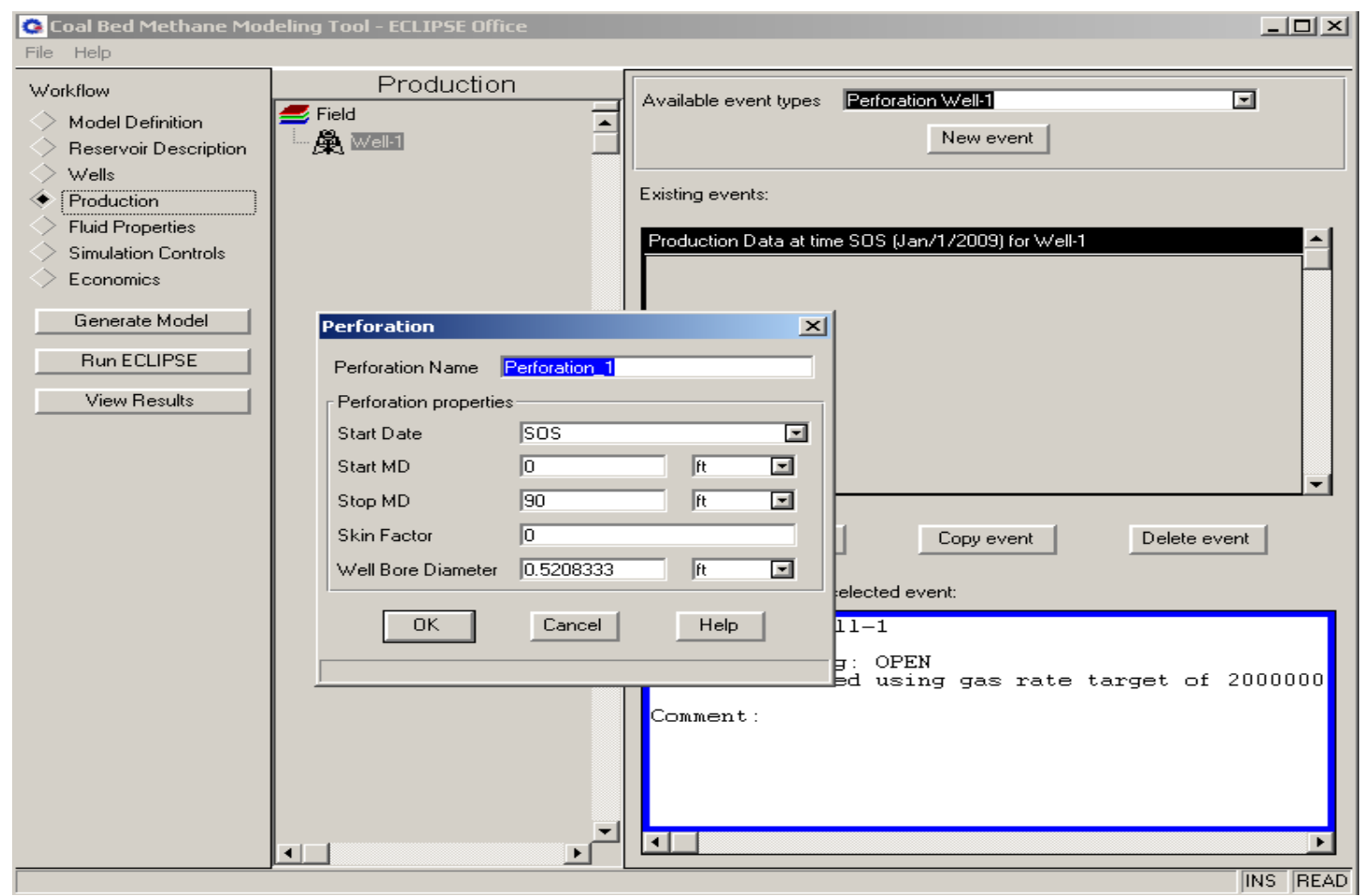

Figure A-19 Production well perforation addition for vertical section.

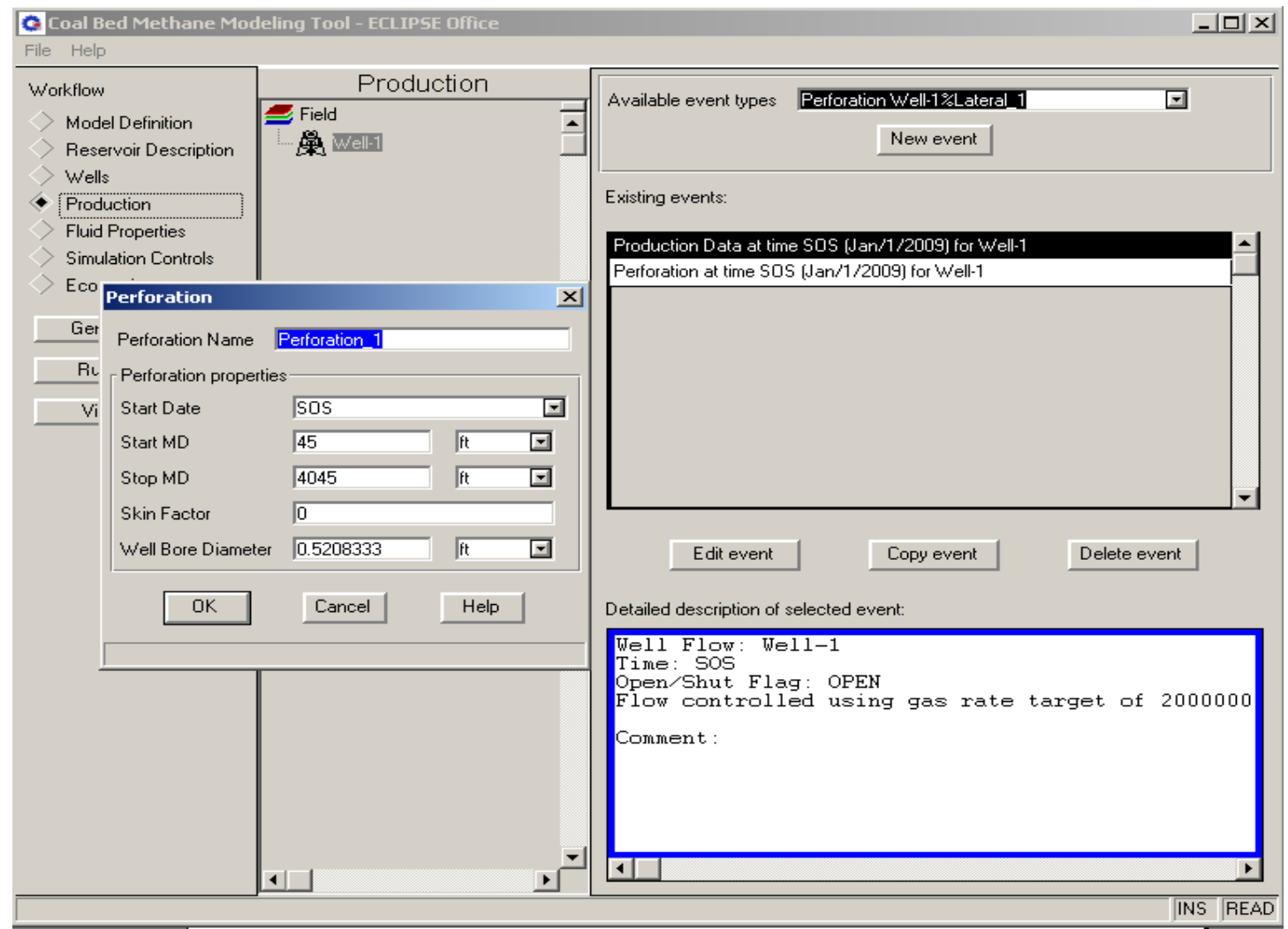

Figure A-20 Production well perforation addition for horizontal section. 
Fluid properties is the next section of the workflow tab. In this section, reference temperature of 120 degrees Fahrenheit and 0.65 gas gravity was used.

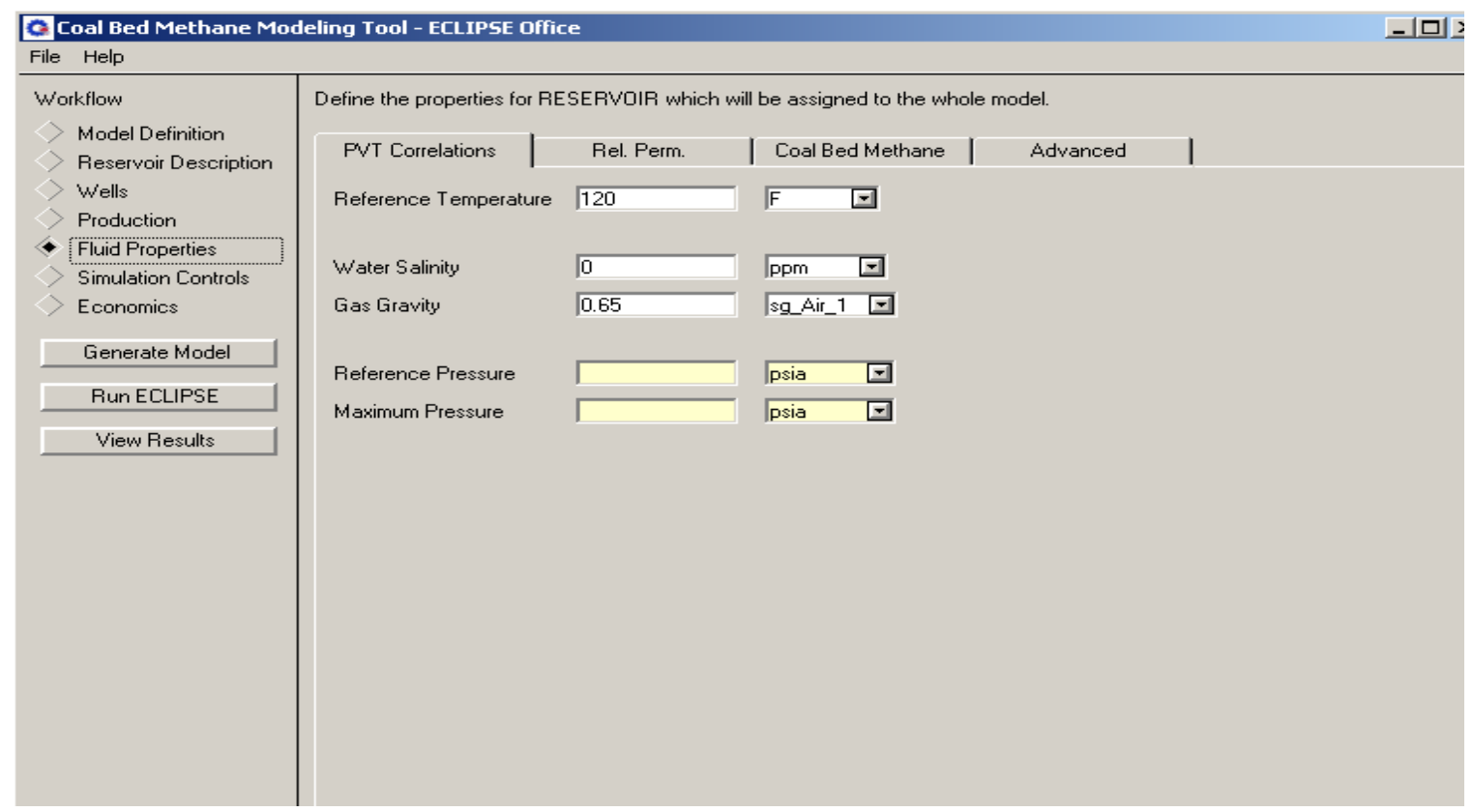

Figure A-21 Fluid properties workflow for PVT correlations.

Next, the relative permeability correlations are defined for gas and water using Corey factors. The default values used are shown in Figure A-22 and Figure A-23.

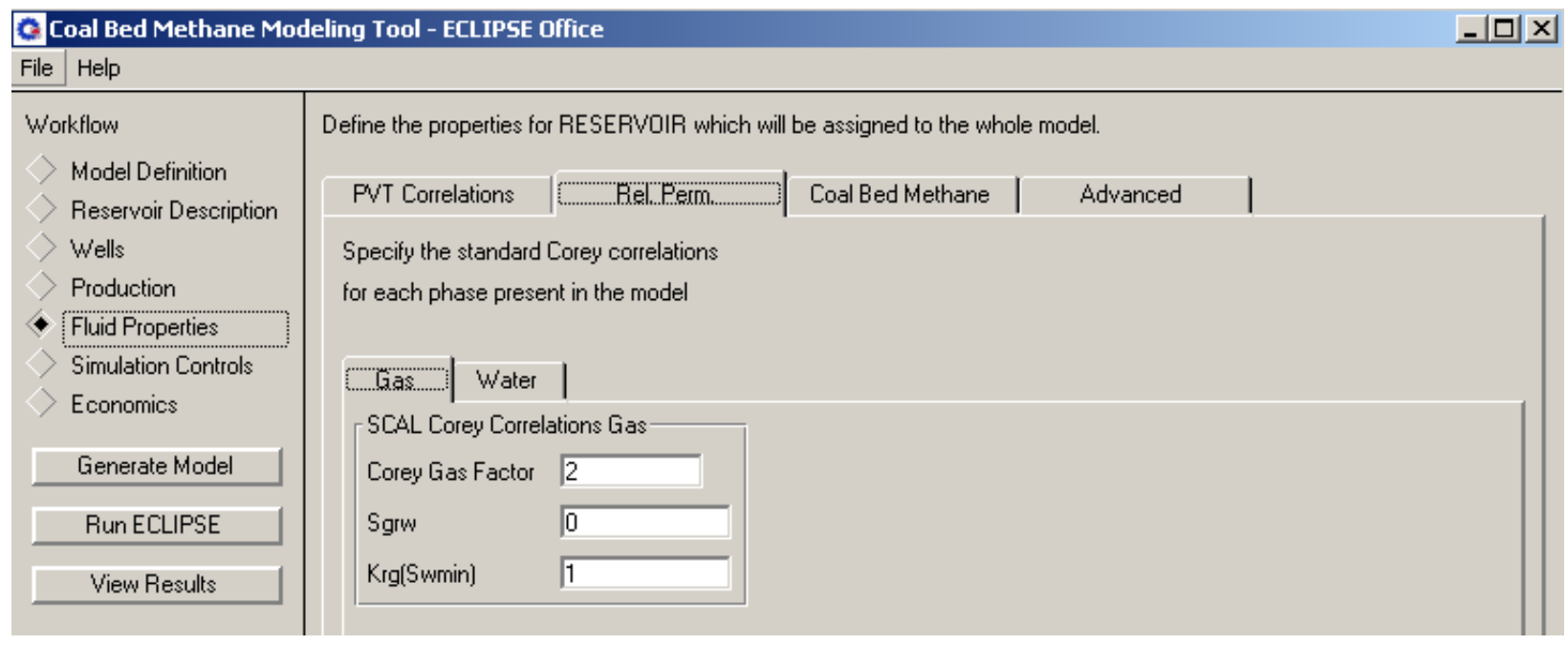

Figure A-22 Fluid properties workflow for relative permeability correlation (gas). 


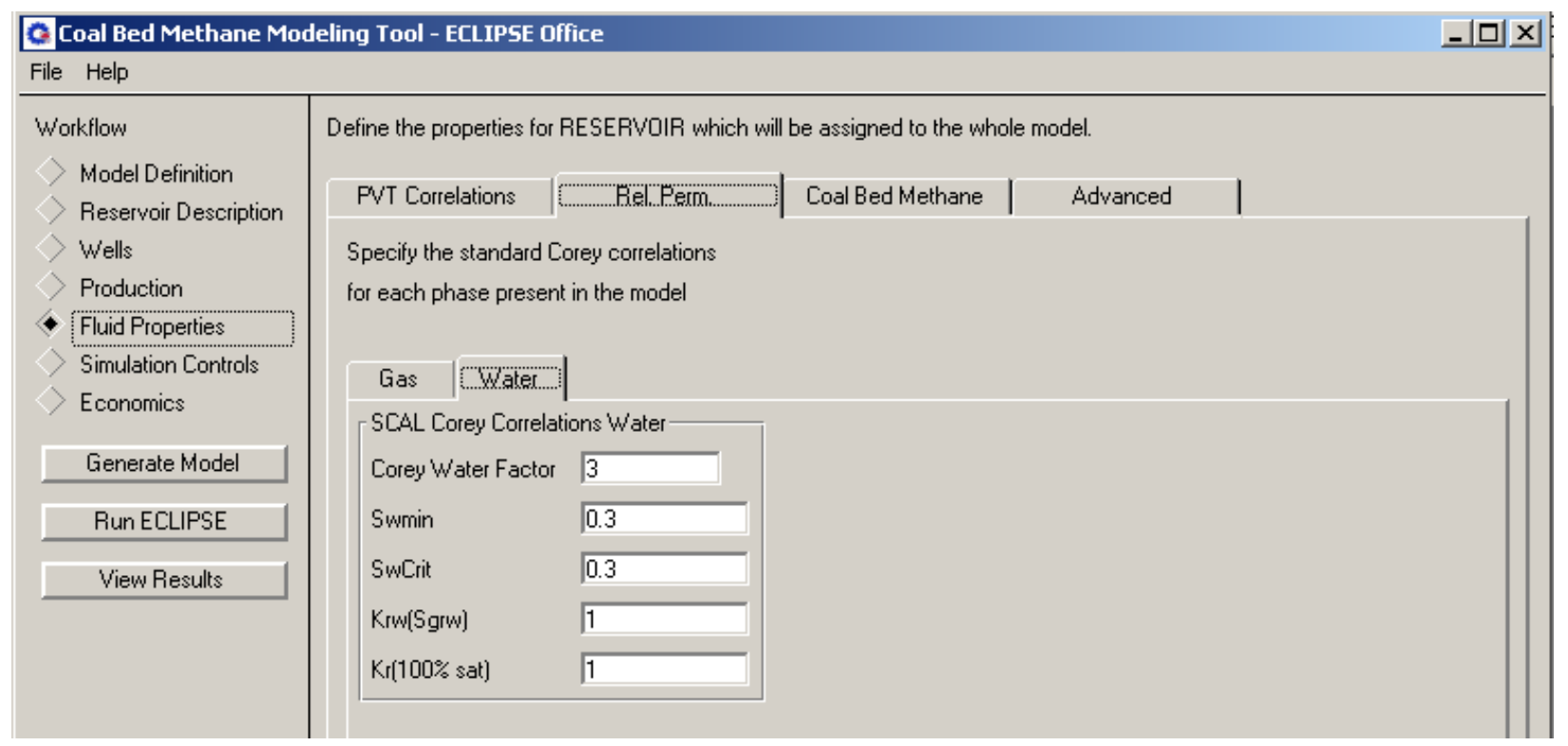

Figure A-23 Fluid properties workflow relative permeability correlation (water).

Next is the coal bed methane section of the fluid properties. Figure A-24 shows the properties used for diffusive flow and Langmuir isotherm input values. The values given in Figure A-24 represent properties of Marcellus shale used in all runs.

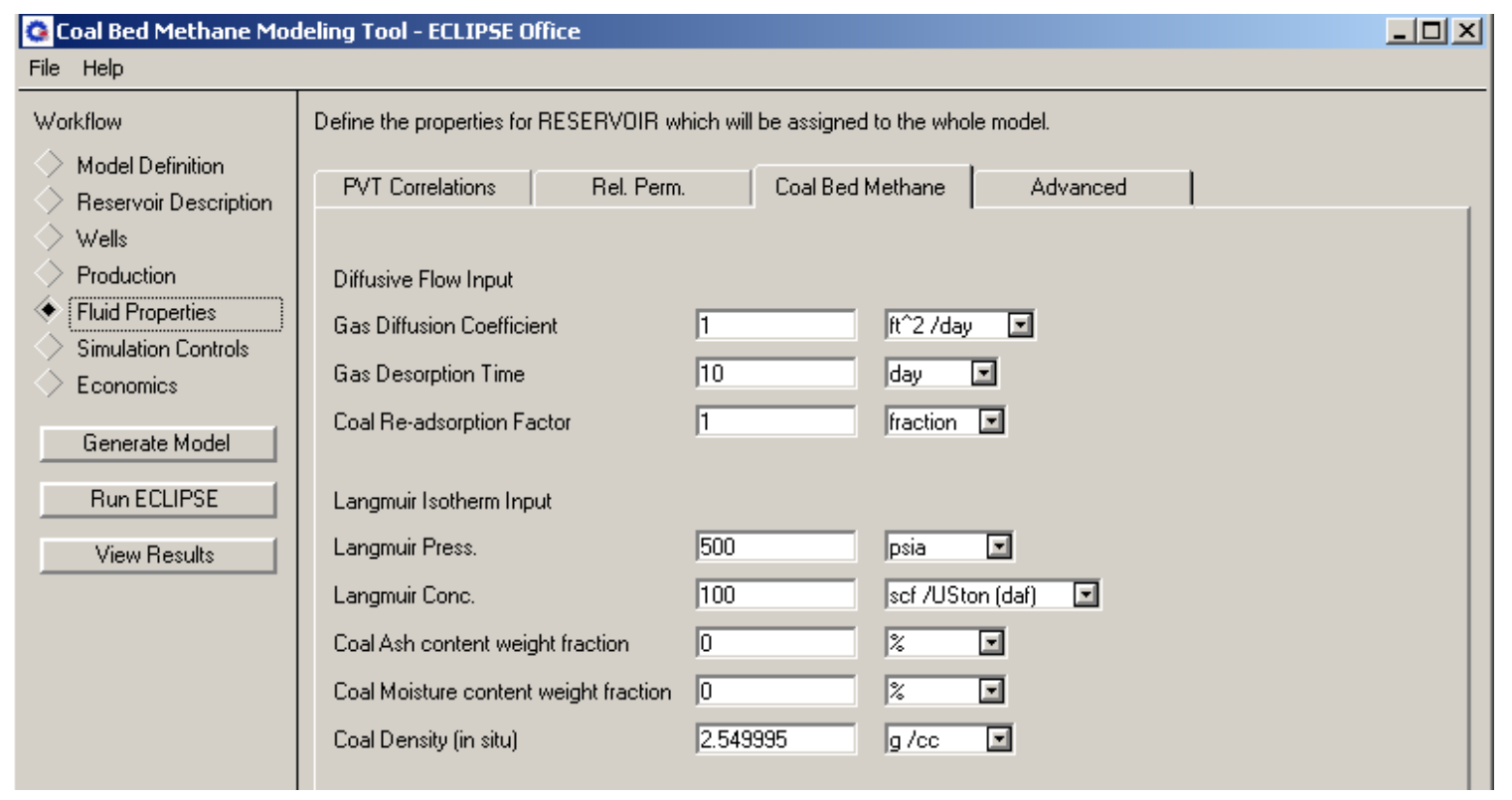

Figure A-24 Fluid properties workflow for coal bed methane. 
Figure A-25 shows the advanced fluid properties tab, and the options available for this section. In this study, the advance section was not used.

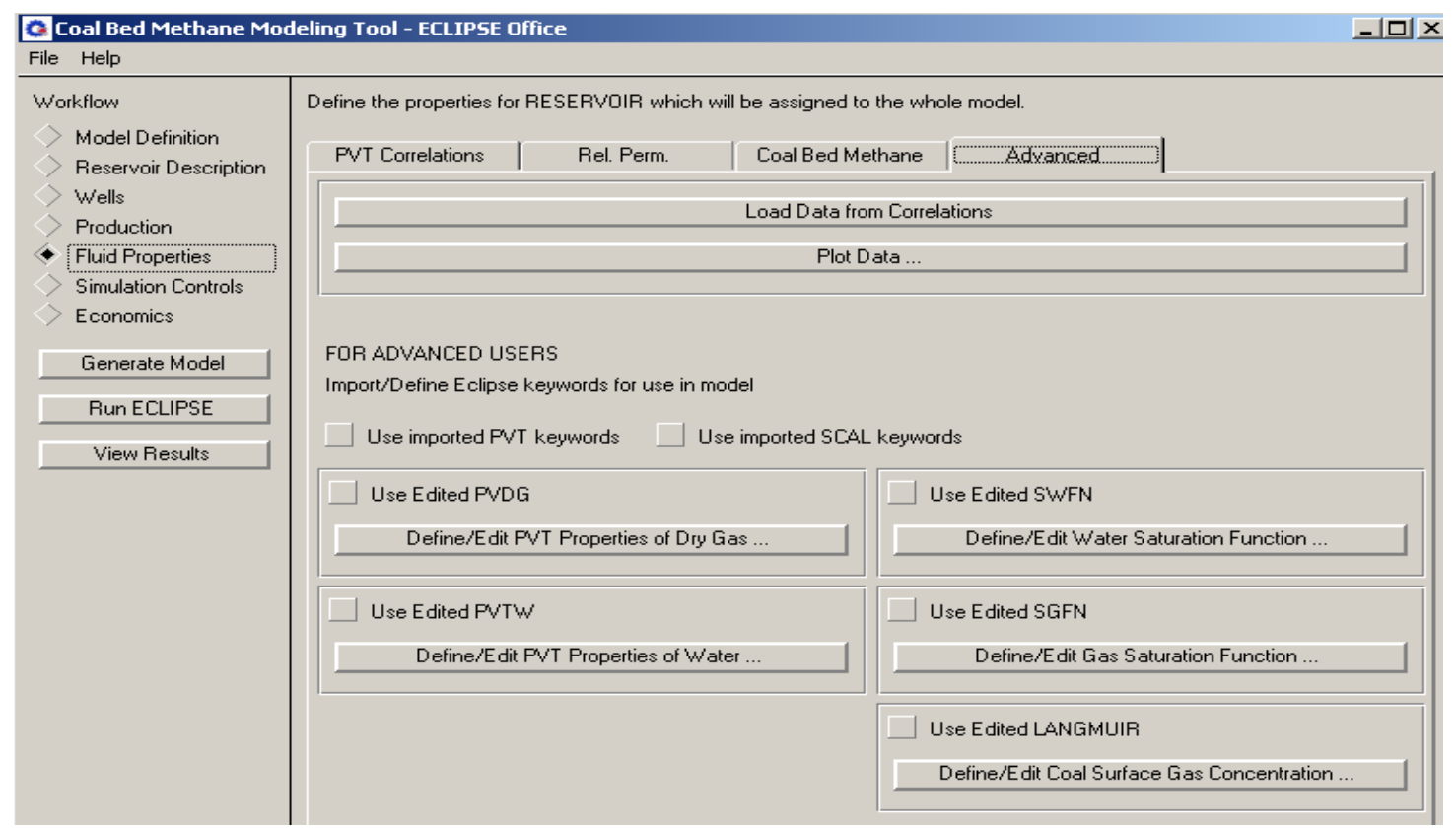

Figure A-25 Fluid properties workflow for advanced controls.

Figure A-26 and Figure A-27 show the simulation controls for grid size and time reporting steps used in this study.

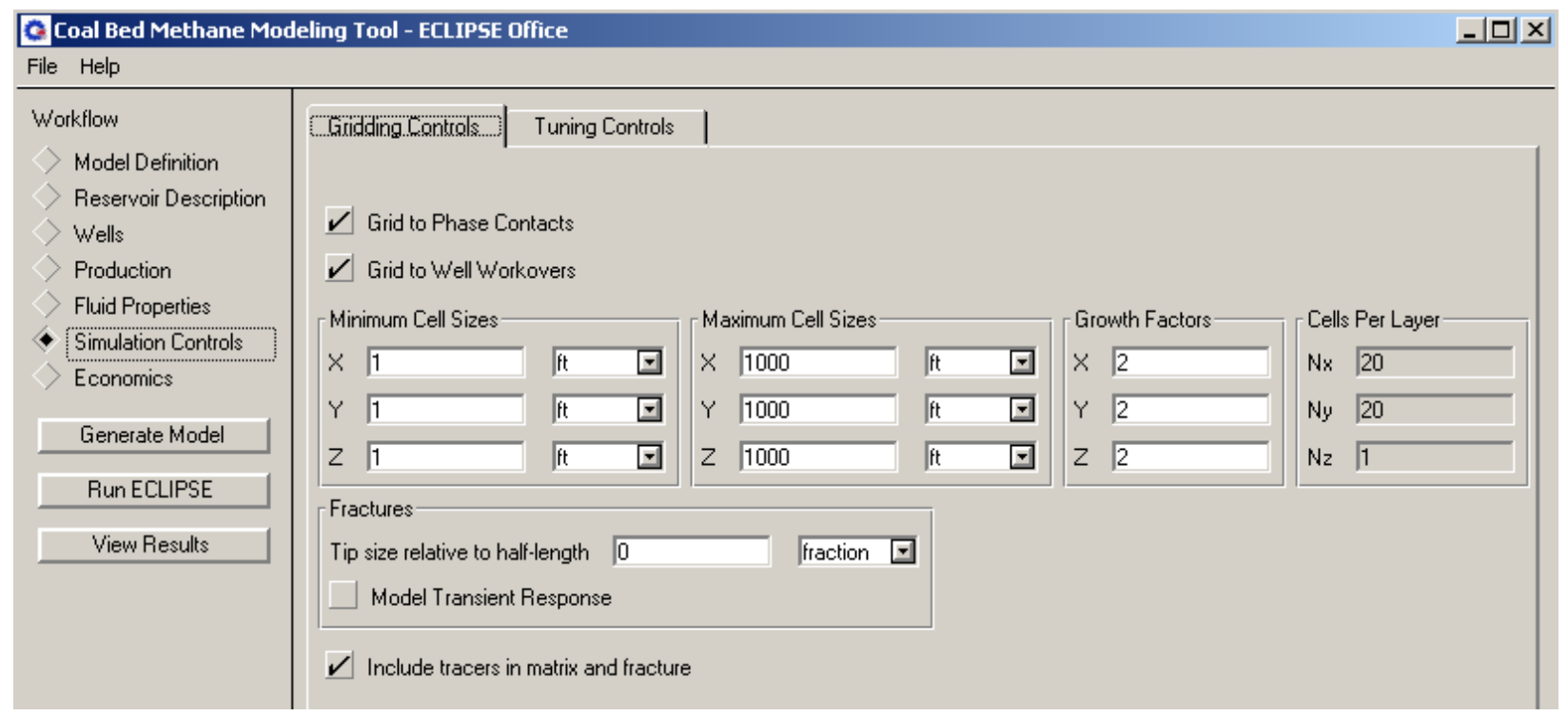

Figure A-26 Simulation controls workflow for gridding controls. 


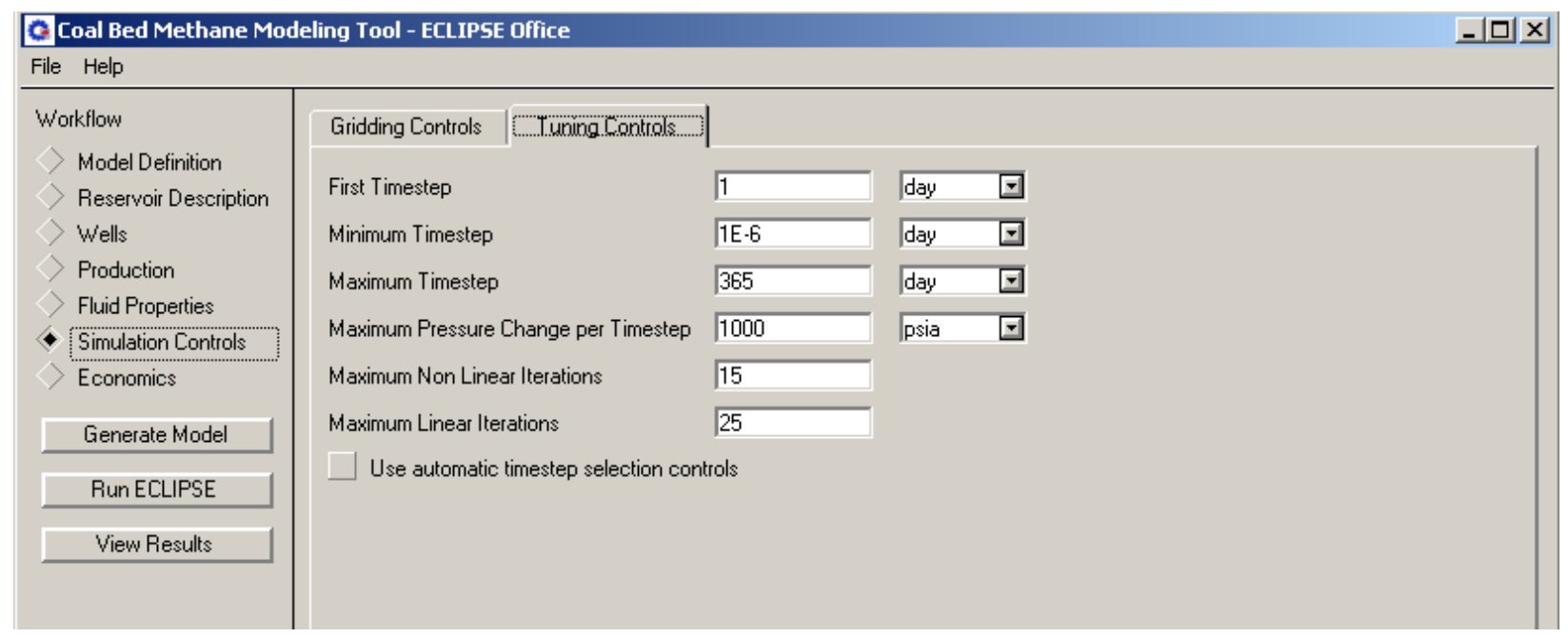

Figure A-27 Simulation controls workflow for tuning controls.

The last part of the workflow was the economics. In this section NPV value is calculated with given cost values. In this research, this economics section was not used in the program but was calculated separately.

\begin{tabular}{|c|c|c|c|}
\hline \multicolumn{3}{|c|}{ C. Coal Bed Methane Modeling Tool - ECLIPSE Office } & $-\mid \square x$ \\
\hline \multicolumn{4}{|c|}{ File Help } \\
\hline Workflow & Calculate NPV & & \\
\hline$>$ Model Definition & Capital Expenditure & 田 & \\
\hline Reservoir Description & & & \\
\hline$>$ Wells & Producer Capex & $\$$ & \\
\hline$>$ Production & Injector Capex & $\$$ & \\
\hline$>$ Fluid Properties & Opex/day & $\$$ & \\
\hline Simulation Controls & & $\nabla$ & \\
\hline \multirow[t]{2}{*}{ Economics } & Producer Upex & $\nabla$ & \\
\hline & Iniector 0 pex & $\$ \quad \nabla$ & \\
\hline Generate Model & Water cost $\$$ & stb $\quad$ - & \\
\hline Run ECLIPSE & Gas cost $\$$ & Msct & \\
\hline \multirow[t]{3}{*}{ View Results } & Water price $\$$ & stb $\quad$ 田 & \\
\hline & Gas price $\$$ & Msct & \\
\hline & Discount Rate & $\% \quad \square$ & \\
\hline
\end{tabular}

Figure A-28 Economics workflow.

The workflow is followed by generalizing the model with proper specifications. Figure A-29 shows the generated model for the $4000 \mathrm{ft}$ horizontal well with three fracture treatments. 
The wellbore and generated fractures are shown as solid white lines. The white lines in the center in the y direction is the center of the wellbore. The other two white marks in the y direction are the heel and toe of the wellbore. The three white lines in the $\mathrm{x}$ direction are the center of the wellbore and the outer extent of the fracture half length.

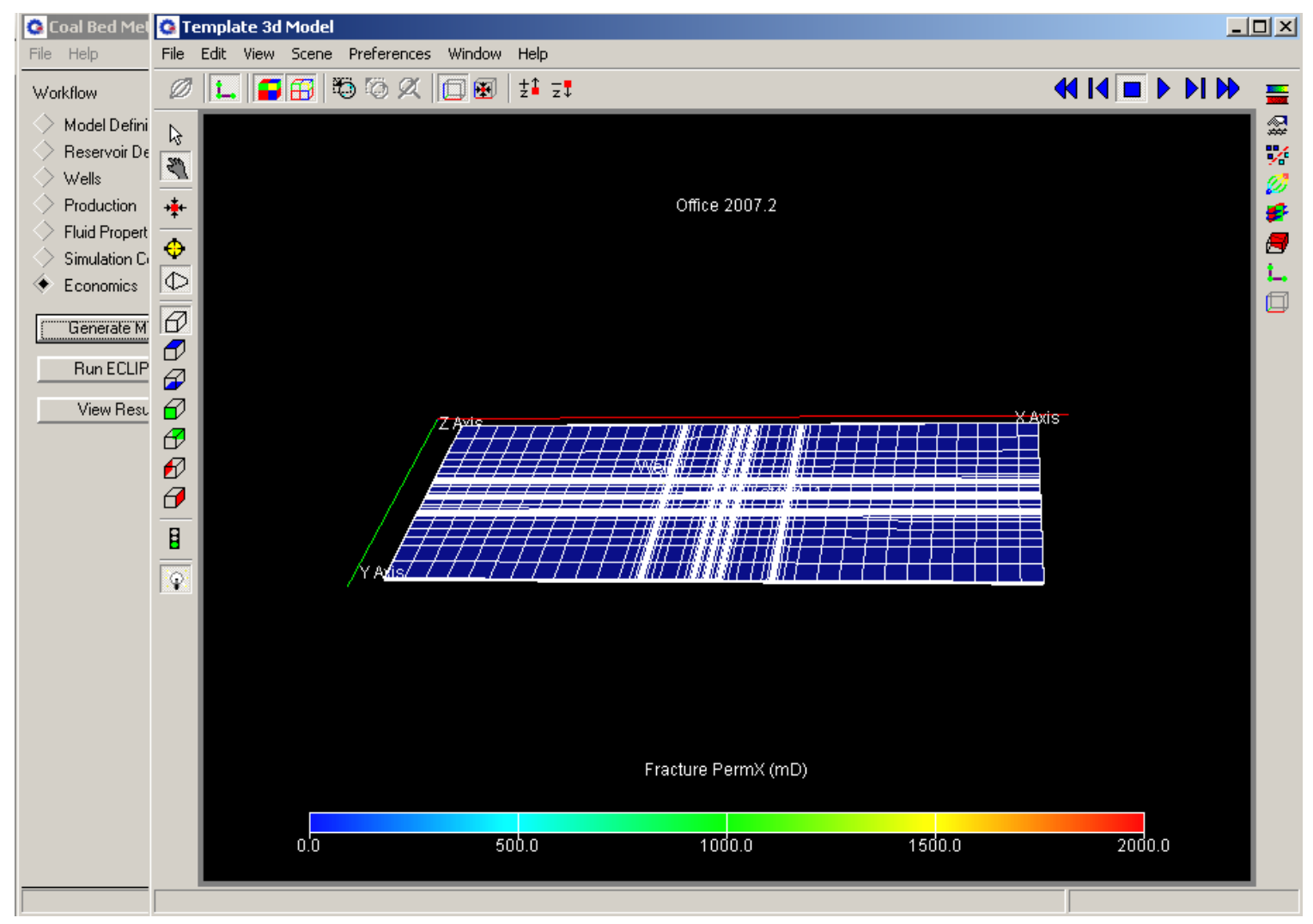

Figure A-29 Generated reservoir model with $4000 \mathrm{ft}$ horizontal wellbore and three fracture treatments.

During the calculation process, the program displays calculated values as shown in Figure A-30. 


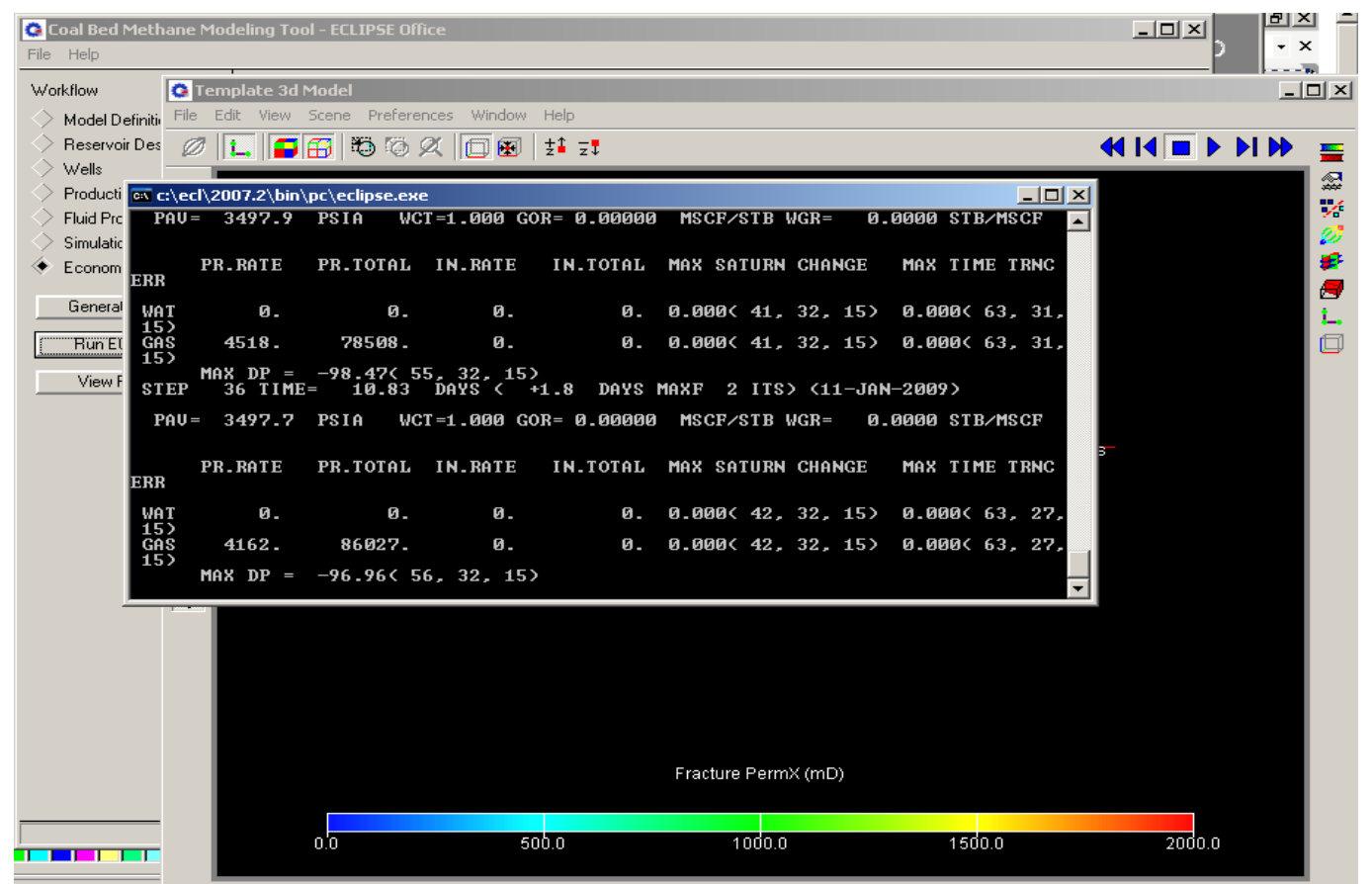

Figure A-30 Display during the runs.

At the completion of calculation or in the event the runs are terminated by the program a message table is generated as shown in Figure A-31. If everything runs correctly there will only be white comments and/or some yellow warnings. If there is a problem, the messages are shown in red, and the program will not run. The warning messages indicate the cause of the terminations of the run and the user can make the necessary corrections.

\begin{tabular}{|c|c|c|c|c|c|c|}
\hline \multicolumn{6}{|c|}{ O Messages Table for TEST-1_E100.MSG } & $-1 \square$ \\
\hline \begin{tabular}{|l|l|} 
Row & Type \\
\end{tabular} & Date & Time & \multicolumn{4}{|l|}{ Description } \\
\hline 1 Message & \multicolumn{2}{|c|}{$1 / 1 / 20090.000$} & \multicolumn{4}{|c|}{ CHECKING FOR LICENSES } \\
\hline \begin{tabular}{l|l|}
2 & Message \\
\end{tabular} & $1 / 1 / 200 \mathrm{~s}$ & 0.000 & \multicolumn{4}{|c|}{ MISSING FRACTURE CELL CORNER POINT DEPTHS COPIED FROM MAATRIXCELLS } \\
\hline 3 Message & $1 / 1 / 2009$ & 0.000 & \multicolumn{4}{|c|}{ NEITHER OLDTRAN,OLDTRANR NOR NEWTRAAN SPECIFIED TRANSMISSIBILITIES TO BE CALCCULATED USING NEWTRAAN } \\
\hline \begin{tabular}{l|l|l|}
4 & Comment \\
\end{tabular} & $1 / 1 / 2009$ & 0.000 & \multicolumn{4}{|c|}{ NO NON-NEIGHBOUR CONNECTIONS FOUND } \\
\hline 5 Comment & $1 / 1 / 2009$ & 0.000 & \multicolumn{4}{|c|}{52839 DUALL POROSITY CONNECTIONS FOUND } \\
\hline \begin{tabular}{l|l|}
6 & Message \\
\end{tabular} & $1 / 1 / 2009$ & 0.000 & \multicolumn{4}{|c|}{ NUMBER OF ACTIVE CELLS IS 105678} \\
\hline \begin{tabular}{l|l|}
7 & Message \\
\end{tabular} & $1 / 1 / 2009$ & 0.000 & \multicolumn{4}{|c|}{73575 CHARACTER VARIABLES USED } \\
\hline \begin{tabular}{l|l|}
8 & Warning \\
\end{tabular} & $1 / 1 / 2009$ & 0.000 & \multicolumn{4}{|c|}{ A MAXIMUMM OF 4 TRACERS HAVE BEEN DECLARED IN RUNSPEEC BUT ONLY 2ARE SPECIFIED IN THE PROPS SECTION. YOU CAN SAVE } \\
\hline 9 Message & $1 / 1 / 2005$ & 0.000 & \multicolumn{4}{|c|}{ RESTART FILE WRITTEN REPORT 0} \\
\hline 10 Warning & $1 / 1 / 2005$ & 0.000 & \multicolumn{4}{|c|}{ LINEAR EQUATIONS NOT FULLY CONVERGED - RUNN MAY GO FASTER IF YOU INCREASE LITMAX [ = 25 - TUNING KEYWORD] } \\
\hline 1 & & & & & & 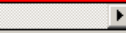 \\
\hline$\checkmark$ Error & \multicolumn{2}{|c|}{$\checkmark$ Message } & \multirow[t]{3}{*}{ Search in Description } & & & Find \\
\hline$\checkmark$ Bugs & \multirow{2}{*}{\multicolumn{2}{|c|}{$\begin{array}{l}\sqrt{V} \text { Comment } \\
\boldsymbol{V} \text { Problems }\end{array}$}} & & & & \\
\hline \multirow[t]{2}{*}{$\checkmark$ Warning } & & & & & & \\
\hline & & & Close & Help & Open Current PRT File & \\
\hline
\end{tabular}

Figure A-31 Warnings and error messages. 
If the program runs correctly, results can be viewed as shown in Figure A-32. The results shown in Figure A-32 are for the total gas production and water production for a $400 \mathrm{ft}$ horizontal well.

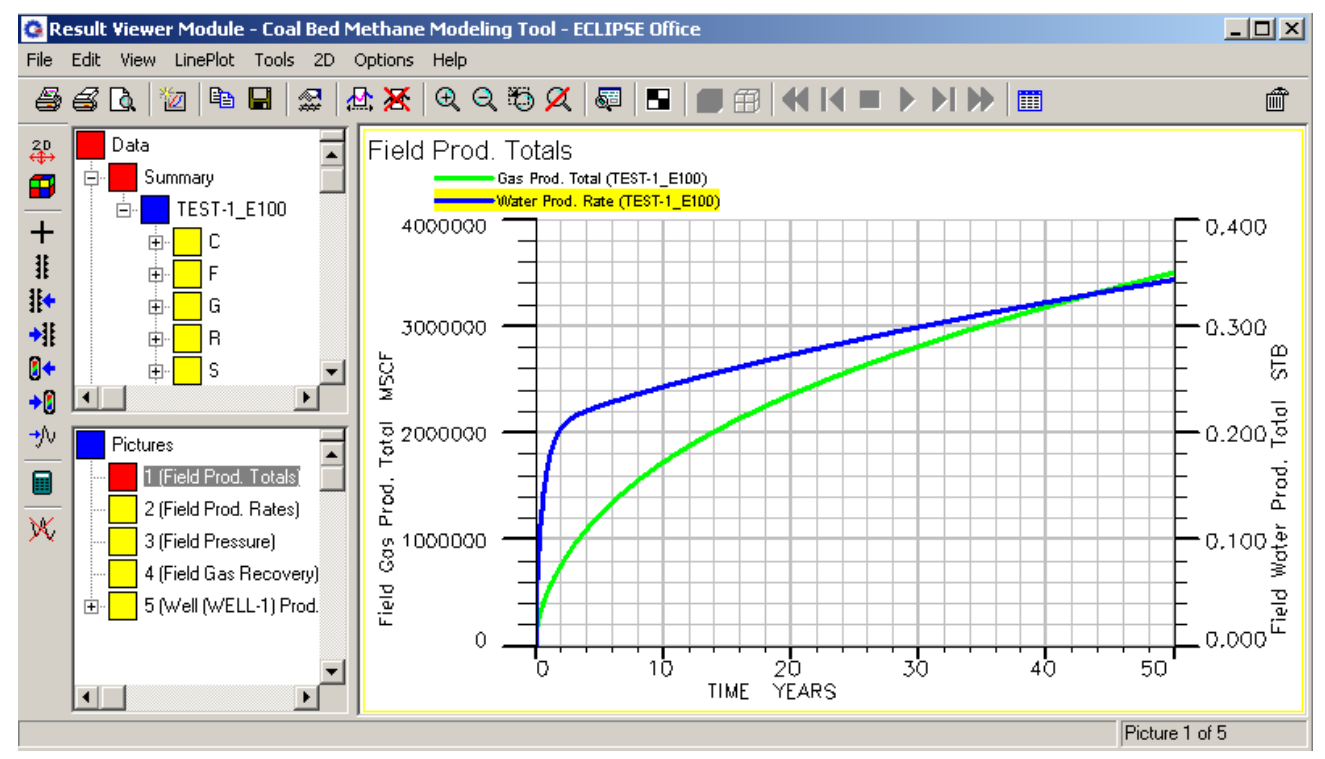

Figure A-32 Results viewer example of field production totals.

The summary of results can be viewed for different properties. Figure A-33 shows the wells total water and gas production over the 50 years simulation period in one graph. In another graph, the total pressure drop of the field over the same time period and in another graph the daily gas and water production rates are shown. 


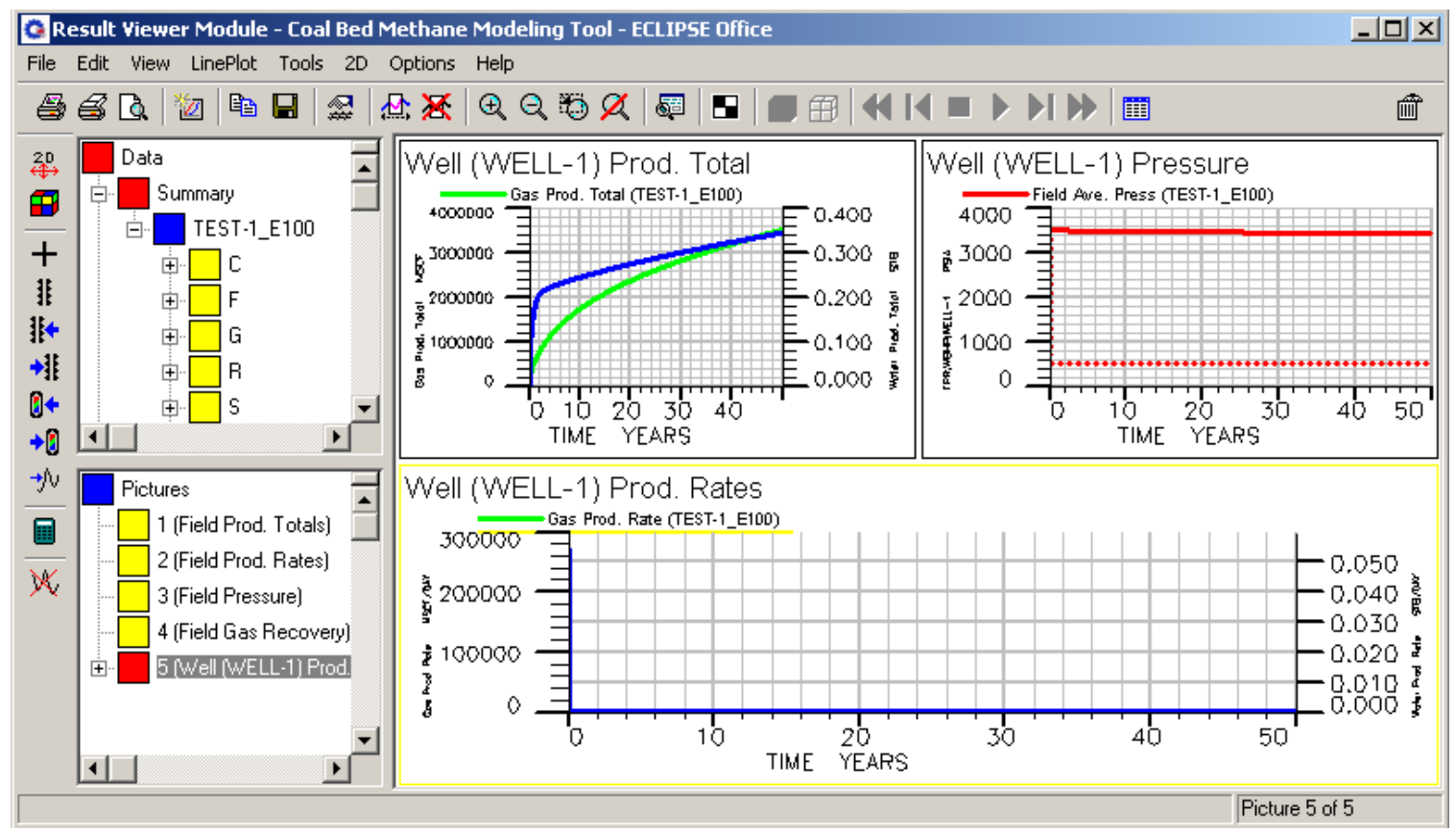

Figure A-33 Summary of results. 


\section{Appendix B}

Table B-1 Comparison of NPV and IRR values at 15\% and \$3/MCF.

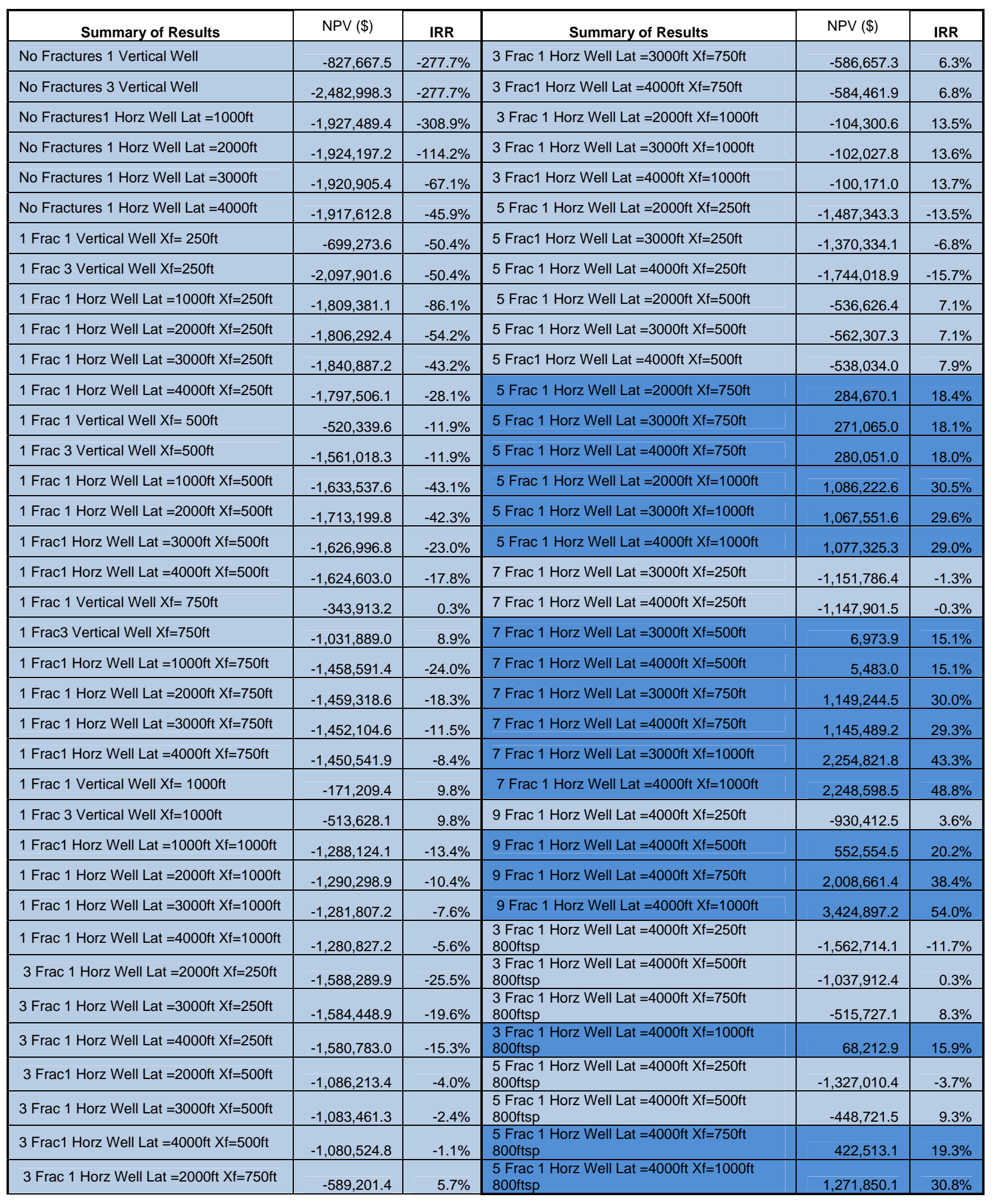

